University of Louisville

ThinkIR: The University of Louisville's Institutional Repository

Electronic Theses and Dissertations

$12-2013$

\title{
Navigating the field : an examination of rhetorical spaces in the Journal of sex research.
}

Deanna McGaughey-Summers

University of Louisville

Follow this and additional works at: https://ir.library.louisville.edu/etd

\section{Recommended Citation}

McGaughey-Summers, Deanna, "Navigating the field : an examination of rhetorical spaces in the Journal of sex research." (2013). Electronic Theses and Dissertations. Paper 947.

https://doi.org/10.18297/etd/947

This Doctoral Dissertation is brought to you for free and open access by ThinkIR: The University of Louisville's Institutional Repository. It has been accepted for inclusion in Electronic Theses and Dissertations by an authorized administrator of ThinkIR: The University of Louisville's Institutional Repository. This title appears here courtesy of the author, who has retained all other copyrights. For more information, please contact thinkir@louisville.edu. 
NAVIGATING THE FIELD: AN EXAMINATION OF RHETORICAL SPACES IN

THE JOURNAL OF SEX RESEARCH

BY:

Deanna McGaughey-Summers

B.S., Administration of Justice, University of Louisville, 1996

M.A., Sociology, Ohio University, 2000

M.S., Administration of Justice, University of Louisville, 2002

\author{
A Dissertation \\ Submitted to the Faculty of the \\ College of Arts and Sciences of the University of Louisville \\ in Partial Fulfillment of the Requirements \\ for the Degree of \\ Doctor of Philosophy \\ Department of English \\ University of Louisville \\ Louisville, Kentucky
}

December 2013 
Copyright 2013 by Deanna McGaughey-Summers

All Rights Reserved 

NAVIGATING THE FIELD: AN EXAMINATION OF RHETORICAL SPACES IN

THE JOURNAL OF SEX RESEARCH

BY:

Deanna McGaughey-Summers

B.S., Administration of Justice, University of Louisville, 1996

M.A., Sociology, Ohio University, 2000

M.S., Administration of Justice, University of Louisville, 2002

A Dissertation Approved on

November 26, 2013

by the following Dissertation Committee:

Dissertation Director

Dr. Karen Kopelson

Dr. Debra Journet

Dr. Thomas Byers

Dr. Aaron Jaffe

Dr. Patricia Gagné 


\section{DEDICATION}

This dissertation is dedicated to Dr. Patricia Gagné and Dr. Richard Tewksbury who provided me with invaluable mentoring at the beginning of my academic career. It's been about twenty years since you involved me in your research and I remain indebted and grateful to you both. 


\section{ACKNOWLEDGEMENTS}

I would like to express the deepest appreciation to my committee chair Dr. Karen Kopelson, for her patience, thoughtful guidance, and encouragement throughout the course of this project. In addition, I would like to thank my committee members: Dr.

Debra Journet, Dr. Tom Byers, Dr. Aaron Jaffe, and Dr. Patricia Gagné for their time and invaluable scholarly input and support for my research.

I would also like to express my gratitude to Russell, Mom (who I deeply miss), Dad, Cheryl, Tracey, Junior, Daisy, Kandi, Onslo, Richard, and all other friends and family who have supported me in my academic and personal life. 


\section{ABSTRACT \\ NAVIGATING THE FIELD: AN EXAMINATION OF RHETORICAL SPACES IN \\ THE JOURNAL OF SEX RESEARCH \\ Deanna McGaughey-Summers}

November 26, 2013

In this dissertation, I adopt a praxical theory of rhetorical space to identify and examine how members of The Society for the Scientific Study of Sexuality draw on or invoke rhetorical spatiality in their research published in the Journal of Sex Research. My specific research questions were: (1) What types of rhetorical spaces do sexologists create? and, (2) What rhetorical strategies do sexologists use to create rhetorical spaces?

The dissertation is divided into five chapters that present different investigations of the production of rhetorical space in The Journal of Sex Research. Chapter One introduces the theoretical and methodological foundation for the examination of rhetorical space in the Journal of Sex Research.

Chapter Two incorporates Edward Soja's (1993) theory of thirdspace into the literature on rhetorical space to examine how sexologists create rhetorical cyberthirdspaces that represent and regulate sexualities in online environments. In particular, the second chapter presents three rhetorical cyber-thirdspaces (erotic oasis, pornosphere, and Jim Crow Cyb) created by sexologists publishing in the Journal of Sex. Each of these three rhetorical cyber-thirdspaces represents and perpetuates a different theory of the causes and consequences of sexuality on the Web in relation to the argument that the 
Internet has democratized sexuality. The rhetorical cyber-thirdspaces differ, however, with respect to the implications of the democratization of sexuality identified by the scholars conducting the research on the cyberspace. Chapter Two also examines how problems associated with research design (theoretical ambiguity, conceptual ambiguity, methodological formalism, exaggeration of causal events, extrapolation from limited cases, proxy evidence, misplaced concreteness, and self-testing) inform the construction of rhetorical cyber-thirdspaces in the Journal of Sex Research.

Chapter Three draws on Ernest Bormann's (1972, 1980. 1986, 2001, and 2006) theory of symbolic convergence and fantasy theme analysis to examine how sexologists invoke the imagination as a reinvention device in arguments regarding the nature and effects of women's rape fantasies. Specific attention is directed toward how sexologists have created a new rhetorical vision of the rape fantasy that sexualizes or eroticizes rape, while at the same time maintaining the assumption that women are not willful rape victims. And Chapter Four examines how the editors and contributors to a special issue of the Journal of Sex Research devoted to the medicalization of sexuality draw on spatial rhetorics, particularly spatial metaphors and appeals to contextualization, to encourage sexologists to broaden their disciplinary boundaries. The dissertation ends with a conclusion, in Chapter Five, which argues that rhetorical space functions as an invention strategy that sexologists use to create or support arguments about sexual social control, agency, or disciplinary boundaries with respect to cyberspace, imaginative space, and disciplinary space. 
TABLE OF CONTENTS

ACKNOWLEDGEMENTS ...................................................

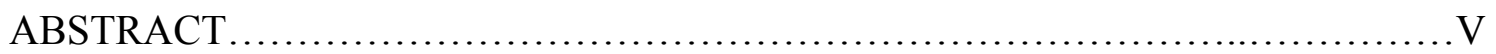

CHAPTER 1: SEXOLOGY AND THE PRODUCTION OF RHETORICAL

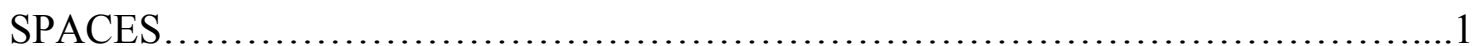

CHAPTER 2: OH THE PLACES WE'LL GO!: THE RHETORIC OF DEMOCRATIZATION IN DISCURSIVE STAGINGS OF RHETORICAL

CYBER-THIRDSPACES .................................................29

CHAPTER 3: IMAGINATIVE SPACE AND THE EROTICIZATION OF RAPE IN NEW RHETORICAL VISIONS OF RAPE FANTASIES .......................74

CHAPTER 4: VISUALIZING THE FIELD: SPATIAL METAPHORS, MEDICALIZATION OF SEXUALITY, AND DISCIPLINARY SPACE. .104

CHAPTER 5: CONCLUSIONS ............................................... 127

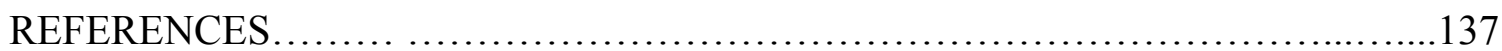

CURRICULUM VITAE.................................................. 156 


\section{CHAPTER 1: SEXOLOGY AND THE PRODUCTION OF RHETORICAL SPACES}

In the humanities and social sciences, the "spatial turn" refers to the privileging of place, geography, and context in theory and research (Guidi, 2009; Warf and Arias, 2009). In rhetoric and composition, the spatial turn has encouraged the development and application of a critical spatial theory that identifies how space is implicated in material realities of a particular time and place (Barnett, 2012). According to critical spatial theorist Barnett (2012), space is "less a fixed, neutral, or transhistorical idea and more a dynamic, ongoing process of relations involving people, discourses, objects, ideologies, histories, and the built and natural environments that together help establish the conditions of lived experience in the world" (p. 1). Rhetoricians and compositionists adopting a critical space perspective focus on how spatiality structures rhetorical acts. Space is not simply a context where communicative acts take place; instead, space is an agent that creates or influences the content and reception of rhetorical acts.

Recent scholarship on rhetoric and space has drawn on critical spatial theory to examine how space informs the content and delivery of discourse. Lorraine Code's (1995) work on rhetoric and gendered locations, for instance, has illustrated how "territorial imperatives structure and limit the kinds of utterances that can be voiced within them with a reasonable expectation of uptake and 'choral support': an expectation of being heard, understood, and taken seriously (p.ix).” Similarly, Nedra Reynolds's (2004) work on "new maps of writing" has highlighted how the location of writing 
informs the navigation, arrangement, and development of writing. For Reynolds (2004), rhetoric and space are mutually constitutive (see also Johnson, 2002; Johnson, 2000). Other rhetoricians and compositionists have further specified the role of spatiality in communicative acts by conceptualizing "rhetorical space," which suggests that social space assumes a communicative function outside of, and irreducible to, authorial intentions.

In “On Gender and Rhetorical Space," Roxanne Mountford (2001) defined "rhetorical space" as "the geography of a communicative event [that] may include both the cultural and material arrangement whether intended or fortuitous of space" (p. 41). In her research, Mountford (2001) analyzed the rhetorical function of the pulpit in creating clerical authority that (re)produced gender hierarchies. Mountford (2001) found that the rhetorical space of the pulpit functioned as a text, and arguably an author, within religious discourse. Accordingly, Mountford (2001) advocated an approach to space that involved an examination of how physical structures, and geographies, functioned productively or creatively in communicative events. Mountford's (2001) work on rhetorical space differed from scholarship that emphasized spatiality as a container or conduit for communication by underscoring the productive and creative nature of space. Nan Johnson's (2002, see also, Johnson, 2000) definition of rhetorical space as "framing certain kinds of rhetorical opportunities that reflect the ways a culture has defined where significant cultural conversations take place" (p. 75), represents the kind of context-based definition of rhetorical space that Mountford (2001) avoids. Context-based definitions of rhetorical space are not wrong, per se; instead, they are limited because they do not address the generative nature of spatiality. 
In this dissertation, I enter the conversation on rhetorical space by examining how rhetorical space has been invoked as an invention, or reinvention, device in sexological research published in the Journal of Sex Research by the Society for the Scientific Study of Sexuality (the oldest, and largest, professional society devoted to the scientific study of sexuality $)^{1}$. My dataset includes sexological research articles published in the Journal of Sex Research between 1963 (when the journal was founded) and 2012 by the Society for the Scientific Study of. The Society's publications are a rich site for analyzing rhetorical space in sexological research because the publications are widely cited as an authoritative source by sexuality scholars working in the fields of anthropology, biology, education, history, medicine, psychology, sociology, sex therapy, and the humanities.

One of the theoretical assumptions motivating this dissertation is the notion that social spaces generate and normalize sexualities. In their article on space, place, and sexual sociality, Gree, Follert, Osterlund, and Paquin, (2010) explain that:

Space is generative of sexualities in ways akin to cultivating properties of language, history, law, and culture in that it frames experience, organizes proximity, and distances, allocates, or denies opportunities for practice and possesses symbolic properties that are heavily communicative of function and sociality (p. 11).

Moreover, a large body of research examining how spatiality provides material and conceptual sites for constructing, manipulating, and enacting sexualities has recently been published by sexuality scholars, geographers, feminists, rhetoricians, and sociologists

\footnotetext{
${ }^{1}$ The Journal of Sex Research is published by Routledge and has an impact factor of 1.948 , is ranked 6/92 in social sciences, interdisciplinary, and 41/114 in psychology, clinical.
} 
(see Cooper, 2002; Curran, 2005; Fox, 2007; Gameson and Moon, 2004; Green, Follert, Osterlund, and Paquin, 2008; Harrison, 2010; Hubbard, Matthews, Scoular, 2008; Jacobs, 2004; Knopp, 2007; Johnson and Longhurst, 2010; Jeysaingham, 2010; McLean, 2008; Oswin, 2008; Waitt, Markwell, Gorman-Murray, 2008; Seidman, 2009). Most of the research on space and sexuality has focused on how concrete geographical sites influence the practices and experiences of sexuality. My approach, in contrast, focuses on how sexological discourse invokes rhetorical space to construct arguments about sexuality and social control. Each chapter included in this dissertation presents an investigation of a particular sexualized or sexualizing rhetorical space produced in the Journal of Sex Research.

The present chapter outlines the theoretical frame that drives the research included in the substantive chapters that follow. There are three sections in this chapter that set up the analysis of rhetorical space and sexology: (1) Rhetorical Space as a Praxical Rhetoric, which provides an extended discussion of how I draw on Mountford's (2001), and others, theory of rhetorical space; (2) Sexology and the Normalization of Sexuality in Rhetorical Space, which, through a brief overview of major scholarship on the sociohistorical construction of sexuality, "excavates" the role of spatiality in sexology; and, (3) a section where I provide a brief overview of the chapters on the rhetorical spaces included in this dissertation.

\section{RHETORICAL SPACE AS A PRAXICAL RHETORIC}

This dissertation examines the production of rhetorical space in sexological discourse published by The Society for the Scientific Study of Sexuality in The Journal of 
Sex Research. My analysis is informed primarily by Roxanne Mountford's ${ }^{2}$ (2001) notion of rhetorical space as the "geography of a communicative event" (p. 41). Mountford's (2001) theory highlights the generative role of rhetorical spaces in larger systems of discourse. The generative role of rhetorical space is illustrated in Mountford's (2001) demonstration of how the physical space of the pulpit has contributed to genderbased subjugation by reinforcing clerical authority. In short, the pulpit functioned as a controlling feature of rhetorical situations that justified the institutionalization and normalization of the subjugation of women. Generative theories of rhetorical space, then, demonstrate the complexities of spatiality in communication.

In the interests of clarity, I characterize generative theories of rhetorical space as praxical rhetorics. Praxical theories of rhetoric emphasize performativity, or the generative function, of rhetoric. Shanyang Zhao (1991) introduced the concept of praxical rhetoric in his article, "Rhetoric as praxis: An alternative to the epistemic approach," by explaining that:

$[\mathrm{R}]$ hetoric is a form of social praxis because the task of rhetoric is to generate normative knowledge which guides human action rather than to search for factual knowledge which conforms to reality; to generate normative knowledge is to examine the conditions of human being-in-theworld and to accept normative knowledge is to accept a way of living; although rhetorically constituted, normative knowledge is grounded in the life contingencies in which we find ourselves and with which we have to cope (p. 257).

\footnotetext{
${ }^{2}$ I am focusing on Mountford's (2001) work because, according to the Arts and Humanities Citation Index, it has been the most widely cited research that illustrates the notion of a praxical theory of rhetorical space.
} 
Zhao (1991) argued that the construction of norms and normative knowledge are rhetorical accomplishments that cannot be reduced to the intentions or effectiveness of an author or rhetor. Zhao's (1991) notion of praxis highlights how rhetoric generates and structures social interactions and social structures. Zhao's (1991) argument that rhetoric is praxical is not new. Lloyd Bitzer (1968) addressed the issue of praxis (though not referring to it as such) in "The Rhetorical Situation," by arguing that rhetoric is active because it alters reality through the creation of discourse that changes reality via "the mediation between thought and action" (p. 4). Zhao's (1991) work differs, however, by specifying the "doing" of rhetoric as normalization, or standardization of cultural ideologies. As a praxical rhetoric, rhetorical spaces normalize cultural ideologies by encouraging people, as inhabitants of social spaces, to act, interact, and perceive in particular ways.

Mountford's (2001) theory of rhetorical space exemplifies a praxical theory of rhetorical space by illustrating how spatiality constructs hegemonic gender ideologies and guides gendered behavior. She found, for example, that the pulpit reinforces pre- and proscriptions (norms) that create and maintain men and women's literal and figurative "place" in society, which demonstrates how gender ideologies are reified spatially. The praxical theory of rhetoric highlights how micro-level rhetorical acts create macro-level discourse that institutionalizes social constructions of reality. Institutionalization of social constructs, however, is largely ignored because spatiality is often experienced as neutral. In what follows, I'll overview how a praxical theory of rhetorical space frames the analysis in this dissertation.

\section{Constructing a Praxical Theory of Rhetorical Space}


Roxanne Mountford's (2001) praxical theory of rhetorical space was developed in conversation with interdisciplinary scholarship on spatiality ${ }^{3}$. Mountford (2001) drew on French sociologist Henri Lefebvre's (1974) theory on the social production of space; French philosopher Gaston Bachelard's (1994) work on spatial metaphors; and, Feminist geographer Susan Ruddick's (1995) work on the social imaginary to create a theory that represents a praxical theory of rhetorical space. In general, interdisciplinary scholarship has posited social space as a cultural and material creation that produces social reality and social relations. Social theories of spatiality have provided rhetoricians with an opportunity to engage macro-level issues by demonstrating the social and cultural nature of spatiality. Mountford (2001), for example, was able to construct a theory that explained how gender subjugation has been created through spatial relations because she had a theoretical "toolkit" that illustrated how spatiality produced space that created social exclusions and inclusions based on socially constructed realities, or social imaginaries.

Spatial Metaphors and the Social Imaginary

Mountford (2001) framed her examination of gender and rhetorical space in relation to Gaston Bachelard's (1994) work on spatial metaphors described in his book, The Poetics of Space. According to Bachelard (1994), spatial metaphors addressing "here," "there," "outside," and "inside" construct our sense of self. More specifically, he argued that "[o]utside and inside form a dialectic of division, the obvious geometry of which blinds us as soon as we bring it into play in metaphorical dimensions" (Bachelard, 1994, p. 211). Furthermore, spatial metaphors are reified because they are tied to

\footnotetext{
${ }^{3}$ My discussion of Mountford's (2001) theoretical antecedents for her construct of rhetorical space is based on a tracing exercise of her article on rhetorical space.
} 
material structures that create the illusion of space as objective and neutral (Bachelard, 1994). This process is socially and politically significant because it produces material spaces that have heuristic power over individual by forcing particular forms of social interaction and behavior, particularly those centered on practices of exclusion and inclusion. Within the context of Mountford's (2001) work, exclusionary and inclusive practices structured the church in relation to differences between the congregation and preacher as well as between men and women. The physical space of the pulpit represented and physically enforced this structure. The relationships that had been created by the spatiality of the pulpit triggered a social imaginary, or a construction of reality that culminates in lived experience (Ruddick, 1997).

The Multidimensional Nature of Spatiality

As mentioned earlier, Mountford's (2001) praxical theory of rhetorical space draws on Lefebvre's (1974), notion that space is not something "out there" waiting to be discovered; instead, space is a phenomenon we construct and transform through symbolic and cultural interactions. The argument that space is a discursive construction that reinforces hegemonic beliefs that structure social interactions and social institutions is reflected in Lefebvre's (1974) argument that "[e]very language is located in space. Every discourse says something about space (places or sets of places), and every discourse is emitted from space" (Lefebvre, 1974, p. 132). Social space is always negotiated through language and other symbolic systems, and, conversely, communicated within a spatial context.

The multidimensional nature of space is captured in Lefebvre's (1974) theory of spatiality as a triad of perceived (or material) space; conceived (or represented space); 
and, lived (or representational) space. Perceived space involves the empirical components of space and spatial practices that accompany specific spaces. Conceived space is created by the powerful (e.g., architects or designers) and is transmitted through knowledge and ideology. Lived space is relational and dynamic; it's the space of inhabitants. Multidimensionality is an important component of a praxical theory of rhetorical space because it highlights how spatiality is informed by, but not reducible to, social contexts, social interactions, and social designs of communicative acts.

Lefebvre's (1974) theory on the social production of space has also emphasized the role of neutrality in our understanding of how spatiality creates and maintains cultural ideologies. In short, the rhetorical nature of spatiality is overlooked because social space is perceived as neutral, which often masks how space is used as a technique of power. Lefebvre (1994) clarifies the role of neutrality as follows:

Space is not a scientific object removed from ideology and politics; it has always been political and strategic. If space has an air of neutrality and indifference with regard to its contents and thus seems to be "purely" formal, the epitome of rational abstraction, it is precisely because it has been occupied and used, and has already been the focus of past processes whose traces are not always evident on the landscape....Space is political and ideological. It is a product literally filled with ideologies (p. 31).

Social spaces communicate and structure "place" in society. Consider, for example, how zoning laws are invoked to ensure that sex-related businesses such as strip clubs and adult bookstores are kept at a distance from middle- and upper-class schools and neighborhoods because they are perceived as contributing to "neighborhood 
deterioration“ (Hubbard, Matthews, Scoular, and Augustin, 2008); how states' often appeal to rhetorics of territorial "invasion" to oppose same-sex marriage (Webster, Chapman, and Leib, 2010); how women's movement in public spaces is constrained by sexual threats (Skeggs, 1999); issues of gay gentrification and ghettoization (Knopp, 2007); how governments change landscapes to thwart "indecent" activities (Kelly \& Munoz-Laboy, 2005); and how sexuality is constructed around various binaries and boundaries - public vs. private. These spatial practices illustrate how spatiality functions as a form of social control as well as rhetorical devices that create and transmit cultural discourses that structure power relations and enforce sexual social control.

Essentially, Mountford's (2001) theoretical influences, and her analysis of the pulpit as a rhetorical space, has contributed to the development of a more complex and sophisticated understanding of rhetorical space that illustrates how spatial metaphors and social imaginaries construct and reify spatial realities. Mountford's (2001) work has presented rhetorical spaces as performative and praxical rather than simply sites from which rhetors perform. Rhetoricians following Mountford (2001) have further refined the praxical theory of rhetorical space by focusing on the malleability of rhetorical spaces, how rhetorical spaces are implicated in social relations and exercises of power, and rhetorical spaces structure, literally and figuratively, our lived environments.

Extending and Elaborating Mountford's (2001) Rhetorical Space: Malleability,

\section{Power, and Normalization}

In "The Rhetorical Space of Robben Island," Marback (2004) examined how the geography and materiality of Robben Island, a South African prison that held antiapartheid leaders, drew on the intersection of spatiality and rhetorical authority to create 
representations and narratives of apartheid. The island represented a geographical communicative event that created the cultural and material conditions of apartheid. In some cases, the isolation of the island invoked a sense of dread and fear for those who embraced anti-apartheid ideologies, but in other cases, the island represented triumph over tragedy. The island functioned to thwart anti-apartheid activities by creating the ever-present threat of punishment and served as a location for enforcing and resisting colonial hierarchies.

The key feature of Marback's (2004) analysis was the finding that no one ideology could be communicated through the island because "space functions as a malleable resource" (p. 7). Marback (2004) demonstrated that "[a]ppeals could be made through it, but no appeal could command or contain it" (p. 19). The meaning of the island was constantly pivoting in relation to discourses of apartheid. At one point in its history, for example, Robben Island represented the consequences of anti-apartheid sentiments; at another point, it represented tragedy; and, when created as a museum, the prison represented triumph over tragedy. In each case, the physical structure narrated a discourse of apartheid. Marback's (2004) analysis of the island shed light on how the structure communicated persuasively as a geographic location as well as how said communication was altered through historical change. The pivoting nature of the communication illustrated how the island, as a geographic location, existed independent of the creative intent of its original author or designer. The island represented cultural narratives about apartheid, but these narratives did not necessarily represent the original intent of the author/designer of the prison. The island, as a geographic structure, and 
praxical rhetorical space, assumed a role as rhetor and as text in the generation of discourses on apartheid.

Other research has emphasized and elaborated on the role and function of power within rhetorical spaces. Elizabeth Wright's (2005) research on rhetorical memory places/spaces, for example, illustrated how spatiality functioned in collective, cultural, and social memories tied to subjugated groups. In "Rhetorical Space in Memorial Places: The Cemetery as a Rhetorical Memory Place/Space,“ Elizabethada Wright (2005) examined how spaces have, and can be, used as a rhetorical device in communicative events. However, rather than focusing exclusively on one particular rhetorical space, Wright (2005) examined how multiple rhetorical memory spaces (the cemetery, memorials, and monuments), have been used to commemorate, or exclude and marginalize, minority groups. In her work, Wright (2005) focused on the lack of collective memory places for women of all races, and for people of color of both genders. She found that collective memory places of marginalized groups were "privatized" or "domesticated" by being relegated to local public memory places such as the graveyard and cemetery unless those minority groups mobilized to redress such exclusion. Adelaide Johnson's “The Women's Movement” statue of Elizabeth Cady Stanton, Susan B. Anthony, and Lucretia Mott, which was commissioned to represent the passage of the Nineteenth Amendment, exemplifies the privatization or domestication of collective commemoration of women's contribution to American society and history. Shortly after its commission, the statue was moved from the Capitol Rotunda to the Capitol Crypt. And, in 1963, the name of the statue was changed from "The Women's Movement" to "The Portrait Monument" and the names of Stanton, Anthony, and Mott were removed. 
Women's contribution to the history of the United States went unrecognized in the public memory. However, in 1997, seventy-five years after its commission, the statue was returned to the Rotunda after members of women's organizations complained about lack of access to the memorial and were able to counter claims posed by governmental officials that the monument was too heavy and ugly to include in the Rotunda. The geographic placement of the monument sustained and communicated the message that women's historical experiences and collective activities were not central to the story of America and it provided a context for demanding women's rights. This is significant for a number of reasons, not the least of which is that memories are often connected to spaces and places which can invoke memories and their accompanying historical and social narratives.

Wright's (2005) work on rhetorical memory spaces has also contributed to our understanding of how spatiality is used in privatizing commemorations of exploited groups. Wright (2005) noted that there are few monuments or public memorials for those who have been racially exploited because the lack of such representations has allowed the white majority to avoid complicating democratic beliefs of equality. Privatizing commemorations of marginalized groups have maintained white privilege by presenting a version of American history that has reinforced narratives of equality and democracy. The controversy surrounding the Portsmouth African Burial Ground in New Hampshire exemplifies the political issues involved in the issue of public memory. Although there had been maps that pointed to a burial ground for those who had been enslaved, the existence of the burial ground in New Hampshire had never been investigated until construction of a new sewage system was initiated. The graves of men, women, and 
children who had been enslaved were uncovered and this finding sparked heated discussions among residents regarding New England's role in slavery and whether or not the community had a responsibility to recognize the burial ground as a sacred space. Some residents argued that the burial ground needed to be marked as a sacred site to recognize those who had been enslaved and the role of slavery in the creation of their community. Others, particularly local businesses, contested the argument that the site was sacred because marking the site as sacred, which would limit the expansion of those businesses and potentially compromise and disrupt capitalism. Many business owners suggested that the graves be moved to a separate location so as not to disturb economic progress. The men and women who were buried in the Portsmouth Burial Ground were not recognized as people worthy of commemoration; instead, some as a nuisance perceived their presence for the community. The suggestion to move the remains of those located in the burial ground recalled the treatment of Native American sacred sites. Officials redefined Native American burial sites as sacred spaces by relocating the remains to museums. The removal or relocation of these graves erased the sites as sacred grounds, while also objectifying those who were buried in those graves. In addition, the process of relocation redirected the history of minority group members' experiences and roles in narratives of American history. Wright's (2005) work on rhetorical memory spaces demonstrated how spatialized power relations have contributed to social stratification.

More recent work representing a praxical theory of rhetorical space and extension of Mountford's (2001) original work, has focused on how normalization of social structures and ideologies is an effect of the design of rhetorical spaces. In "A Woman's 
Place is in the School: Rhetorics of Gendered Space in Nineteenth-Century America," for instance, Jessica Enoch (2008) analyzed how spatial metaphors based on the prison and the home transformed the 20th century schoolroom from a masculine space that represented discipline to a feminine place that represented nurturing. Enoch (2008) described her research as an examination of how rhetorics of space, those spatial practices that explain "what the space should be, what it should do, and what should go on inside it" (p. 276). She argued that rhetorics of space have the potential to make a space either powerful or diffused by ascribing value associated with the space and by suggesting or prescribing the kinds of occupants that should (and should not) move into and out of that space. She noted, in particular, that "space itself becomes gendered through rhetorical means, functioning either to welcome women or refuse them entry" ( $p$. 293). Additionally, Enoch (2008) urged rhetoricians to further investigate the kinds of rhetorical activities that surround and are infused in space, or how people "lay claim to, are barred from, and move into space, but also how spaces are empowered or disempowered through both overt and subtle rhetorical shifts in the discursive and material environment” (p. 289). Enoch's (2008) work has contributed to praxical theories of rhetorical space by addressing the discursive constructions of spatiality.

Jordynn Jack's (2009) work on spatiotemporal rhetorics is similar to Enoch's (2008) research on the gendered schoolroom because both scholars examine the process of rhetorical space construction. In "Acts of Institution: Embodying Feminist Rhetorical Methodologies in Space and Time," Jack (2009) draws on Pierre Bourdieu's (1991) theory of acts of institutions and Doreen Massey's (1993) theory on the intersection of space and time, to produce a methodology that feminist rhetoricians and other researchers 
interested in rhetorical spaces can draw on to investigate and theorize how normative practices are produced in rhetorical spaces. In the context of her research, Jack (2009) examines how gender norms, bodies, and social relations are constructed via spatiotemporal rhetorics that use acts of institutions centered on clusters of rhetorics regarding women's delicacy, appearance, and domesticity create and maintain female subjugation. Her research focus was on how these rhetorical clusters shaped women's work and the physical structure of the factory in World War II.

Pierre Bourdieu's (1991) concept of "acts of institutions" is central to Jack's (2009) methodological framework. Acts of institutions "create or exacerbate minor differences between men and women in order to perpetuate a system of masculine dominance" (Bourdieu, 1991, p. 289). These differences are created through the figure of antithesis that positions two things (male and female, for example) as dichotomous realities. Jack (2009) argues that rhetoricians can use the concept of acts of institution to deconstruct how various categories of analysis (in the context of her research, bodies, dress, space, and time) create rhetorical spaces that maintain binaries in society. In addition to examining acts of institutions, Jack (2009) encourages rhetoricians to analyze the interaction among several categories of analysis to create a more nuanced understanding of rhetorical space.

Considered together, the literature on rhetorical space discussed previously exemplifies the praxical nature of rhetorical space. To briefly review, Mountford (2001) introduced a theory of rhetorical space that emphasized the praxical or generative role of spatiality in communicative acts and discursive formations. Those who have followed Mountford (2001) have refined and elaborated her work by demonstrating the 
malleability of rhetorical spaces (Marback, 2004; Wright, 2005), the role of spatiality in social constructions and perpetuations of social inequalities (Marback, 2004; Wright, 2005; Enoch, 2008; Jack, 2009), and how social relations, identities, and institutions are normalized (Enoch, 2008; Jack, 2009). Based on the research I outlined, I am taking the following as axiomatic:

- Rhetorical spaces are forms of praxical rhetoric that work in the interests of normalizing cultural ideologies by structuring and organizing the literal and figurative contexts in which people live. Rhetoric and spatiality are mutually constitutive and hold heuristic power over individuals because space is often perceived as neutral.

- Spatiality is a multidimensional phenomena based on intersections between material, conceptual, and lived realities.

- Rhetorical spaces originate in discourse (text, blueprints, etc.), but they are malleable because discourse intersects with material and lived realities.

My general research questions are: how do sexologists use spatial rhetorics to construct theories, motivate research methodologies, and support research findings? How are rhetorical spaces created in the research articles? What types of rhetorical spaces are constructed in the research articles? What general assumptions do sexologists make about sexuality? How is spatiality used to normalize sexuality?

In what follows, I will discuss the "history of sexuality" to provide an overview of the role of sexology in the production of sexuality. This discussion will focus primarily on the work of Michel Foucault (1984), D'Emilio and Freedman (1998) and Jonathan Katz (2007) and explain how sexologists assumed the primary role of constructing the 
"truth" of sexuality. Following the overview of sexology and the construction of sexuality, I will demonstrate the significant, but under-theorized, role that rhetoric and spatiality have played in the formation of sexuality, and processes of sexual normalization, by sexologists.

\section{SEXOLOGY AND THE NORMALIZATION OF SEXUALITY IN RHETORICAL SPACES}

According to several historians of sexuality (Haeberle, 2006; Bullough, 1995; Foucault, 1984; Katz, 2007) sexuality is a relatively new concept that emerged through the efforts of doctors and public health officials who studied sexual behavior and created the idea of "sexuality" as an intrinsic component of the individual. Historians D'Emilio and Freedman (1998) have described the conceptual move from sex as behavior to a natural component of self in their classic work Intimate Matters: A History of Sexuality in America. Focusing on sexual meanings (language of sexuality, terms, metaphors, sources), sexual regulation (authority for determining what is normal and what is deviant; the rules that organize sexuality), and sexual politics (political groups involved in the construction and debates regarding sexuality), D`Emilio and Freedman (1998) have shown that the primary meaning of sexuality has changed from an association with reproduction within the family to an association with emotional intimacy and sexual pleasure for individuals. In the colonial era, for example, the dominant language of sex was reproductive, but in the $19^{\text {th }}$ century, with the emergent middle/professional-class, sexuality was reconceived, through science, as an individual, and "natural" essence. As the construct of sexuality changed, so too did its control. In early America, a unitary system of sexual regulation that involved the church, family, and state rested upon 
consensus about the primacy of familial reproductive sexuality. From the late $18^{\text {th }}$ and $19^{\text {th }}$ centuries, the role of the church in sexual regulation was diminished and the medical professional and sexology emerged as the association that would create an understanding of, and control, sexuality.

In his seminal work on the history of sexuality, Michel Foucault (1984) addressed the issue of sexual social control by complicating the notion that sexuality was a natural feature, or biologically-based drive (the sexual instinct), of the individual that had been socially repressed. Foucault (1984) demonstrated, instead, that the concept of sexuality had in fact been institutionally produced through the family, education, economy, and, most important, sexology. The sexological production, or "discovery," of sexuality created sexual subjects who were controlled and regulated through invisible normalizing strategies within social institutions. In brief, Foucault (1984) described four sexological strategies (the hysterization of women's bodies, socialization of procreative behavior, the pedagogization of children's sexuality, the psychiatrization of perverse behavior) that defined sexuality and served as mechanisms of sexual control on micro- and macrolevels. Sexological research was the driving force in each of these strategies and sexologists assumed the authoritative role of controlling these cultural figures.

Jonathon Katz's (2007) work on the discovery of heterosexuality illustrates Foucault's (1984) argument regarding the role of sexology in the production of sexual subjects. In The Invention of Heterosexuality, Katz (2007) extensively outlined the "discovery" of heterosexuality through sexological discourse published in the late nineteenth century, and throughout the twentieth century. Katz (2007) found that the term "heterosexual" first appeared in 1892 in "Responsibility in Sexual Perversion," 
published by Dr. James Kiernan in the Chicago Medical Recorder. Kiernan presented the heterosexual as a sexual deviant characterized by "an abnormal manifestation of the sexual appetite" (qtd. in Katz, 2007, p. 20). Kiernan's heterosexuals suffered from a condition known as "psychical hermaphrodism," which was characterized by a sexual attraction to those of either sex/gender (what we would today refer to as "bisexuality"). Sexologist Richard von Krafft-Ebing also presented the heterosexual as a deviant in his 1893 text, Psychopathia Sexualis, with Especial Reference to the Contrary Sex Instinct: A Medico-Legal Study, on sexual pathologies. For Krafft-Ebing, heterosexuals desired the other sex/gender, but they were deviant because they received pleasure from various fetishes such as handkerchiefs (Katz, 2007). In short, heterosexuals violated the reproductive imperative that defined "normal" sexuality as that which could lead to reproduction. Constructs of sexuality based on sexual pleasure rather than reproduction were considered deviant and pathological by sexologists.

The medicalization of heterosexuality and its association with perversion lasted in sexological and popular discourse until the early 1930s. In 1909, Dorland's Medical Dictionary defined heterosexuality as an "abnormal or perverted appetite toward the opposite sex" (qtd. in Katz, 2007, pg. 86). This construct was introduced in popular discourse through dictionaries directed toward the general population. "Heterosexuality" debuted in 1923 in Merriam-Webster's New International Dictionary as a medical term referring to a "morbid sexual passion for one of the opposite sex" (qtd. in Katz, 2007, p. 92), but was redefined, and normalized, in 1932 as "the manifestation of sexual passion for one of the opposite sex: normal sexuality" (qtd. in Katz, 2007, p. 92). Heterosexuality began to be redefined when the reproductive imperative was complicated by structural 
changes in society. Two concepts emerged that represented the move from the reproductive imperative to a discourse of sexual pleasure and love: Freud's "pleasure principle" and Ellis's "sex-love.“

The concept of the pleasure principle was developed and advocated by Sigmund Freud in his 1905 text, Three Essays on Sexuality. Freud rejected the reproductive imperative in favor of the pleasure principle. Freud argued that the goal of the sex instinct was pleasure rather than "generation," unless an act moved completely away from reproduction, complicated conformity to society, or kept one in a state of polymorphous perversity. Havelock Ellis, also moved away from the reproductive imperative in his 1919 text on sexual inversion. Ellis did not adopt the notion of pleasure principle; instead he drew on the concept of "sex-love" to indicate normal heterosexuality. Sex-love referred to an erotic attraction to the other gender which would lead to love, then marriage, and perhaps, to reproduction. Although Ellis rejected the reproductive imperative in favor of a notion of sex-love, he differed from Freud by arguing that different- and same-sex attractions were innate, biological givens. Nevertheless, both sexologists participated in the discursive shift from reproduction to pleasure and love.

In the 1940s and 1950s, the association between heterosexuality and the reproductive imperative was reintroduced through the "cult of domesticity." This association is reflected in Ferdinand Lundberg and Dr. Marynia Farnham's 1947 text, Modern woman: The Lost sex. Lundberg and Farhham argued that proper gender roles were violated by "engagement in heterosexual relations...with the complete intent to see to it that they do not eventuate in reproduction" (qtd. in Katz, 2007, p. 96). This 
construct competed with Alfred Kinsey's research on sexuality that questioned whether medicine and science should define acts as normal or abnormal. Drawing on the notion of objective science, Kinsey advocated the idea that there was a continuum, the "heterosexual-homosexual rating scale" of sexual activity and desire. Kinsey also argued that the hetero/homo distinction was a social construction. Through the 1950s and 1960s, sex reformers and counter-culturalists such as sex reformers, feminists, and gay rights activists drew on the idea of the social construction of sexuality to advance their position that normalizing discourses oppressed, and repressed, the experiences of marginalized groups. Although the discourse on "normal sexuality" shifted historically, it was often developed and naturalized by sexologists and, as I will describe later, contextualized through various spatial relationships and rhetorical spaces.

\section{Excavating Rhetorical Space in Histories of Sexuality}

The sociohistorical construction of sexuality and sexual identities, which is represented in the scholarship on sexology's role in the construction of sexuality, has been widely researched by those theorizing the social nature of sexuality. The issue of spatiality, in general, however, has often been ignored in accounts of the sexological construction of sexualities and sexual identities. Geographer Edward Soja (1989) has critiqued historicist approaches by arguing that "[w]e must be insistently aware of how space can be made to hide consequences from us, how relations of power and discipline are inscribed into the apparently innocent spatiality of social life, how human geographies become filled with politics and ideology” (p. 6). Roberta Binkley and Marissa Smith (2006) have made a similar claim regarding historicism in their discussions of the history of rhetoric in their article, "Re-Composing Space: 
Composition's Rhetorical Geography.” Like Soja (1989), Binkley and Smith (2006)

argue that the focus on history has "disguised the importance of space, the place in which power is promulgated" (para. 5). Examining spatiality, then, offers an opportunity to understand and complicate how power is exercised in constructions of sexuality. In this way, I am intervening in scholarship that has privileged historicist approaches to understanding the sexological production of sexuality by drawing on the concept of rhetorical space to illustrate the spatial nature of normalized sexualities.

Although Michel Foucault's (1984) widely cited work on sexuality, The History of Sexuality, largely ignored spatiality, his theory, nevertheless, illustrates how sexuality has been produced through social spaces ${ }^{4}$. In The History of Sexuality, Foucault (1984) connected the domain of sexuality to sexology by connecting knowledge and power. Foucault (1984) represented these strategies of power and discursive techniques; however, I submit that these strategies of power are spatial and operate via the production of rhetorical spaces. The hysterization of women's bodies, for example, was produced in the rhetorical space of the hospital and clinic and in spatial relationships created between doctor and patient; the socialization of procreative behavior was produced in the rhetorical space of the home and in spatial relationships between parent and child; the pedagogization of children's sexuality was produced in the rhetorical space of the school

\footnotetext{
${ }^{4}$ Foucault (1976) did not initially theorize spatiality in his examinations of power; however, in his later work, he acknowledged that spatiality played a fundamental role in the creation and perpetuation of power. In an interview published in 1976 in Heredote, for example, Foucault acknowledged that geography "acted as the support, the condition of possibility for the passage between a series of factors I tried to relate. Where geography itself was concerned, I either left the question hanging or established a series of arbitrary connections" (p. 77) and in "Of Other Spaces," he argued that: "The great obsession of the nineteenth century was, as we know, history: with its themes of development and of suspension, of crisis, and cycle, themes of the ever-accumulating past, with its preponderance of dead men ... the present epoch will perhaps be above all the epoch of space. We are in the epoch of simultaneity: we are in the epoch of juxtaposition, the epoch of the near and far, of the side-by-side, of the dispersed. We are at a moment, I believe, when our experience of the world is less that of a long life developing through time than that of a network that connects points and intersects with its own skein (Foucault, 1986, p. 22).
} 
and in spatial relationships between teacher and student; and, the psychiatrization of perverse behavior was produced in the rhetorical space of the clinic and prison and in the spatial relationships between doctor, or law enforcer, and patient or inmate. These rhetorical spaces were products of sexological discourse on sexuality; they represented sexual relationships; and they normalized sexuality.

\section{CHAPTER OUTLINES}

The chapters that comprise this dissertation represent different investigations of the production of rhetorical space in The Journal of Sex Research. As noted below, the chapters examine cyberspace, the imagination, and the sexological discipline.

Methodologically, the analysis presented in the chapters has been conducted using the constant comparative technique, which is a component of the grounded theory research design developed by Glaser and Strauss (1967). The grounded theory technique is based on coding data to identify categories, and eventually theories, that emerge from the data. At each stage of coding, the data are compared to identify relationships. I will review how I prepared the data, identified units of analysis, and coded the texts in each of the respective chapters.

\section{Chapter 2: Oh, the Places We'll Go!: The Rhetoric of Democratization in Discursive Stagings of Rhetorical Cyber-Thirdspaces}

In chapter two, I incorporate Edward Soja's (1993) theory of thirdspace into the literature on rhetorical space to examine how sexologists create rhetorical cyberthirdspaces that represent and regulate sexualities in online environments. Cyberspace is a significant and interesting space to examine rhetorically because it confuses traditional geographic constructs of space and place. Cyberspace, for example, includes physical 
elements (i.e., computer, connecting from home or work), but nevertheless escapes the traditional conceptualization of a place. Cyberspace is often experienced as "out there" somewhere. The problem with cyberspace involves how boundaries between conceptual and material space are conceptualized. With this in mind, I draw on Edward Soja's (1989) concept of thirdspace to represent a site that synthesizes conceptual and material spaces. I also incorporate insights about rhetorical spaces from Mountford (2001) and Enoch (2008) to identify how cyber-thirdspaces are implicated in rhetorical situations and communicative acts regarding sexualities.

In chapter two, I also explore how sexologists have constructed three rhetorical cyber-thirdspaces, in response to the argument that the Internet has democratized sexuality, thereby creating an "anything goes" context for sexual practices and constructs of identity. Each of the three rhetorical cyber-thirdspaces (erotic oasis, pornosphere, and Jim Crow Cyb) created by sexologists publishing in the Journal of Sex Research appeals to a notion that cyberspace has democratized sexuality by creating an unregulated eroticized space on the Internet. Each of these three rhetorical cyber-thirdspaces represents and perpetuates a different theory of the causes and consequences of sexuality on the Web. The rhetorical cyber-thirdspaces differ, however, with respect to the implications of the democratization of sexuality identified by the scholars conducting the research on the cyberspace.

Sexologists who constructed the Internet as an erotic oasis presented cyberspace as a safe space that creates opportunities to renegotiate marginalized identities. As an erotic oasis, the Internet creates a sexual marketplace or marketplace of mutuality that allows for more self-awareness than other contexts provide. In short, sexologists 
characterizing the Internet as an erotic oasis present the democratization of sexuality as a positive social formation. In contrast, other sexologists posited that the Internet has created an anomic environment that draws people into devious sexual practices that threaten hetero-coupling and encourages or complicates existing sex addiction. Finally, some sexologists challenged the construct of the erotic oasis and pornosphere by highlighting how the Internet reproduces race and ethnicity as well as the homo/hetero dualism implied in the distinction between the erotic oasis and pornosphere.

Chapter two also examines how problems associated with research design (theoretical ambiguity, conceptual ambiguity, methodological formalism, exaggeration of causal events, extrapolation from limited cases, proxy evidence, misplaced concreteness, and self-testing) inform the construction of rhetorical cyber-thirdspaces in the Journal of Sex Research. I found that those constructing the Internet as a pornosphere worked from flawed research designs that resulted in invalid data. This finding is significant because the pornosphere represents hetero-centric assumptions regarding the Internet and sexuality.

\section{Chapter 3: Imaginative Space and the Eroticization of Rape in New Rhetorical Visions of Rape Fantasies}

In chapter three, I turn my attention to how the imagination is invoked as a reinvention device in arguments regarding the nature and effects of women's rape fantasies. My specific focus is on how sexologists have created a new rhetorical vision of the rape fantasy that sexualizes or eroticizes rape, while at the same time maintaining the assumption that women are not willful rape victims. I argue in this chapter that rape is a spatialized construct and that the organization and maintenance of space allows 
sexologists to embrace rape fantasies while rejecting the crime of rape. My analysis draws on Bormann's $(1972,1980.1986,2001$, and 2006) theory of symbolic convergence and fantasy theme analysis, which identifies and explains how shared discourse is created within discourse communities via shared fantasy themes, or narratives.

I found, in chapter three, that the new rhetorical vision of rape fantasies features a fantasizer who controls the imaginative space in which the rape event takes place. The fantasizer does not receive pleasure from suffering, per se, but instead, from playing roles that may include the experience of surrender. Furthermore, in constructing, or moving toward this new rhetorical vision of the eroticized rape fantasy, sexologists have reconstructed theories of masochism to create an imaginative space where one can enjoy an experience that contains elements associated with legal constructs of rape.

\section{Chapter 4: Visualizing the Field: Spatial Metaphors, Medicalization of Sexuality, and Disciplinary Space.}

In chapter four, I examine how the editors and contributors to a special issue of the Journal of Sex Research devoted to the medicalization of sexuality draw on spatial rhetorics, particularly spatial metaphors and appeals to contextualization, to encourage sexologists to broaden their disciplinary boundaries. Medicalization is an inherently spatial concept that is based on location (i.e., locations of expert authority, normalized and institutional practice, etc.) and medicalization is also rhetorical: sexual subjects (consumers, patients, doctors, sexologists) have to be persuaded that medicine is the proper authority on issues related to sexuality. 
In chapter four, I argue that the special issue on the medicalization of sexuality represents an interdisciplinary motivational work of science that motivates sexologists to alter their disciplinary space. Spatial metaphors that function cartographically and topographically are rhetorical devices that the editors and contributors to the special issue have drawn on to create exigence and provide justifications for reconstructing the boundaries of sexology. I also argue that spatial metaphors are efficacious tools for constructing a motivational text because they allow us to "see" the processes and outcomes of medicalization. In short, spatial metaphors render something that is typically abstract and invisible as a concrete and visible reality, which potentially encourages reflexiveness and praxis on the part of sexologists.

\section{Chapter 5: Conclusions}

This dissertation ends with a conclusion that engages my basic assumptions about rhetorical space in sexological discourse. I describe, in particular, how rhetorical space functions as an invention strategy that sexologists use to create or support arguments about sexual social control, agency, or disciplinary boundaries with respect to cyberspace, imaginative space, and disciplinary space. I conclude the fifth chapter with suggestions for future research that involves drawing on Latour's theory of science in action and Smith's theory and method of institutional ethnography to examine how sexological research has been institutionalized in social structures, and to what ends. 


\section{CHAPTER 2: OH THE PLACES WE'LL GO!: THE RHETORIC OF DEMOCRATIZATION IN DISCURSIVE STAGINGS OF RHETORICAL CYBER-THIRDSPACES}

In the introduction to a special section on the relationship between cyberspace and sexuality published in the Journal of Sex Research, guest editor Yitzchak Binik (2001) explained that he assumed that selecting articles to include in the special issue would be an easy task because there was a steady stream of scholarly books and articles examining the relationship between cyberspace and sexuality. Binik and his co-editor John Delamater, however, experienced problems creating the special issue on cyberspace and sexuality because several authors chose to withdraw, rather than revise and resubmit, their work for consideration in the issue. The problems that the editors, Binik and Delamater, experienced encouraged them to create a special section of a regular issue rather than special issue on cyberspace and sexuality. The research they included in their special section featured articles addressing how cyberspace corresponded to existing technologies such as television and music; how cyberspace served marginalized groups in their quest for affirming sexual experiences and identities; the use and implications of pornography on the Internet; and the uses of cyber-resources for sex therapy. Binik (2001) concluded his introduction to the special section of the journal by arguing that although research on cyberspace and sexuality has not yielded substantial insights in our understanding of sexuality, "there is the potential for carrying out important new research 
that will have significant implications for theory and service delivery. This will probably take at least a decade to realize" (p. 282).

The difficulty Binik and Delamater experienced with editing a special issue on cyberspace and sexuality illustrates, more generally, the problems cyberspace poses for research. Cyberspace is troubling for researchers because, as a geography, it complicates the traditional distinction between space and place. In this way, cyberspace is a "strange place" that is experienced in the here and now, but also elsewhere. Strange places do not correspond neatly to geographic constructs of "space," "place," or "spatial-temporality" because they confuse boundaries that establish and facilitate "here," "now," and “elsewhere.” Bammer, Gwin, Katz, and Meese’s (1998) early effort at defining cyberspace by contrasting it with printed books illustrates the difficulty with conceptualizing strange places. Bammer, Gwin, Katz, and Meese (1998) argue that, "[t]he page of a book, like the computer screen, is a frontier through which we enter a non-space space, the space that isn't 'really' there. It is a safe space, which the actual, material spaces in which many people live, is [sic] not" (p. 67). Mary Flanagan (2000); however, has pointed out that the comparison to books is inaccurate because it does not account for how our interactions in cyberspace are implicated in the materiality, or "hereness," of our lives. More recent efforts at conceptualizing or defining cyberspace have fared no better. In fact, it appears that it is becoming more difficult to define cyberspace because the Internet involves so many configurations of technology, identities, experience, location, and social relationships and, hence, creates numerous ways of deconstructing boundaries (Dahms, 2009; Turkle, 2011). Henry Dahms (2009), for example, discusses how software programs that create spaces where car- and air- 
traffic, or retail trade, can be remotely controlled. Conceptualizing cyberspace as a site and/or subject of research, then, requires a clear understanding of "space" and "place."

French social theorist Michel de Certeau's (1984) work on how space and place are socially produced provides a method for conceptualizing cyberspace. According to de Certeau (1984):

A place (lieu) is the order (of whatever kind) in accord with which elements are distributed in relationships of coexistence.... The law of the "proper" rules in the place: the elements taken into consideration are beside one another, each situated in its own "proper" and distinct location, a location it defines. A place is thus an instantaneous configuration of positions. It implies an indication of stability (p. 117).

In contrast, a space (espace) is defined by movement, direction, and time. And, as de Certeau (1984) explains, “[i]n relation to place, space is like a word when it is spoken, that is, when it is caught in the ambiguity of an actualization, transformed into a term dependent upon many different conventions....In short, space is a practiced place” (p. 117; emphasis in the original). Cyberspace is a space because it implies movement within, and between areas; however, it does not correspond to our perceived construct of geographical place as a reference to physical location. Nevertheless, as Barbara Warnick (2007) points out in Rhetoric Online: Persuasion and Politics on the World Wide Web, cyberspace does have material components (e.g., the size of the computer's memory, location in physical space, distance from service provider's infrastructure, and one's available computer equipment) that create and constrain its use. Furthermore, we use spatial language to organize and represent cyberspace (e.g., website addresses, home 
pages, web traffic) and we have to connect to cyberspace from a physical location such as home or work. Therefore, cyberspace includes all the elements of a physical geography; nevertheless, cyberspace escapes the traditional conceptualization of a place. In cyberspace, one can be in multiple places at one time provided that he or she has the necessary equipment (e.g., sufficient memory to open up multiple windows, etc.). Ultimately, the problem with cyberspace involves conceptualizing how boundaries between conceptual and material realities are created and enforced. Postmodern geographer Edward Soja (1996), however, offers a corrective to the confusion of boundaries with his concept of thirdspace.

\section{Thirdspace: Familiarizing the Strange}

One of Edward Soja's (1989) many contributions to theories of spatiality has centered around his argument that "spatiality can be distinguished from the physical space of material nature and the mental space of cognition and representation, each of which is used and incorporated into the social construction of spatiality but cannot be conceptualized as its equivalent" (p. 12). For Soja (1989), spatiality is a multidimensional phenomenon that indicates how material and symbolic realms of social life are analytically distinct, but experienced together. Moreover, Soja's (1989) concept of spatiality deconstructs false dualisms created between material and conceptual realities that have contributed to the illusion to opaqueness (the idea that space is primarily material and concrete) and the illusion to transparency (the idea that space is primarily conceptual and mental). In short, Soja's (1989) notion of spatiality indicates a convergence between space and place or material and conceptual realities.

Soja's (1989) reconceptualization of spatiality was motivated by his re-visioning 
of Henri Lefebvre's (1991) triple dialectic of space, which includes perceived space, conceived space, and lived space. Perceived space (also referred to as "spatial practices" by Lefebvre and "firstspace" by Soja) is empirically observable material or concrete space. Conceived space (also referred to as "representational space" by Lefebvre and "secondspace" by Soja) is a mental representation of space created by planners, social theorists, geographers, and others charged with constructing space discursively. And lived space, is the space people inhabit and move through in their daily lives. Soja (1989) supported Lefebvre's (1991) theory of the social production of space, but updated it to reflect a "trialectics of spatiality" that dismantled the dualistic approach to theories of spatiality, or those that presented perceived and conceived space as separate dimensions, by introducing "thirdspace" - a form of spatiality characterized by a synthesis of Lefebvre's perceived, conceived, and lived space. For Soja (1996), "thirdspace" is a form of space produced from the deconstruction of binaries between conceived and perceived, or first and secondspace. In thirdspaces, “...everything comes together...subjectivity and objectivity, the abstract and the concrete, the real and the imagined, the knowable and the unimaginable, structure and agency, mind and body, consciousness and unconscious..." (Soja, 1996, p. 57). Furthermore, in thirdspaces, lived, conceived, and perceived spaces "contain each other, they cannot successfully be understood in isolation or epistemologically privileged separately" (p. 76), nor can they be understood outside of power relations involving domination and resistance. "Thirdspace," then, represents a "both/and" dimension of spatiality (see Collins, 1990), which synthesizes the material and symbolic realities that create geographical environments. In effect, thirdspace familiarizes strange spaces by operationalizing 
"strangeness" as a quality of thirdspace. Strange spaces are those that do not correspond neatly to geographical boundaries like perceived, conceived, and lived spaces; instead, strange spaces represent a convergence of perceived, conceived, and lived spaces. "Strangeness" is an indicator of thirdspace; part of its definition.

In this chapter, I will examine research articles on sexuality and cyberspace published in the Journal of Sex Research to examine how sexologists transform the Internet, discursively, into a series of rhetorical cyber-thirdspaces. In what follows, I will present my theory of rhetorical thirdspaces, explain how I am approaching the articles as discursive stagings of discourse of sexuality, and explain how three different cyberthirdspaces (the Pornosphere, Erotic Oasis, and Jim Crow Cyb) are created in the sexological discourse. My discussion on how rhetorical cyber-thirdspaces are produced in the sexological discourse includes an examination of how methodological problems in research design contribute to different understandings and representations of the implications of rhetorics of democratization of sexuality in cyberspace.

\section{Toward a Theory of Rhetorical Thirdspace}

In chapter 1, I presented Roxanne Mountford's (2001) theory of rhetorical space as the driving concept of this dissertation. To review, Mountford (2001) defined "rhetorical space" as "the geography of a communicative event" (p. 41). Her conceptualization differed from earlier theories of rhetorical space (see, for example, Lorraine Code, 1995) that presented spatiality as shorthand for "context" within rhetorical situations by emphasizing the generative role of rhetorical spaces in larger systems of discourse. Mountford (2001), for instance, demonstrated in her research on gender and the pulpit that the pulpit, as a rhetorical space, participated in the construction 
of discourses that institutionalized and normalized the subjugation of women. The pulpit served as a space through which those rhetorics were generated. Essentially, Mountford's (2001) generative theory of rhetorical space identifies how micro-level rhetorical acts culminate in macro-level discursive acts and social formations that reinforce and naturalize social stratification.

More recently, in “A Woman's Place is in the School: Rhetorics of Gendered Space in Nineteenth-Century America," Jessica Enoch (2008) analyzed how spatial metaphors based on the prison and the home transformed the schoolroom from a masculine space that represented discipline to a feminine place that represented nurturing. Enoch (2008) described her research as an examination of how rhetorics of space, those spatial practices that explain "what the space should be, what it should do, and what should go on inside it" (p. 276), constructed gendered schoolrooms. She argued that rhetorics of space have the potential to make a space either powerful or defused by giving value to the activities that happen inside that space and by suggesting or prescribing the kinds of occupants that should (and should not) move into and out of that space. Enoch (2008) concluded her work by urging rhetoricians to further investigate the kinds of rhetorical activities that are infused in space, or how people "lay claim to, are barred from, and move into space, but also how spaces are empowered or disempowered through both overt and subtle rhetorical shifts in the discursive and material environment" (p. 289). Enoch (2008) posed three specific questions for researchers to consider: (1) how are gendered spaces made and remade? (2) how do race and culture inform rhetorics of space? and (3) how might we offer new visions of spaces for empowerment? 
I interpret Enoch's (2008) call for research on the construction of spatiality as a call specifically for research that examines how spatiality is used in normalizing rhetorics of space (praxical rhetorical space). The analysis in this chapter represents an answer to such a call by explaining how sexologists draw on a rhetoric of the democratization of sexuality to normalize cyberspace as an erotic environment.

\section{"Thirding" Rhetorical Space}

Rhetoricians of space have not fully incorporated Soja's (1996) construct of thirdspace into their analytic frames; however, compositionists have drawn on the concept of thirdspace to complicate the notion of "locatedness" in writing contexts. In Making Writing Matter: Composition in the English University, for example, Ann Merle Feldman (2008) conceptualized thirdspace as "a geo-rhetorical construction...that honors the way that 'lived space' connects with discourse and location" (p. 178). Feldman (2008) uses "thirdspace" to encourage student-writers to view their writing from a georhetorical stance that takes into account what it means to be present in rhetorical situations. William Burns (2009) has also addressed the potential of "thirdspace" in composition in his article, "The Trialectics of Public Writing on the Street, on Campus, and in Thirdspace." Burns (2009) urged compositionists to use "thirdspace" to complicate the distinction between private and public spaces by demonstrating how, in reality, there are multiple and contested material, social, and discursive conventions and expectations that influence spatial practices, identities, and forms of communication. Burns (2009) used the concept of "publicandprivate" to indicate "spaces, identities, and discourses in which notions of public and private are so closely linked that to separate the terms and experiences would be to lose sight of the interconnectedness and reciprocity of 
these relationships" (p. 36). Similarly, Lauer (2009) has identified how composition students can draw on the construct of thirdspace in their examination and representation of identity construction. Lauer (2009) presented thirdspace "as an ever open space" (p. 57) where binaries that dominate cultural awareness are reconfigured to create alternate possibilities for understanding identities and for constructing identities. Rhetoricians can draw on compositionists' use of thirdspace to examine, more generally, how "strange spaces" complicate understandings of "location" in rhetorical acts and how discourse is implicated in the construction of these spaces.

\section{Discursive Stagings of Rhetorical Cyber-Thirdspaces in Sexology}

The analysis presented in this chapter is based on an examination of eleven articles addressing the relationship between sexuality and the Internet published in The Journal of Sex Research between 1999-2012. I'm following Matus and Talburt (2009) by approaching these articles as institutional documents that produce social facts whose collective authorship construct and legitimate social constructs of reality. These articles represent discursive stagings of cyber-thirdspaces that "naturalize ways of thinking about space and place" (p. 519). Discursive stagings provide insight into how the parties involved (in this case, researchers and their subjects ${ }^{5}$ ) in the construction of discourse present, or stage, their discourse.

For this chapter, I collected all of the articles $(\mathrm{n}=45)$ published in The Journal of Sex Research that contained any of the following terms in the title or abstract:

\footnotetext{
${ }^{5}$ In this chapter, because I'm concerned with the representation of spatiality in sexology, rather than adjudicating the accuracy of the researchers' work, I am not citing the articles by name in text, but I do include parenthetical citations. I'm approaching the articles in the same manner as one would approach interviews in qualitative research.
} 
cyberspace, Internet, or online. Following the initial collection process, I excluded the book reviews and coded each remaining article in relation to the role the Internet plays in the researcher's analytic frame $e^{6}:$ (1) research instrument (the Internet was used as a means for collecting data or disseminating research, but had no explanatory role in the analytic frame) or, (2) explanatory mechanism (the Internet played an explanatory role within the researcher's analytic frame). Second, I excluded the articles drawing on the Internet as a means for collecting data or disseminating research and coded each of the remaining eleven articles that approached the Internet as an explanatory mechanism in relation to the following variables: (1) the researcher's exigency and purpose; (2) the researcher's basic assumptions regarding sexuality, the Internet, and the relationship between sexuality and the Internet; (3) the role and characteristics of the research subjects; (4) research designs; and, (5) the research findings and interpretation. Finally, I used the constant comparative technique ${ }^{7}$ to identify how researchers have transformed the Internet into rhetorical cyber-thirdspaces that frame and motivate discourses of

\footnotetext{
${ }^{6}$ I drew on Charles Ragin's (2010) interpretative model of social research as a guide for my analysis. His model specifies how ideas and social theory create analytic frames that produce specific representations of social life by providing "conceptual tools for differentiating phenomena within the category (what makes them more and less successful; more and less formal; more this, less that; and so on)“ (p. 64). These elements are, in turn, used to create images of social reality. This process is significant because researchers are able to relate their work to that of other researchers in order to accumulate knowledge about society. The analytic frame (which is always located in relation to a field of accumulated knowledge) functions as a discursive snapshot of reality.

${ }^{7}$ The constant comparative technique is a component of the grounded theory research design developed by Glaser and Strauss (1967). The technique is based on coding data to identify categories, and eventually theories, that emerge from the data. At each stage of coding, the data are compared to identify relationships. I used this technique to identify the spatial imaginaries (based on comparisons of exigency, etc.). I should note that some qualitative researchers are opposed to the use of grounded theory in research other than that based on in-depth interviews (see Suddaby, 2006).
} 
sexuality and sexual social control.

In general, I found that sexologists have constructed three rhetorical cyberthirdspaces that represent the relationship between cyberspace and sexuality: (1) The Erotic Oasis; (2) The Pornosphere; and, (3) The "Jim Crow Cyb." Each of these spatial imaginaries appeals to the notion that cyberspace has democratized sexuality, or that the Internet is an unregulated area that is available at low cost to large numbers of relatively obscure people; however, these spatial imaginaries represent opposing views regarding the implications of the democratization of sexuality. More specifically, the erotic oasis represents democratization as a process that has created cyberspace as an open and welcoming space where people can construct their own sexual identities, practices, and sexuality. In contrast, the pornosphere represents democratization as a process that creates cyberspace as an impetus for personal and social pathologies such as sex addiction and divorce. And, the "Jim Crow Cyb" represents democratization as a process that has created and legitimated racism, ethnocentrism, and segregation on the Internet. Each of these rhetorics of space will be described in more detail in the sections that follow.

\section{Rhetorical Cyber-Thirdspaces in the Journal of Sex Research}

\section{The Erotic Oasis}

An erotic oasis "is a location considered physically and socially safe...from threats of exposure. Erotic oases provide individuals with opportunities to gather and pursue mutually desired sexual interactions and include both private and public settings" (Tewksbury, 2002). As an oasis, the Internet is represented as a cyber-thirdspace where marginalized groups exercise agency in relation to the construction and negotiation of 
identities and community. The following passage from an article in the Journal of Sex Research on how the Internet creates opportunities to demarginalize sexual identities appeals to the rhetoric of democratization to explain how the Internet, as an erotic oasis, is a site for sexual agency because the Internet provides local access to sexual resources that are otherwise unavailable to marginalized, or potentially marginalized, people and groups:

In a sense, the Internet has democratized access to sexually related material. Erotic bookshops and video stores can generally be found only in urban areas, often in the seedier parts of town, and with a limited offering of materials. Little erotic material had traditionally been made available that caters to women and women have had little opportunity to discover its existence. Now, however, erotic material of all kind is freely available to anyone with access to the Internet. Individuals can obtain, peruse, and create erotica without leaving the privacy of their own homes (McKenna, Green, and Smith, 2001, p. 302).

The democratization of sexuality provides access to endless numbers of sexual resources that are, otherwise, unavailable in the "real world" by synthesizing the sociogeographical. The synthesis of socio-geographical boundaries is represented in the following passage from an article describing the benefits of Internet technology for sex education: "Internet-mediated e-learning...enables those who reside in remote locations, or who are physically confined, to receive varied educational programming of high quality....[that allows] rapid communication between learners and instructors, and enable ‘classroom discussions' among physically isolated learners” (Barak and Fisher, 2001, p. 
324). The synthesis of socio-geographical boundaries allows individuals to be in two places at one time. An individual can participate, for example, in a sex education discussion from the privacy of his or her home.

The erotic oasis also alters spatial-temporal relationships. The following passage from an article on seeking sex online illustrates how the Internet renegotiates spatiotemporal boundaries by removing interactional norms and sundries: "The Internet allows for the avoidance of the 'attitude' and social cues and conventions that slow down the progress to sexual interaction” (Ross, Rosser, McCurdy, \& Felder, 2007, pp. 70-71). Various sexual niches provide people with an opportunity to "save time" by filtering potential sexual partners. The notion that the Internet alters space and time is also represented in the following discussion of the "sexual marketplace." The author of an article theorizing the implications of the Internet for sexual interactions argues that: Sex has....become, through the Internet, 'fast' -- it can be likened to take out versus a sit-down meal. The advantage of the Internet is that it is able to be engaged relatively anonymously, and, in the case of cybersex, without having to leave the house and at any time of the day or night. Snacking at the sexual smorgasbord for cybersex is as easy as having a candy bar while sitting at the computer. Thus, while previously sexual contact with another person was limited largely to the 'eat out' or 'fast food' variety, cybersex has added a new possibility of having sex that is less lonely than masturbation (Ross, 2005, p. 347).

The previous passage indicates how, in addition to providing resources, the erotic oasis provides an opportunity to reconstruct hegemonic constructs of sexuality. Furthermore, 
the researcher suggests that we lack the language necessary for representing cybersex, which implies that cyberspace has the potential to create new sexual realities.

A more common sexological representation of the erotic oasis centers around the idea of the "marketplace of mutuality," which is represented below:

Sexual fantasies usually remain a solitary affair, culminating in daydreams or masturbation. Occasionally they may, with the discovery of a partner who... is prepared to act them out, be mutual. As a marketplace for finding such mutuality, the Internet is unmatched in its scope, unlimited by geography, time, or numbers in its catchment area (Ross, 2005, p. 344). This passage illustrates the idea that the sexual marketplace offers access to additional resources that can ultimately change the construct of sexuality and it adds the idea that acts or desires that were once isolated (a spatial understanding) are now relevant to social interaction. Participants or inhabitants in the sexual marketplace can connect to similar others who can help them fulfill their fantasies - a sexual opportunity that is not necessarily available to them in the "real world." The erotic oasis, then, provides an opportunity for connecting with those who have similar desires and a way to begin facilitating community, or a "safe haven."

The notion of the safe haven resonates with the construct of community in cyberspace. As a discourse, the safe haven construct draws on rhetorics of "safety" and "community," but differently than the rhetoric of space has been used in heteronormative discourses in offline spaces. Rhetorics of safe space often, though not exclusively, support straight-privilege, for example, by creating and assigning blame for sexual victimization when marginalized and exploited others move out of spaces designated as 
"safe" (Skeggs, 1999). In the context of the sexological discourse I examined for this chapter, however, rhetorics of safe cyberspace presented the Internet as safe haven from difficulties associated with constructing sexual identities and desires. One group of sexologists, for example, characterized cyberspace as a "salve where there is little opportunity for or where there are barriers to the development of communities" (Brown, Maycock, and Burns, 2005, p. 63). Cyber safe havens provide an alternative context for engaging and participating in the queer community without outside pressure. This opportunity is represented in the following passage, which involves a researcher explaining how his subjects have explored their sexual identities in cyberspace:

[Those] who were in the process of exploring or understanding their sexuality...described the Internet as a space to gain information, learn about being gay...covertly interact with a reference group through whom they could be socialized and acquire the knowledge, norms, attitudes, and language of the gay community" (Brown, et. al., 2005, p. 67).

Another sexologist who found a similar pattern argued that this web experience has provided "...the possibility of an additional stage in that coming out process: lurking on the internet...to watch the interactions, learn some of the language, and gain an understanding of what being gay is about. In a sense, the internet is equivalent to a oneway window into a gay bar: the individual can observe but not be observed" (Ross, 2005, p. 348). Michael Brown (2000) has addressed the issue of the closet and coming out in his work on "closet space." Brown (2000) has argued that the most important and refreshing insight of Eve Sedgwick was her argument that the closet was located in ironic relations of knowing-by-not-knowing; a place where stigma could simultaneously be 
hidden and visible. Closet space within the erotic oasis represents a site where one can be in and out simultaneously (see also, Knopp, 2007). The erotic oasis offers new insights into how queer desires and practices are spatialized. As a safe haven within an erotic oasis, cyberspace allows for more agency or self-awareness than other contexts may provide.

Safe havens allow for new opportunities not only with respect to exploring or proclaiming sexual identities and desires, but also, as the following passage from an article on demarginalization of sexual identity illustrates, for creating satisfying sex relations and negotiating "spoiled" identities:

Those who are currently lacking in satisfying real-world relationships -for instance, the socially anxious and the lonely -- are more likely to locate and express what they feel to be their true selves on the Internet rather than in real life....[T]hose who lack satisfying real world sexual relationships and those who are constrained in expressing their real sexual needs to offline partners are more likely to turn to the Internet for their sexual self-expression....the result is a demarginalization of one's sexual self-- specifically, the acquisition of a positive sexual identity where before there were feelings of isolation and shame (McKenna, Smith, and Green, 2001, p. 309).

The notion of demarginalization suggests that as a queer space, the Internet provides an opportunity, a "safe haven," to play with, and resist, heteronormative structures. One technique for resisting pressures from outside communities includes re-invoking the public-private distinction by "pulling the plug" on threatening or unsatisfying 
interactions. This technique is represented in the following passage from an article describing how gay men use cyberspace to facilitate relationships:

$[\mathrm{T}]$ he fact that they could disconnect from the Internet at any time provided an experience of control over their privacy and how much of themselves they chose to present, which they did not experience in other spaces....This safety from 'spoiled identities' may relate to why the Internet may be so popular among gay men. Regarding most other environments, gay men spoke about having to negotiate their identity and the identity of others with limited clues....On the internet, there is less risk of misinterpretation, as much is negotiated first without the need to identify themselves and the men can be very specific about who and what they are looking for (Brown, Maycock, and Burns, 2005, p. 67-8).

Within the safe haven, participants are able to proclaim a self-constructed, rather than socially ascribed, sexual identity. The safe haven affords one the opportunity not only for self-constructed identities, but also for self-constructed narratives. The freedom associated with the ability to construct identities is reflected in the following statement made by a research subject in an article investigating the role of race and ethnicity in online ads. The respondent explained that, "online is totally different. You can have a different identity, you can be anyone who you want to be" (Paul, Ayala, and Choi, 2010, p. 531). A respondent in a different article added, “....when people talk about being on the down-low, it's just another way of saying, "What I do needs to be kept as discrete as possible" (Wilson, Valera, Venteneac, Balan, Rowe, and Carballo-Dieguez, 2009, p. 404). In the context of a safe haven, the issue of discretion is reconstructed as personal 
choice rather than as an expression of internalized homophobia. The safe haven, in general, affords sexual agency with respect to constructing one's sexual identity and creating a sexual narrative that represents the construction of self. This trend has also been noted by Harrison (2010) in his discussion of the online queer migration. He notes that point-to-point communications, like chat rooms, have provided an opportunity to reconstruct personal narratives in heterodominant culture.

Finally, the safe haven, as an element of the erotic oasis, also represents an environment that affords fewer physical and emotional threats. This sentiment is represented in the following quote from a respondent interviewed for research on gay men's experiences on the Internet. He explains, "I feel the Internet is safer. I don't really know why....I mean if they are going to come around there is a history on the Internet and they can track them down if I get murdered or something - I am not sure if that is true but that's what it is in my head. But if you get murdered at the beach no one is going to know anything" (Brown, Maycock, and Burns, 2005, p. 68). Another respondent interviewed for the same article added that, "You can do it in the safety of your own home. That security....yeah, I think it is a thing of comfort in your own environment" (Brown, Maycock, and Burns, 2005, p. 68). These passages indicate how the technologies of the computer and Internet function as safety features or a way to use selfsurveillance in the interests of agency.

The erotic oasis is a rhetorical cyber-thirdspace where one has all the necessary resources, via the sexual marketplace, to create a safe haven that affords him or her the opportunity to create an affirming sense of self or demarginalize a "spoiled" identity. Sexologists who created this discursive staging of the erotic oasis were motivated by the 
assumption that the Internet afforded sexual "others" an opportunity for agency and selfnarration. In characterizations of the Internet as an erotic oasis, the democratization of sexuality was presented as a positive social formation that has created inclusive communities and challenged social control.

\section{The Pornosphere}

The pornosphere is a second type of rhetorical cyber-thirdspace. Like the erotic oasis, the construct of the pornosphere is based on researcher's evaluation of the democratization of sexuality on the Internet. The pornosphere differs from the erotic oasis; however, because the democratization of sexuality is perceived as contributing to an anomic sexual environment within and outside of the Internet.

As a "pornosphere," the Internet is presented as a medium within a larger category of media that includes film, music, and television. Sexologists conceptualizing the Internet as a pornosphere, however, believe that the Internet is more dangerous than other forms of media because of the lack of formal and informal mechanisms of social control. In an article on sex addiction, for instance, the author argued that traditional media have been regulated by federal decency standards that have limited the types of sexual interactions represented in the media or how they are represented. These same regulations have not yet been used to manage and regulate sexuality in cyberspace. In the pornosphere, the Internet is presented as a "vehicle for the circulation of much more hard core and fetishized images...[that are] available in the privacy of one's own home rather than solely in 'adult' bookstores or movie theaters..." (Albright, 2008, p. 175). Problematic places of sexuality, like "red-light districts," are brought into the home, which decreases "the possibility of moral sanction toward viewing even such hard core 
and taboo imagery as child porn, bestiality, or violent sadomasochistic sex" (Albright, 2008, p. 175).

Generally, recent arguments about the dangers of porn have focused on the notion that porn incites violence. The imagery associated with the "dangers" of porn has encouraged the idea that pornography could inflame or ignite antisocial emotions and arousal; yet, doing away with it altogether could incite arguments regarding free-speech. Therefore, the control of pornography has often been accomplished through a "politics of concealment" whereby local governments confine pornography to urban environments. The zoning laws that began in the 1970 s, for instance, have been used to prevent sexrelated businesses from opening up in the vicinity of homes, schools, and churches, and these laws have thus moved sex-related businesses to the peripheries of urban areas (Hubbard, et. al., 2008). Furthermore, these zoning laws have prevented co-location of sex-related businesses within 1000 feet of one another (Seidman, 2009). These laws have been upheld in court by the assumption that they keep out anti-social elements that could contribute to neighborhood deterioration (Hubbard, et al., 2008). Such decisions allow the state to uphold the idea that pornography is a right, yet also potentially dangerous (Seidman, 2009).

In many respects, debates, and sexological research on cyber-porn, have been used to mark public and private spaces, and thus provide institutional support for the creation of "hierarchies between good and bad sexual practices and sometimes between good and bad citizens ” (Seidman, 2009, p. 96). Often, these hierarchies have involved elite male groups controlling sexual discourse through appeals to fears of a breakdown in familial and romantic relationships, a breakdown allegedly inspired by the 
democractizaton of sexuality (Plante, 2006).

Many of those who conceptualize cyberspace as a pornosphere assume that people are inherently drawn to "devious" constructs of sexuality and that there is a linear progression from "normal" to "deviant" desires and practices and that as experts they have the right to determine what is normal and what it is deviant. The following passage from an article on the effects of cyberporn illustrates the theory of normal and deviant desires:

We must expect...that just as individual consumers of pornography tend to tire of a certain level of explicitness and need more, so, too [sic]would the market, acting as an individual. Thus, the more pornography is consumed at one level, the less arousing this material becomes, as the consumer becomes used to--satiated with--the material. This satiation leads the consumer to seek out newer, more explicit, and more violent forms of sexual material that will again arouse him/her....(Barron and Kimmel, 2000, p. 165).

The passage above outlines a theory of linear progression from "normal" desires to violent representations and also implies justification for sexual social control. The notion of inherent dangers provides support for the assumption that external social controls such as legal regulations are needed to maintain normalcy (Seidman, 2009). There is also an assumption that the notion of what is considered "violent" is an agreed-upon ideology. Furthermore, the "market," invoked as an individual, is presented as a potential victim of the pornosphere.

The pornosphere, like the erotic oasis, draws on the notion a marketplace; 
however, in the pornosphere, the marketplace is presented as an institution with weakened social control. Authors of an article on pornography and masculinity, for instance, argued that "[pornography] is more democratic, with greater mass access and far less dependence on commercial advertisers. It is as close as one can get to men's direct expressions of their own fantasies, unconstrained by the demands of the marketplace or the high costs of producing and distributing those fantasies to others" (Barron and Kimmel, 2000, p.166). The pornosphere, then, is represented as a structure that undermines efforts at controlling problematic intrinsic and extrinsic sexual desires.

Sexologists often tie the problems created in the pornosphere to gender relations in hetero-coupling. The "Centerfold Syndrome," which refers to unattainable standards of beauty or sexiness for women to achieve, reflects one such implication of participating in the pornosphere. A sexologist explains that, "[t]he constant barrage of images of everwilling, sexually insatiable, augmented, and air-brushed women will leave males no longer desirous of 'real-life' women as potential sexual partners, something that has been termed the 'Centerfold Syndrome"' (Albright, 2008, p. 176). This sexologist also asserted that “...plastic surgery has risen enormously, including breast augmentations...labioplasty, hymen replacement, and vaginal tightening, which may be an attempt...to [create] an expectation that they look like these new role models (i.e., porn stars)" (Albright, 2008, p. 185). The researcher concluded that men benefit from their participation in the pornosphere by having access to supplemental sexual materials, whereas women are victimized by the unattainable ideals that are represented in pornographic images. The accessibility of porn and other erotic materials is problematic, in this account, because of the implications for heteronormative coupling. Women within 
hetero-couplings are presented as potential victims of the standards of beauty and sexuality that are created and perpetuated in the pornosphere.

The theoretical framework that sexologists use in their construction of the pornosphere often creates the connection between cybersex and social disorder, particularly with respect to marriage, but also in terms of re-creating social formations that contribute to misogyny. One such theory is the "goodness/poorness of fit" theory, which suggests that antisocial personality characteristics will encourage individuals to seek out antisocial sexual content (goodness of fit) and those who do not possess these characteristics will avoid antisocial sexual content (poorness of fit). Researchers adopting the goodness/poorness of fit theory argued that "most individuals have a lifetime learning history and a set of expectancies about acceptable and unacceptable sexual behavior that is sufficient to deter them from accessing or acting on antisocial sexual content on the Internet" (Fisher and Barak, 2001, p. 313). Therefore, sexual and social problems occur for those people who do not have proper social controls such as the family or education system. Social exchange theory, represented below, illustrates a second theory that associates cybersexuality with the breakdown with the family:

Social exchange theory states that people will stay in a relationship in part when attractive outsiders are not readily available....The Internet provides ready access to a huge pool of potentially attractive others: Perhaps people already married or in committed relationships are unhappy and are "testing the waters" to see if an attractive other would respond to them online, allowing them to transition out of the marriage. Thus, Internet personals actually may be fostering divorce through providing 
easy access to a multitude of attractive alternatives to their marital partners (Albright, 2008, p.184).

The assumption in the previous passage is that the democratization of sexuality has a direct and negative influence on a hetero-couple's relationship. The relationship is presumably strong on its own without the threat of an outside source that entices individuals out of the home.

The appeal to the breakdown of the family was also cited frequently in sexological work on sex addiction. Sexologists working in the area of sex addiction often represent the pornosphere as a catalyst for sex addiction because of the vast sexual resources the pornosphere offers. The central issue; however, concerns how online affairs are conceptualized. One sexologist, for instance, argued that, "[ $\mathrm{t}]$ raditionally, infidelity has been viewed as having physical contact with someone outside of marriage or a significant relationship. Internet sex has the potential to change the parameters of infidelity" (Griffins, 2001, p. 340). Changing the parameters by which we understand infidelity creates confusion around the definition of the family and the norms that control romantic and sexual relationships. The pornosphere, like the erotic oasis, is assumed to alter sexual meanings and opportunities for sexual practices; however, in the pornosphere, the alternatives are perceived as a threat to the construct of family and marriage.

Finally, some sexologists associated the pornosphere with the re-creation of misogynist social structures. Two sexologists, for example, characterized Internet newsgroups as "the closest things to the all-male locker room that exist in the pornographic world: A world, in a sense, entirely without women, a world in which men 
control absolutely all facets of the scene in which women do not insert themselves as corporeal beings" (Barron and Kimmel, 2000, p. 166). These sexologists also argued that the homosociality element has been ignored in the literature because scholars tend to "read" pornography as a discourse about men's relationships with women, when, in fact, the Usenet functions as a space that offers homosocial competition, or "a relationship among men in which the sexual victimization of women is a currency among men, used as a way to facilitate upward mobility in a masculine hierarchy" (Barron and Kimmel, 2000, p. 166).

The pornosphere, in many respects, represents a dystopic view of the Internet and sexuality. It represents a "worse-case" scenario of what could happen in a world where sexuality is unregulated. A sexologist arguing that the Internet potentially provides a new opportunity for the development or encouragement of sex addiction suggests that, The Internet may provide an alternative reality to the user and allow them [sic] feelings of immersion and anonymity (which may lead to an altered state of consciousness)....There may be people using the medium of the Internet because (a) it overcomes the embarrassment of going into shops to buy pornography over the shop counter and (b) it is faster than waiting for other non face-to-face commercial transactions (e.g., mail order). Anonymity may encourage deviant, deceptive, and criminal online acts such as the development of aggressive online personas and downloading of illegal images (e.g., pornography) (Griffiths, 2001, p. 335).

The pornosphere inverts the implications of the democratization of sexuality for an erotic oasis by associating democratization with familial problems typically surrounding gender 
norms and ideologies. In the pornosphere, positive and affirming relationships are not facilitated. Instead, the pornosphere undermines positive and affirming relationships. The threat to a hetero-centric constructs of "love" and "intimacy" lurks in the background of the arguments made by those who have constructed the Internet as a pornosphere. Michael Ross (2005), drawing on Anthony Giddens' work on sexuality, has argued that the Internet has transfigured sexuality by removing the association between reproduction and sexuality and allowing "emotional and physical fulfillment to occur with an electronic partner who may or may not bear much resemblance to the physical partner who is typing at the keyboard. This is not just an ultimate removal from reproduction; it is also an ultimate removal from social sexuality" (p. 343). The association between pornography and the breakdown of the family appears to be rooted in concerns about the transfiguration of intimacy, which is also rooted in hegemonic discourses of love.

Eva Illouz (2011) explains that in hegemonic discourses on sexuality "the emotion of love cannot be separated from the social rules pertaining to the control of women's and men's sexuality, the regulation of marriage, and the ways in which property is transmitted" (p. 194). Hegemonic discourses on love have encouraged the idea of "soulmates," or the idea that we all have one true love that is all-encompassing and irreplaceable (Illouz, 2011; Kipnis, 2003). Furthermore, Illouz (2011) argues that we live in a culture where,

love plays a central role in the definition of self and in which actors engage in a wide variety of symbolic practices to create, experience and maintain the emotion of love....It is heterosexual but not necessarily 
oriented toward child-bearing and child-rearing; it is connected to marriage, but can easily thrive without it; it privileges intensity and excitement, yet aims or claims to be long-lasting. Finally, it is individualistic...in the sense that it gives expression to the innermost unique and authentic aspects of the self (p. 196).

As a dystopic representation of the erotic oasis, the pornosphere represents a world without (a hetero-centric) love and external social controls. For those presenting the Internet as a pornosphere, the threat to hetero-centric love and external social controls is potentially dangerous whereas those who conceptualize the Internet as an erotic oasis suggest that the threat to hetero-centric love and external social controls is potentially empowering.

\section{The "Jim Crow Cyb"}

The "Jim Crow Cyb," a third rhetorical cyber-thirdspace, includes elements of the erotic oasis and pornosphere. It is similar to the erotic oasis by presenting cyberspace as a thirdspace where sexual others, however defined, can exercise agency in their pursuit of sexual satisfaction; however, as with the pornosphere, the Jim Crow Cyb complicates the utopian construct of the oasis by highlighting how cyber-thirdspace contributes to social divisions based on race and class.

Nancy Oswin (2008) has argued that the focus on the heterosexualization of space can create a dichotomy between straight and queer places that masks how sexuality is deployed with respect to race and class. Oswin argues that "queering...analysis thus helps to position sexuality within multifaceted constellations of power" (p. 100). Phillip 
Hubbard (2000) has made a similar argument by noting that exploring geographies using a hetero/homo binary ignores the complex and contradictory ways that sexuality intersects with other forms of social difference such as race, class, and gender. The Jim Crow Cyb, then, complicates the hetero/homo dualism implied in the distinction between the pornosphere and erotic oasis. The issue here is intersectionality, which references the rejection of race, class, gender, and sexuality as essentialist constructs, in favor of an approach that highlights how these constructs intersect to create social realities (Valentine, 2007). Intersectionality is defined more formally as "the way in which any particular individual stands at the crossroads of multiple groups" (Minow quoted in Valentine, 2007, p. 12; see also Collins, 1990). Intersectional analyses illuminate hidden, but interlocking, systems of domination to reveal power relations. In the case of the rhetorical cyber-thirdspaces discussed in this chapter, intersectionality highlights how cyber-thirdspaces are marked by race and class. As the following passage illustrates, the Jim Crow Cyb illustrates how the Internet functions as cyber-thirdspace:

Typically, the likelihood of experiencing racial and ethnic hostility is situated within a dimension of physical space, with private spaces viewed as the most protected and public sites seen as leaving one most exposed to discriminatory experiences....Internet-mediated hook-ups enable one to negotiate such contacts in the privacy of one's home--perceived by our respondents as an advantage. This creates a curious paradox where one's most private space both serves as a haven and isolates one while encountering racial and ethnic prejudice (Paul, Ayala, and Choi, 2010, p. $535)$. 
Although the Internet is presented as a space of equal opportunity because of the anonymity it is perceived to create, it nevertheless functions to segregate and objectify. An interviewee quoted in an article on Internet sex ads explained that "[i]n the online world, it's all about specifics so it's either, you know, 'looking for Asian,' or 'no Asians, please.' So it's kind of like, it's hard not to, you know, it's hard not to ignore it [sic]. It's constantly in your face" (Paul, Ayala, and Choi, 2010, p. 532). Another respondent cited in the same article on Internet sex ads explained that, "[O]nce you go online, you're...kind of made into this archetype almost, meaning that as a Black person, a Black male particularly, you're made into this Mandingo fantasy" (Paul, Ayala, and Choi, 2010, p. 532). The hypervisibility of race and ethnicity in cyberspace represented in the previously quoted passages illustrates how constructs of race and ethnicity negatively impact self-esteem. A respondent in an article on sex ads, for example, argued that, ...there is definitely a negative impact on self-esteem with myself or making a general statement, the Asian community that we're not desirable and then when people are IM'ing us, we feel like oh, someone is interested in us and it could be an undesirable person to us but we felt like we need that attention" (Paul, Ayala, and Choi, 2010, p. 534).

Another group of sexologists found a similar pattern that pointed to the role of race in negotiating online sexual relationships. A respondent quoted in an article on Internet sex ads reported that:

[In] the Black [men] for White [men] or White [men] for Black [men] 
chat rooms, just the fact that I am Black, I will have half or nearly half of the White guys in the room message me under the assumption that I'm a top...when it says clearly in my profile that sexually, I'm a bottom. They pay absolutely no attention to this....I could sit in that...chat room for days...and not get one message, but if I create a new screen name that says, 'hot Black top...' I'm getting messages....It makes the dating scene kind of complicated for Black bottoms who are into interracial dating (Wilson, Valera, Ventuneac, Balan, Rowe, and Carballo-Dieguez, 2009, p. 408).

Race and ethnicity are used to erase subjectivity, while also making social differences hypervisible. As the previous passage indicates, race and ethnicity are used to objectify inhabitants and segregate the sexual landscape. The erasure and hypervisibility of race and class illustrates Doreen Massey's (1994) theory of the power geometry. The power geometry is a spatialized form of social control that represents how spatiality is used in the interests of creating and maintaining stratification systems (Massey, 1994). Massey (1994) argues that the power geometries operate via flows and movements within spatial constructs: "Different social groups have distinct relationships to these anywaydifferentiated mobility [sic]: some are more in charge of it than others; some initiate flows and movement, others don't; some are more on the receiving end of it than others; some are effectively imprisoned by it" (p.61). Differentiated mobility is represented in the following quote from an article on Internet sex ads:

Due to the solitary nature of computer-facilitated searches for sex partners, there are fewer buffers to such discriminatory experiences than in the course 
of conventional social interactions. While one can readily terminate contacts suggestive of racial or ethnic stereotyping and prejudice, this is a limited option for managing such negative experiences for MSM of color. Important forms of coping -- for example, the ability to draw on social support and opportunities for direct confrontation and education--are minimized. Although individuals' personal identities might be sheltered by the anonymity of cyberspace, thereby mitigating the emotional toil of rejection...there is no way to cocoon oneself from the repetitious emphasis on race or ethnicity as a key factor in determining one's sexual "desirability" to others (Paul, Ayala, and Choi, 2010, p. 535).

Ultimately, the previous passage and Massey's (1994) theory of power-geometry illustrate how cyber-thirdspaces are organized in relation to privilege and oppression. These geometries create and maintain macro-level stratification systems, such as racialized heteronormativity, and determine micro-level interactions. Spatiality functions as a form of social control that communicates one's "place" in society with respect to race and class.

\section{Issues with Research Design}

The most notable distinction between the pornosphere, the erotic oasis, and the Jim Crow Cyb concerns research design. The articles representing the Internet as an erotic oasis and Jim Crow Cyb all represent valid research designs. The research informing the pornosphere, however, represented several methodological errors or problems, which I present in the section that follows, that render the research invalid. Many scholars acknowledge that science is not the corrective to rhetoric, that, in 
fact, science requires rhetorical devices and techniques to create and present research findings to appropriate interpretative communities. Sandelowski and Barroso (2008), for instance, have illustrated how researchers draw on various literary and rhetorical devices such as metaphors, correlation coefficients, graphs, charts, and coding schemes, to shape the presentation of their work and encourage their readers to accept their findings as valid and reliable indicators of what they were researching. Jasper and Young (2007) have also identified several rhetorical techniques that researchers use to construct truth-claims. These rhetorical techniques are: theoretical ambiguity, conceptual ambiguity, methodological formalism, exaggeration of causal events, extrapolation from limited cases, proxy evidence, misplaced concreteness, and self-testing.

\section{Theoretical Ambiguity}

Jasper and Young (2007) argue that theoretical ambiguity occurs when "causality is simply fudged in vague theoretical arguments that cannot quite be pinned down, a problem that more precise descriptions might resolve. In place of causal clarity, [researchers] substitute a sensibility or language: they rely on the pre-commitments of their audiences" (p. 273). In short, theoretical ambiguity is an effect of a discourse being so institutionalized that the basic assumptions are taken-for-granted. Scholars who read this research are able to "fill in" the gaps with their existing theoretical, or disciplinary allegiances. Theoretical ambiguity is illustrated in an article discussing how adolescents use the media to seek sexual content. The sexologists who conducted the research for this article identified a "feedback loop," which represented the theory that,

the more sexual activity adolescents engage in, the more likely they are to be exposed to sex in the media; and the more they are exposed to sex in 
the media, the more likely they are to have progressed in their sexual activity. Focusing on the simultaneity between behavior and exposure shifts research attention from estimating exposure effects on behavior, the more conventional "media effects" perspective, to the treatment of exposure to sexual media content as a behavior in its own right. Thus, exposure to sexual media content is a dynamic process under the control of individuals" (Bleakley, Hennessy, Fishbein, 2011, p. 309).

The feedback loop is a tautological argument that contains no theoretical substance. Nevertheless, the concept represents the assumption that there is a causal connection between sexual activity among teens and representations of sexuality in the media. The feedback loop relies on others' axiomatic support of the stated, but logically unsupported, theory. In this situation, sexologists rely on their readers' assumption that there is a causal connection between sexual activity among teens and sexuality in the media. As such, the theory of the feedback loop is not perceived as needing support.

\section{Conceptual Ambiguity}

Conceptual ambiguity occurs when "related concepts substituted for one other, with evidence about one taken as evidence about the other" (Jasper and Young, 2007, p. 273). Conceptual ambiguity is represented in an article on whether or not the concept of pornography differs across media. In this article, the researchers conflated a very specific, and small, subculture on the Internet with the Internet. The researchers emphasize that they are providing "a careful methodological procedure to compare different pornographic media to ascertain the differing levels of violence" (Barron and 
Kimmel, 2000, p. 162); yet, these researchers chose a Usenet (an online newsgroup where people post and respond to articles) sample to represent Internet newsgroups as a whole. From there, the researchers justified their choice of subjects by explaining that, [I]t provides a convenient data pool. While the World Wide Web has certainly caught the public's eye more than newsgroups, there is virtually no way to construct a list of all pornographic web sites from which to sample. Further, while some pornographic web sites do contain studies, the majority primarily contain pictures, and thus do not provide the narrative elements important to this study. We used alt.sex.stories precisely for its narrative content. Finally, while many web sites with pornographic material have begun to charge for access, the Usenet remains free to all with access to the Internet (Barron and Kimmel, 2000, 162.)

The researchers found that the Usenet was most like to contain violence by "a wide, and statistically significant...margin" (Barron and Kimmel, 2000, p. 164). They also found that $[\mathrm{w}]$ here violence occurs it is disproportionately caused by men in Usenet scenes, and an even smaller percentage in magazines" (Barron and Kimmel, 2000, p. 164) and they concluded that:

[T]he Usenet shows men in dominant positions, as victimizer and not victim, in far greater proportion than do magazines and videos, which is also suggestive that democratization of pornography has increased both the violence and amount of misogyny -- women as victims-- contained in the images (Barron and Kimmel, 2000, pp. 165-166). 
The researchers use this information to construct the pornosphere as a violent homosocial space that perpetuates misogyny. While it is true that these researchers found that Usenet pornography was exceedingly violent, their work contributes to conceptual ambiguity by failing to acknowledge how small and specialized the Usenet was in relation to Internet newsgroups and the Internet as a whole.

In reality, the Usenet was an Internet discussion system where people could read and respond to articles and other posts (i.e., news). It was precursor to message boards and forums. There was no central server system; instead, newsgroups were operated through the user's Internet Service Provider. Furthermore, different news topics were organized into specialized groups called hierarchies. The "alt" hierarchy, which was the hierarchy the researchers drew on, was an alternative to the established hierarchies. It was created by one of the original creators of the Usenet, Brian Reid (1993) specifically to house conversations that were deemed inappropriate in more general areas of the Usenet. Furthermore, the Usenet has been notoriously difficult to access. Technically, the alt newsgroups within the Usenet are a counterculture within a subculture within cyberspace. The researchers created a rhetorical cyber-thirdspace of the Internet based on a small group that was, by definition, out-of-the-ordinary.

\section{Methodological Formalism}

Methodological formalism involves the rhetorical representation of quantified data (Jasper and Young, 2007). The issue of "rhetorical numbers" has been addressed by Sandelowski and Barroso (2008) who argued that statistics are not simply numerical translations of data, they are also "literary displays" that provide rhetorical power and epistemic authority to the research findings. Joanna Wolfe (2010) has also argued that 
the rhetorical performance of statistics has been ignored by scholars because statistics are perceived as forms of inartistic proof.

The problem of methodological formalism is represented in an article on Internet sex addiction when the sexologist appealed to a widely cited article as evidence, but then acknowledged that the claims made in the article were unsupported. The author of the article on sex addiction wrote that "[A researcher] estimates that one in five Internet addicts are engaged in some form of online sexual activity (primarily viewing online pornography and/or engaging in cybersex), however, there appears to be no empirical evidence to back up this statistic" (Griffiths, 2001, p. 336), but then substantiates the cited research with other cited research. For example, he writes that, "Until very recently, empirical data surrounding excessive online sexual behavior was lacking. However, this situation is slowly starting to change. There have been a few studies of excessive Internet use which have found that a small proportion of users admitted using the Internet for sexual purposes" (Griffiths, 2001, p. 337). One of the studies he cited had examined a group of cyber-sexually compulsive Internet users and defined them as such using an existing measurement, combined with the time they spent online. Another cited study examined "potential Internet sex addicts" who consisted of a group of people enrolled in an outpatient psychiatric clinic for "problematic cybersexual activity" that included masturbating or self-touching while communicating with someone over the Internet" (Griffiths, 2001, p. 338). Methodological formalism in this case is not simply a reference to how numbers are interpreted substantively or statistically, but also references how numbers have been constructed and framed in relation to other quantified data.

\section{Proxy Evidence}


Proxy evidence involves citing previous studies "indiscriminately or out of context, even when their findings are mixed" (Jasper \& Young, 2007, p. 273). Jasper and Young (2007) explain that proxy evidence is problematic because "much regularly cited research is actually designed for testing the claims of an even earlier theory. Data are to be shaped by their polemical context, and it is hard to...obtain just the right data to test your own claims. Using other people's data, gathered to test other people's claims, is especially treacherous" (p. 275). Additionally, proxy evidence is problematic because the researcher also replicates any problems such as biases that were included in the original work. The problem with proxy evidence is illustrated in the following passage which involves a sexologist drawing on popular magazines to create exigence in an article on Internet sex seeking:

It seems the more taboo overt sexuality becomes, the more the Internet may be feeding into sexual curiosity and desires: A 2001 study found that $80 \%$ of Arabic Internet traffic goes to sex sites online....These findings lend credence to Ross et als assertion that the Internet's success is based on the link between "high demand for a huge variety of sexual needs (and) a huge supply"' (Albright, 2008, p. 175).

The Ketterman (2001) study that this sexologist cites is "1,000 Arabian Nights of Sex," published on Wired.com. The statistic regarding eighty-percent of the Arabic Internet traffic visiting sex-related sites was drawn from a statement that Ramzi El Khoury, the founder of an Arabic-Language Internet portal, cited (without reference to any formal research) during the International Summit on Internet and Multimedia. Ketterman's (2001) article actually detailed a debate that Khoury had with another participant at the 
International Summit on Internet and Multimedia. In fact, Ketterman (2001) noted that Khoury believed that the use of the Internet was a good thing because it encouraged free thinking about the outside world. There was no claim made to the effect that the more taboo overt sexuality becomes, the more the Internet is feeding into sexual curiosity.

The sexologist discussed in the previous passage argued that sexologists need more research on "sex seeking behaviors of adults online, in order to develop a more nuanced picture of viewing porn and seeking sex online" (Albright, 2008, p. 2008). Her research goal was to "explore data generated by a survey of a large sample of Internet users not predefined as sexual compulsives" (Albright, 2008, p. 177) and she drew on secondary data that had been collected by Elle/MSNBC.com from a survey posted on MSNBC.com for one week in February of 2004. Participants were recruited via announcements that were made in Elle Magazine, posted on the main page of MSNBC, and posted on Elle.com. Seventy-five percent of her respondents were male and ranked higher in educational attainment than the general population; ninety-three percent of the men identified as heterosexual, three-percent as bisexual, and three-percent as gay. Ninety-percent of the women identified as straight, $8 \%$ bisexual, and $2 \%$ lesbian. Thirtypercent were never married, 15\% were formerly married, and 55\% were currently married (Albright, 2008). This sexologist's data was in no way representative of her study population, nor suitable for making claims regarding sex seeking on the Internet. She did acknowledge the problems with the sampling by explaining that "sampling issues that need further exploration are the fact that this was a nonrandom convenience sample drawn from visitors to a major U.S. news organization site, which may not fully represent the population of all Internet users" (Albright, 2008, p. 184). Nevertheless, she 
characterized her work as an extension and replication of an earlier research study on sex seeking and the Internet.

\section{Exaggeration of Causal Effects}

Causal effects are exaggerated when "weaker causal effects are exaggerated into stronger ones" (Jasper and Young, 2007, p. 273). Exaggeration of causal effects was evident in a study on sex-seeking online when a researcher found that those who were married were five times more likely to be seeking a serious relationship than those who are single and, from that, inferred that "Internet personals actually may be fostering divorce through providing easy access to a multitude of attractive alternatives to their marital partners" (Albright, 2008, p. 184). Moreover, this researcher argued that:

Gays and lesbians, followed by bisexuals, were more likely than singles to be seeking a serious relationship online, and gays and lesbians were twice as likely to have met more than fifty people and three times as likely to report meeting more than 100 people, suggesting that they may be utilizing the Internet for casual sexual hookups, as found in previous studies" (Albright, 2008, p. 184).

The claims noted above are problematic considering the proxy evidence she used to construct her study. Most of her cited research is invalid for making claims about her study population. I reviewed, for example, her secondary sources and found that her sources addressed the following topics: experiences of underage or college students ( 7 of 41), gender experiences with porn (4 of 41), the construction of intimacy (1 of 41), couples therapy ( 2 of 41$)$, popular/non-academic sources on trends ( 6 of 41$)$, finding offline partners ( 1 of 41), outdated sources (a decade or older) ( 3 of 41), sex addiction (13 
of 41), sex seeking of partners online ( 2 of 41$)$, sex seeking porn online ( 2 of 41$)$. The one article that covered searching for offline partners was written by Daneback, Mansson, and Ross (2007) who reported that they found that "using the Internet to find sex partners may be less hazardous for the general Internet users than pointed out by prior research about this behavior often focusing on specific subgroups of Internet users" (p. 100). The researcher who examined online sex-seeking also cited McKenna, Green, and Smith's (2001) work on demarginalization of sexual identity and Ross, Rosser, McCurdy, and Feldman's (2007) work on the advantages and limitation of seeking sex online. These works, which I also examined as evidence of erotic oases in this chapter, do not support the claims that she made. Finally, the Traeen, Sorheim, and Stigum (2000) research that she cited in her bibliography did find that gays and lesbians were more likely than straights to use pornography during Internet chats; however, the researchers also reported that "gender was the most significant variable for prediction of pornography use" (p. 245). The proxy evidence that the sexologist in question used did not support her representation of her research findings.

\section{Extrapolation from Limited Cases}

Extrapolation from limited cases occurs when "claims are tested with case studies rather than samples of cases, allowing selective use of evidence" (p. 273). I submit that the use of research surrogates, often college students enrolled in introductory courses, represents extrapolation from limited cases because of the partial representation of the target population that research surrogates provide. The use of college students is problematic because they may not be representative of the larger population about whom the researcher seeks to generalize. Peterson (2001) has found that college students tend 
to be a more homogenous group than non-students, but this does not "appear to uniformly translate into more powerful hypothesis tests or larger effect sizes than would be observed for samples of non-students. Although great homogeneity implies less noise or extraneous variability in data, it may also reduce the magnitude of differences or minimize relationships that do exist among variables" (p. 458). Peterson (2001) cautions researchers from using these subjects to generalize to study populations unless the study population is college students. Earl Babbie (2012) raises a similar point by arguing that "[college students] seldom produce data of any general value. It may be useful for pretesting a questionnaire, but such a sampling method should not be used for a study purportedly describing students as a whole" (p. 73). In many cases, however, researchers use college students as research surrogates, or convenience samples, which creates unreliable and invalid evidence.

The problem with extrapolating from limited cases is represented by a sexologist reporting his findings on research predicting Internet pornography use and arousal. This sexologist sought to investigate the interconnection between personality and media with respect to how people choose and respond to pornographic media by conducting research on college students recruited from in introductory communication in a large public University located in the midwest. The students received research credit for their participation in the web-based questionnaire. A total of 337 participated, 179 participants were women and 158 of the participants were men. The median age was 20 . Only one participant identified as homosexual and three participants identified as bisexual. Eightyfive percent of the participants were Caucasian (Bryant, 2009). This sample was not representative of the group to whom the researcher sought to generalize, nevertheless, the 
researcher never identified the shortcomings of his work.

\section{Misplaced Concreteness}

Misplaced concreteness occurs when "variables are inflated into concepts and theories, just as theories are reduced to one or two variables" (Jasper and Young, 2007, p. 273). The following claim made by a sexologist focusing on sex-seeking represents misplaced concreteness: "Internet personals actually may be fostering divorce through providing easy access to a multitude of attractive alternatives to marital partners" (Albright, 2008, p. 184). The dependent variable in this statement is "divorce," and the independent variable is Internet personals as they are assumed to provide access to those who were otherwise unavailable. This claim; however, is not supported by research that the sexologist had cited, which drew on in-depth interviews and surveys they collected from heterosexual participants in mainstream Internet chat rooms. McKenna, Green, and Smith (2001) surveyed and interviewed participants in terms of the participants' reasons for using the sex-related chat rooms on the Internet, how their participation in the chat rooms affected their offline sex and relationship lives, and how the participants were affected by social judgements. McKenna, Green, and Smith found that the main reason for using the Internet was offline safety concerns followed by the need for a frequent sexual outlet and a desire to expand one's sexual knowledge and repertoire. They also found that "[t]hose who were stymied from expressing their sexual preferences, needs, and desires with offline partners spent more time engaging in online sexual activities" (McKenna, Green, and Smith, 2001, p. 309). The sexologist who made the original claim that use of Internet pornography fosters divorce skewed her findings by inflating and misrepresenting concepts and theories drawn from proxy evidence that reported findings 
unsupportive of the original claim.

The three rhetorical cyber-thirdspaces I described, the erotic oasis, pornosphere, and Jim Crow Cyb, all represent different ways sexologists have constructed cyberthirdspace in relation to a rhetoric of democratization. In the pornosphere, democratization is represented as a force that has contributed to the breakdown of social controls, discourse on love, and hetero-coupling by making pornography too accessible. In contrast, other sexologists argue that democratization has created an erotic oasis where sexual "others" can craft their own identities and sexual narratives as well as access others who can help create an affirming and satisfactory sexual community. Finally, the Jim Crow Cyb complicates the heterosexuality/queer division that exists between the pornosphere (heterosexual) and erotic oasis (queer) by illustrating how racism and ethnocentrism intersect with sexuality to create a segregated virtual environment.

All three rhetorical cyber-thirdspaces represent opposing views on the implications of the democratization of sexuality in cyberspace. In the erotic oasis, cyberspace is an environment where one can agentically meet sexual partners and construct an affirming self-identity and narrative. In contrast, the pornosphere represents a dystopic view of cyberspace. Both rhetorical cyber-thirdspaces represent the Internet as an unregulated space that allows for the reconstruction of sexual identities, behaviors, and desires as well as a deconstruction of the hegemonic construct of sexuality. The difference between the two, however, is that the pornosphere represents these changes as anomic and threatening to the family as an institution and to discourses of love and intimacy that support the family. The Jim Crow Cyb highlights the problems with conceptualizations of the Internet as a pornosphere and as an erotic oasis, which presumably represent a 
heterosexual/homosexual binary between the erotic oasis and pornosphere. The Jim Crow Cyb complicates the erotic oasis via race and ethnicity; nevertheless, it supports the assumption that the erotic oasis creates sexual opportunities for queers. Most importantly, the Jim Crow Cyb emphasizes the importance of intersectionality, in this case, between race, ethnicity, and sexuality.

I also found that sexologists constructing the pornosphere worked from flawed research designs that resulted in invalid data. This finding is significant because the pornosphere represents hetero-centric assumptions regarding the Internet and sexuality. This finding also encourages consideration of how these discourses are reified by the proliferation of flawed research.

To further our understanding of the implications of flawed research on discourses on sexuality, researchers should conduct tracing exercises or Foucauldian genealogical analyses to analyze how the discourse on pornography has reified hetero-centric constructs of sexuality. One possible approach is to identify a widely-cited and seminal article on pornography and trace its movement through discourse and accumulated knowledges on sexuality with a particular focus on how the discourse has informed social and professional practices such as sex therapy.

A second suggestion for further research is a rhetorical examination of sexual cyberplaces. I suggest drawing on Nicholas Burbules' (2002) work on the web as a rhetorical place to guide such research. In "The Web as a Rhetorical Place," Nicholas Burbules (2002) examined how hyperlinks in webpages operate semantically and navigationally by suggesting meaningful associations that facilitate connections and movement. Burbules (2002) distinguishes between presenting cyberspace as rhetoric of 
space versus a rhetoric of place. The idea that the web is a rhetorical space "captures the idea of movement with it, the possibility of discovering meaningful connections between elements found there; but does not capture the distinctive way in which users try to make the web familiar, to make it their space - to make it a place" (p. 76; emphasis in the original). In contrast, as a rhetorical place, cyberspace represents a socially meaningful space that includes navigational and semantic elements and it also represents a locational dimension. Space captures movement, but it does not capture how users make the web familiar. 


\section{CHAPTER 3: IMAGINATIVE SPACE AND THE EROTICIZATION OF RAPE IN NEW RHETORICAL VISIONS OF RAPE FANTASIES}

In chapter two of this dissertation, I examined how sexologists created three praxical rhetorical cyber-thirdspaces (the erotic oasis, pornosphere, and Jim Crow Cyb) by appealing to a rhetoric of the democratization of sexuality. I conceptualized rhetorical cyber-thirdspace as a form of rhetorical space that is characterized by a deconstruction of the dualisms (conceived and lived space, for example) that have been used to understand the relationship between space and place. In chapter three, I continue to examine rhetorical space, however, I move from cyberspace to the imagination as a rhetorical space. My definition of imagination ${ }^{8}$ is drawn from Blanca Torres-Olave's (2012)

\footnotetext{
${ }^{8}$ See "Refiguring Fantasy: Imagination and Its Decline in U.S. Rhetorical Studies," by Joshua Gunn (2003) for an extensive overview of three paradigms (the mimetic, creative/productive, and postmodern/imaginary) that reflect how "imagination" has been conceptualized in the history of social and rhetorical theory. To briefly review, the mimetic paradigm represents an Aristotelian construct of imagination that presents the imagination as a mental quality that mirrors images in the mind. Gunn (2003) notes that the mimetic paradigm was the dominant way of conceptualizing the imagination until the Renaissance when a perspective that presented the imagination as a creative force of the individual abstracted from the social and cultural context displaced the mimetic paradigm. The creative/productive construct of the imagination was represented in the work of Kant and the German Idealists and the aesthetic theories of nineteenth-century Romantics who celebrated the individual as the originator of all things meaningful. The third paradigm, the postmodern/imaginary paradigm, emerged in the twentieth-century via complications of the notion of the abstract individual. The postmodern/imaginary paradigm highlighted the role of society in the construction and experience of the imagination and, in doing so, served to critique the humanist construct of the individual, and, as will be shown below, allowed rhetoricians to examine communicative acts as products of social environments rather than simply as products of an individual rhetor's skills. The construct of imagination I am using in this chapter, Torres-Olave's (2012) construct, is consistent with the third paradigm.
} 
article, "Imaginative Geographies: Identity, Difference, and English as the Language of Instruction in a Mexican University Program.” Torres-Olave (2012) posits the imagination as "a creative process through which individuals produce new images that allow them to relate to themselves and others" (p. 122-123). Torres-Olave's (2012) definition of imagination suggests that the imagination is crucial in shaping the discourses that define rhetorical communities. Imagination references a geographical activity or a space of creativity that individuals can use to construct social realities and relationships. Torres-Olave's (2012) definition of imagination differs from those constructs that posit imagination as removed from, or in opposition to, reality. In fact, imagination is a site from which people can understand and experience the world (Dawney, 2011) rather than escape from the world. In this way, the imagination constitutes a space characterized by a convergence of elements such as objectivity and subjectivity or conceptual and physical realities.

In this chapter, I focus on how sexologists have been constructing a new rhetorical vision of rape fantasies that reject theories of masochism and the construct of the "willing rape victim" while embracing the eroticization of a rape event within the imaginative rhetorical space controlled by the fantasizer. This chapter is framed by Ernest Bormann's (1975) theory on symbolic convergence and methodology of fantasy theme analysis to describe how sexologists are creating a new rhetorical vision of the "rape fantasy."

\section{Symbolic Convergence and Fantasy Theme Analysis}

Ernest Bormann's (1980) theory of symbolic convergence is a rhetorical theory that identifies and explains, "the communicative processes by which human beings 
converge their individual fantasies, dreams, and meanings into shared symbol systems" (p. 189). As a general theory of communication, Bormann's (1972) symbolic convergence theory theorizes invention as an activity of the collective and social imaginary rather than a lone rhetor. Bormann (1972) argues that "[a]lthough individual imaginations are responsible for "chaining" fantasies, they are not the origin of them; rather, "community consciousness" is the primary locus of fantasy, and no one theme, type, or vision originates in the solitary individual" (p. 49). The individual is not removed from the discourse, instead, he or she is the impetus for symbolic convergence within a rhetorical community. Hence, his theory focuses on the production of persuasive discourse via group and mass fantasies. Bormann's theory (1985) illustrates how fantasy themes, which are defined as dramatizing messages that "function to allow individuals to present or show to the group-mind a common experience and serve to shape that experience rhetorically into social knowledge (Shields and Preston, 1985, p. 104), fulfill rhetorical needs and constitute rhetorical strategies for creating narrative descriptions of reality that characterize the discourse of rhetorical communities. Analyzing fantasy themes, then, allows for insight into how social reality is constructed and transformed throughout rhetorical communities. The purpose of analyzing fantasy themes is to identify the development of a shared consciousness, identity, and community. Symbolic convergence also illustrates how rhetorical communities convert members within and outside that community to a new consciousness and rhetorical vision. In this chapter, I am focusing on how The Society for the Scientific Study of Sexuality's discourse on sexual fantasies, masochism, blame avoidance, and adversarial transformation discussed

\footnotetext{
${ }^{9}$ In Bormann's (1972) work, the concept of chaining refers to the spreading or transmission of ideas and symbols.
} 
in sexological discourse has framed existing rhetorics of rape fantasy and has encouraged new rhetorical visions of erotic rape fantasies. Rape fantasies have been problematic for sexologists because they are relatively common forms of fantasies among women but they are paradoxical because if they were to occur in reality, they would be traumatic. In this chapter, then, I am focusing on how sexologists normalize and eroticize rape fantasies without suggesting that fantasists wish to be raped. As I will show later in this chapter, this process involves positioning the imagination as a rhetorical space that exists independent of the sites where "real" rape occurs and is controlled by the fantasist.

To conduct the research presented in this chapter, I originally identified all the articles $(\mathrm{n}=22)$ published between 1963-2012 in the Journal of Sex Research that referenced some variation of "fantasy," "imagination," or "cognition" in the title of the article. From my initial search I narrowed my dataset to those articles addressing masochism, rape fantasies, force fantasies, and submission fantasies $(\mathrm{n}=10)$. I found that in the 1960s, the articles centered on the role of sexual fantasies in sex therapy. In the 1970s, researchers addressed, and complicated, how earlier sexologists had used the construct of "perversion" (particularly the notion of female masochism) in theories and research on sexual fantasies. In the 1980s and 1990s, the research on sexual fantasies focused on the role of fantasies in sexual arousal and sexual performance. And in the 2000 s, research has centered around redefining, or revisioning, the issue of "rape fantasies" and sexual performance. In general, I found that sexologists publishing in The Journal of Sex Research uniformly recognized that it was impossible for women to fantasize about being raped, when rape is conceptualized as a form of power and 
domination, yet, sexologists have identified a space where fantasists can eroticize rape events without suggesting women want to be raped.

My point of intervention in this discourse is through sexologists' efforts to revision an eroticized rape fantasy, which has occurred in the last four years (2009-2012) in scholarship on rape fantasies. My argument is that sexologists have been working toward a new rhetorical vision of the rape fantasy that eroticizes rape events into a theory of why fantasists enjoy rape fantasies, but do not wish to be raped in concrete reality. Earlier sexologists had argued that rape was never sexual or erotic, and therefore, women could never truly fantasize about rape because such an assumption suggests that women secretly want to be raped or are willing rape victims. Contemporary sexologists researching rape fantasies, however, maintain that there are no willing victims of rape, nor that women secretly wish to be raped, but argues that rape fantasies are erotic under certain circumstances (in imaginative space). In other words, current theorists are incorporating an erotics of rape in the interests of rejecting the idea that fantasists secretly wish to be raped. In doing so, sexologists have complicated the assumption that the imagination mirrors reality and/or desire. To understand and present how sexologists are creating this new rhetorical vision (new because it synthesizes eroticism and rape) I draw on Bormann's (1975) rhetorical theory of symbolic convergence and methodology of fantasy theme analysis, which is described below.

\section{A FANTASY THEME ANALYSIS OF EROTIC RAPE FANTASIES}

Fantasy theme analysis has enjoyed widespread application to interdisciplinary studies addressing issues such as sports fantasies (Zagacki and Grano, 2003), virtual organizations (Kendall, Kendall, and Kah, 2006), political cartoons (Benoit and 
Klyvkovaki, 2001), legal discourse (Arsenault, 1997), TV coverage of crime (Bormann, 1982), hate groups online (Duffy, 2003), popular books on motherhood (Dobris and White-Mills, 2006), and television commercials (Crouse-Dick, 2002). There have, however, been few studies that have applied fantasy theme analysis to scientific discourse, with the exception of James Chesebro's (1980) article "Paradoxical Views of 'Homosexuality' in the Rhetoric of Social Scientists: A Fantasy Theme Analysis,' an article that represents an early version of the type of rhetorical analysis presented in this chapter.

In "Paradoxical Views of 'Homosexuality' in the Rhetoric of Social Scientists: A Fantasy Theme Analysis," James Chesebro (1980) complicated how the term "homosexuality" had been used by social scientists in research on sexuality. Chesebro (1980) found in his research that there were two general fantasies perpetuated through the scientific discourse on sexuality: "the homosexual as degenerate" and "mainstreaming the homosexual." Chesebro (1980) argued that these fantasies created a paradoxical rhetorical vision of sexuality within sexology because "homosexuality" "seems to startle and confuse social scientists as much as it does those outside that scholarly community. The social scientists themselves may have likewise sensed dissatisfaction with the two fantasies, for a third fantasy seems to be emerging" (p. 136). The emerging fantasy was centered on the idea of a gay community, which Chesebro (1980) identified as a "cultural compatibility fantasy" and argued was "more likely to produce insightful understandings regarding the social and cultural meanings of same-sex relationships" (p. 137). Chesebro (1980) urged social scientists to move away from biologically- (or behaviorally-)based definitions of sexuality, which he argued were limited and inaccurate. Chesebro's (1980) 
research was significant because it illustrated how the scientific community contributed to, and participated in, cultural conversations (i.e., the social imaginary) regarding sexuality and also identified how scientists could construct, and were constructing, new imaginaries in ways that complicated the association between sexuality and pathology. In this chapter, I am a doing a similar type of research by conducting a fantasy theme analysis of the construct of "rape fantasies" focusing specifically on how the current sexological rhetorical vision of rape fantasies, which will be described later, is being changed through various rhetorical strategies and innovations that are ultimately complicating the understanding of "fantasy" in rape fantasies.

Methodologically, fantasy theme analysis involves analyzing the fantasy theme elements within a dramatizing message that contributes to the creation of a rhetorical vision (a composite drama or narrative that unites a rhetorical community). Identifying the fantasy theme elements involves "[d]etermining who is the central character, the opposing force, other characters, what the basic scenario is, how reality links are accounted for, what the insider cues are, what the ultimate legitimizer is, etc." (Kidd, 1998, para. 18). Typical fantasy theme analysis research questions include: (1) Who is involved in the drama? (2) Where do the dramas take place? (3) What are the storylines or plotlines? (4) What meanings are inherent in the dramas? and, (4) How does the fantasy theme chain out to others? (Bormann, 1972). Fantasy theme analysis allows the researcher to see how the elements operate rhetorically to create a rhetorical vision that unites and provides direction for a particular rhetorical community. Together, these elements create a rhetorical vision that defines a reality for the rhetorical community and an examination of these elements provides an understanding of how rhetorical visions are 
constructed and perpetuated through rhetorical communities. In what follows, I will use Bormann's (1975) theory of symbolic convergence and fantasy theme analysis to address the role of the imagination (as a rhetorical space), discourse on masochism, blameavoidance theory, and adversarial transformation in creating a new rhetorical vision of the rape fantasy in sexological research published in The Journal of Sex Research. Following that, I will describe the methodological and theoretical rhetorical innovations, presented in the data set, that are complicating the way that gender has been conceptualized by sexologists in articles on rape fantasies.

\section{The Problem of Location in Conceptualizing Rape Fantasies}

In fantasy theme analysis, "settings" refer to material and immaterial places that provide a concrete reference point or a measure of proximity (i.e., "the typical classroom") in relation to the dramatizing message. In the context of rape fantasies, the setting includes reality and imagination. The setting is significant in rape discourse because setting, or space, has been a significant factor in the adjudication of truth. Rape claims, for example, are often examined through the context or setting: Where did it occur? Who was there? Answers to questions such as these are used in the determination of whether a crime has occurred. The issue of setting in the adjudication of truth regarding rape fantasies is no different. Discourse on rape fantasies has debated the relevance of the rape fantasy with respect to the setting, namely the question of the role of imagination in relation to reality. Those who believe that the imagination mirrors reality, or desires in reality, assume that rape fantasies indicate that the fantasist wishes to be raped, whereas those who believe that the imagination is opposed to reality do not assume that fantasies of rape indicate actual desires on the part of the fantasist. Each of 
these examples illustrates how spatiality performs rhetorically in the discourse.

Imagination and reality are rhetorical spaces that perform a truth-telling function in rape discourse.

In the context of research on sexual fantasies in general, and rape fantasies in particular, fantasies typically reference conscious mental imagery or cognitions that include sexual activity or that are sexually arousing (Bivona and Critelli, 2009). Sexologists cite sexual fantasies as important areas of sexological research because of their frequency and presumed role in sexual identities and experience. Sexual fantasies are also presumed to play a significant role in sexual satisfaction among women (Shulman and Horne, 2006, p. 2006). Sexologists publishing in The Journal of Sex Research have found that women who fantasize frequently are less likely to experience sexual guilt and the notion that "sexual fantasies are a private experience about which others are typically unaware and, because of this private nature, women can engage in them freely without threat of discovery" (Shulman and Horne, 2006, p. 358). These qualities are considered to be revelatory for researchers because the fantasies, free from social constraint, "reveal underlying psychological processes, motives, predispositions more clearly than overt behavior" (Critelli and Bivona, 2008, p. 57). Sexual fantasies have a "neither here nor there" quality, as a rhetorical space, and are experienced and perceived as real/unreal. Within the context of rape fantasies, the imagination is problematic, as will be described below, because sexologists have difficulty rectifying the components (i.e., reality and fantasy) of the space. The paradox of rape fantasies is that they involve being aroused by an experience that, should it have occurred outside of the imagination, would be experienced as abhorrent. 
The paradox of the rape fantasy illustrates why setting is so important in fantasy themes and rhetorical visions. As Shields and Preston (1985), point out, settings can be loaded rhetorically (e.g., "the American Frontier," "the Iron Curtain," "the Dark Continent") and encourage powerful emotional responses. Rape fantasies function likewise because they appear to suggest that fantasizers wish to be raped. The following passage from an article on the history of rape fantasies research demonstrates this paradox by comparing rape fantasies to fantasies about extramarital affairs:

For some, an affair would be exciting, both as fantasy and in actuality, but they may not want to engage in actual infidelity because of negative consequences to the marriage. In contrast, rape would be avoided not only because of unpleasant consequences, but, more importantly, because the experience of the rape itself would be abhorrent. And although fantasies about unpleasant events, such as feared performance evaluation, are not rare, these fantasies are not pleasurable. In contrast, fantasies of forced sex are often exciting, pleasurable, and sexually arousing...(Critelli and Bivona, 2008, p. 57).

Typically, researchers conceptualize the rape fantasy in reference to existing legal definitions of rape that are centered around the use of force, threat of force or incapacitation, and consent, but emphasize the subject position imagined by the fantasist within imaginative space, the fantasist embraces elements that correspond to legal definitions of rape; however, the fantasist reconstructs the subject positions in a way that allows for the eroticization of the rape event. One group of researchers, for example, conceptualize a rape fantasy as one that involves the use of physical force, threat of force, 
or incapacitation to “coerce a woman's self-character in a fantasy into sexual activity against her will” (Bivona and Critelli, 2009, p. 33). The same researchers adopted a similar definition of rape fantasy in an earlier article, but emphasized the role of subject positions and characteristics in the rape fantasy by explaining that "from the point of view of the self-character, there is non-consent, and these are rape fantasies. From the viewpoint of the fantasizer, an implicit consent has been given and these fantasies might be viewed as ritual displays of male dominance and female surrender" (Critelli and Bivona, 2008, p. 58). The examples illustrate how the fantasizer controls activities that occur within the imaginative space. The fantasist renegotiates and eroticizes the traditional-legal narrative of rape in a way that asserts sexual agency, including the agenic qualities of sexual arousal and gratification.

Imaginative space ultimately allows the fantasizer the opportunity to construct a narrative that draws on sexual force and submission without ascribing the status of "willing victim." Such constructs renegotiate the role of spatiality in the rhetoric of rape by emphasizing sexual subjectivity and agency within the context of the rape event. In imaginative spaces, the fantasizer and self-character maintain control over the events that are occurring in the space. The role of control is represented in another article on the development of rape fantasies, where the researchers note that the difference is that in a rape fantasy "no actual violation of body and will is experienced, the fantasist also has complete control, while a lack of control characterizes rape" (Shulman and Horne, 2006, p. 368). Sexologists construct a fantasy theme that suggests, "women engage in these fantasies for the purpose of sexual arousal and pleasure, not out of desire for an actual rape or force experience" (Shulman and Horne, 2006, p. 368). The imaginative space of 
eroticized rape allows fantasizers a safe space where, as the following passage indicates, pleasure and safety are not in opposition. The dangers of the real world are removed. Zurbriggen and Yost (2004), for example, explain, "if a woman gives into sexual pleasure she invites the danger of violence and punishment. Pleasure and safety are in opposition for women, which force them to choose one over the other. The realm of fantasy may be a private and safe sphere in which women can experience desire and pleasure free from danger" (Zurbriggen and Yost, 2004, p. 290). These authors also note that male desire and pleasure are privileged in the real-world and therefore, women are encouraged to focus on their partner's experience. But this is precisely what has been disconcerting in literature on rape fantasies and what constitutes the paradox of rape fantasies for sexologists: women are fantasizing about something that, in "real" life, would be

traumatic although they presumably have the ability to construct a narrative of consensual sex. At this point in the history of the discourse on the paradox of rape fantasies, sexologists create symbolic convergence by eroticizing rape events that occur in imaginative space. The positive introduction of eroticism into the discourse is best understood within the context of historical discourse on masochism, which constitutes what Bormann (1975) would identify as a plotline in the rhetorical vision of rape fantasies in the discourse.

\section{Re-Visioning Rape Fantasies: Rejecting Masochism}

In fantasy theme analysis, understanding the development of a rhetorical vision within a rhetorical community involves not only attention to setting, but also attention to plotlines, or narratives within community discourse. Bormann (1985) discusses this feature of fantasy theme analysis through his concept of the "here and now" by 
explaining that "shared fantasies are coherent accounts of experience in the past or envisioned in the future that simplify and form the social reality of the participants. The community's shared dreams of the future, no matter how apocalyptic or utopian, provide artistic and comprehensible forms for thinking about and experiencing the future" (p. 12). The "here and now" references the spatial-temporal elements of a rhetorical visions which indicate where one is, has been, and is going with respect to the conversation. The "here and now" points to the progression of ideas within rhetorical visions, or composites of dramatic events.

In symbolic convergence theory and fantasy theme analysis, rhetorical visions motivate action and provide an interpretive lens to use when explaining or understanding reality. Those who participate in the construction and perpetuation of rhetorical visions constitute a rhetorical community who "share fantasies that depict themselves as better than outsiders and their rhetorical innovations as an improvement over current ways of viewing the world" (Bormann, 2001, p. 12). Furthermore, different types of rhetorical visions direct or influence specific social actions. Pragmatic rhetorical visions; for example, are characterized by a shared consciousness based on shared goals; social rhetorical visions that are based on a shared consciousness centered around the responsibilities that come from interpersonal relationships, and righteous rhetorical visions that represent a shared consciousness based on a shared cause or position (Bormann, 1972). As Ball (2001) explains, a rhetorical vision, (or master analogues, to use her term) is a deep structure that leads to particular action. She explains, for example, that "a vision linked to a social analogue would stress human relations, and a pragmatic analogue would stress expediency, utility, and so on" (Ball, 2001, p. 219). 
Rhetorical visions, then, are performative discourses that guide action and create and sustain rhetorical communities. To understand rhetorical visions, in general, one must focus on the "here and now" discourses that are used to frame their visions.

In the research presented in this chapter, I found that each type of rhetorical vision is represented in the fantasy theme of the erotic rape fantasy. Sexologists create a pragmatic rhetorical vision of the rape fantasy by sharing a goal of empirical research; they create a social rhetorical vision by articulating their responsibilities to the scientific community represented by the Society for the Scientific Study of Sexuality, and they represent a righteous rhetorical vision based on the shared position that a woman can fantasize about rape without that fantasy representing a desire to be raped. Imaginative space, in this context, does not mirror actual space, so it is erroneous to assume that rape fantasies can indicate feelings about rape on the part of the fantasizer. Sexologists are working toward a new rhetorical vision of the rape fantasy by calling for a theory that can explain the paradox of rape fantasies, which is why women choose to fantasize about rape when they could as easily initiate a consensual fantasy (Critelli and Bivona, 2009). The experience appears to be incompatible with spaces of fantasy and reality and, as such, this research calls for a new rhetorical vision of the rape fantasy and willing rape victim myth. Researchers note that they seek to develop a more integrated, comprehensive, and contextual explanation of the phenomenon of rape fantasies so that individuals can better understand why the speculation that women want to be raped is in error by arguing that:

[S]implistic wish fulfillment is not supported empirically, as women who have erotic rape fantasies are not more likely than other women to be rape 
victims....If having rape fantasies revealed a motive for actual rape, one would expect at least a moderately strong relationship between fantasy rape and actual rape, as each woman makes numerous decisions on a daily basis that easily could increase the likelihood of actual rape, if that were desired (Critelli and Bivona, 2008, p. 67-68).

Moving beyond the rhetorical vision of rape fantasy as wish fulfillment has occurred through various disciplinary rejections of theories centered around the concept of masochism. These discursive rejections also speak to how sexologists establish the "here and now" of their discourse. In general, The Society for the Scientific Study of Sexuality has complicated and rejected theories of masochism such as Deutsch's (1944) psychoanalytic theory that suggests that rape fantasies represent women's unconscious and innate masochism. Deutsch's theory is that girls are encouraged to become masochistic because they are physically and emotionally weaker than boys and are rewarded for rejecting aggressive forces and drives and for being passive. Related to Deutsch's (1944) theory of female masochism are theories that suggest that women are taught and rewarded for being masochistic via patriarchal society. In an article that examined whether rape fantasies were pathological or empowering, the researchers explained the connection between patriarchy and masochism by discussing Brownmiller's (1975) theory on sexual subordination, which they note suggests that rape fantasies originate from patriarchy. According to Brownmiller's theory, women have internalized the idea that they are submissive. Sexologists complicate such assumptions by noting, "rather, such fantasies highlight the erotic allure of the fantasist in that she (or he) is irresistible to the seducer (Hawley and Hensley, 2009, p. 569). In general, theories 
such as Deutsch's (1944) theory of female masochism and Brownmiller's (1975) theory of patriarchy have been rejected because they have not analyzed what actually occurs in imaginative space of rape fantasies. Supporters of theories of masochism and patriarchy like those described above err by encoding imaginative space as indicative of actual or lived space.

Theories of masochism have long been critiqued in The Journal of Sex Research for being overly simplistic with respect to understanding sexual desires and identities. In "Masochism and the Female Sexual Role," the first article on masochism published in the Journal of Sex Research, for instance, Robertiello (1970) complicated the Freudian assumption that posited women as naturally masochistic, or the idea that masochism was an inborn and psychological trait of the female sex role. He agreed with feminists that the assumption that women were naturally masochistic resulted from the ascription of pathology by analysts on female patients. He defines masochism as the "turning of destructive drives against the self" (p. 57) and notes that, to some extent, all people experience these phenomena. The sexual masochist is one who "cannot enjoy the sexual act unless it is accompanied by pain, humiliation, or submission" (p. 57). The key distinction in Robertiello's (1970) construct of sexual masochism is between submission and surrender. Submission involves a person making oneself lesser than another whereas surrender references the act of giving one's self to an activity. Surrender is a form of letting go that does not imply masochism. In this sense, Robertiello (1970) argues that Freudian theorists conflate "surrender" and "submission" and, in doing so, misunderstand and misapply the concept of masochism. He also argues that the idea that sexual intercourse is inherently sadist and masochistic is similarly misguided because this 
assumption assumes that women are naturally masochistic and men are naturally sadist and is the "same kind of foggy thinking [that] applies to the idea of the male role in sex being more active and the female role being more passive" (p. 58). Nevertheless, Robertiello (1970) does argue that women, and men, can develop masochistic tendencies, which he regards as pathological and resulting from inadequate mothering for a child. Robertiello (1970), then, introduces the idea that cultural and interpersonal conditioning creates pathological expressions (in this case, masochism) of sexuality and these are not reducible to essentialist constructs of masculinity and femininity. Robertiello's (1970) deconstruction of masochism has been central to the development of a rhetorical vision of rape fantasies that has allowed for the eroticization of the rape event without suggesting that women inherently want to be raped. In this early work, Robertiello (1970) rejected the idea that masochism is inherent to heteronormative sexual desire and practice. Such an argument provides a space to consider how an act or experience becomes or is interpreted as masochism. Furthermore, Robertiello (1970) created an opportunity to affirm receptiveness in sex (via surrender) without the ascription of victimhood. Robertiello (1976) followed his article on masochism with an article on the role of the mind, which allows for the opportunity to create an imaginative space that is not defined, or reducible to, "actual" space.

In "The Decline and Fall of Sex," Robertiello (1976) listed various events that characterized the sexual landscape in the 1970s: increased access to pornography, women's liberation movement, sexology, etc., but argues that there have been some unintended negative consequences to these developments, in particular, the emphasis on anatomy rather than experience. He argues, for example, that "[p]eople have somehow 
forgotten that sex -- the essence of sexuality -- always has been and still is in the mind. Passion is still not anatomical" (p. 70). The mind, and imagination in particular, are for Robertiello (1976) the most significant sex organ, which he exemplifies in the following statement: "Men and women have very powerful and exciting orgasms in their dreams. There is no technique or anatomical stimulation there" (p. 70). He argues that with this in mind, we should concern ourselves not with the perversions, per se, but instead, with our innermost secret desires. He says, "[w]e must go back into our minds and spirits and imaginations now that we know all the techniques and have given ourselves the freedom to use them without guilt....There are no premature ejaculations in dreams and fantasies and no clitoral adhesions either, but there is genuine excitement and a satisfying and exciting orgasm" (p. 71). Robertiello (1976) is particularly concerned with how sexuality has been "scienced" and taken over by sex therapists and notes that he has "the nagging conviction that we have made sex as plastic as most other things in our society" (p. 72). In a move that is remarkably similar to Foucault's (1984) argument in The History of Sexuality, Robertiello (1976) suggests that sexologists are (re)constructing sexual subjectivity in their own interests. Robertiello's (1976) early work on masochism, the first work to reference mind and imagination in the journal, represents important components of the rhetorical vision of the Society for the Scientific Study of Sexuality's notion of erotic rape fantasies. These components include a vision of the sexual landscape as predicated on a mind/body dichotomy (with the mind elevated over body), which in later sexological works is represented as an imagination/reality dualism, and the assumption of sexual agency on the part of women. In contemporary discourse on rape fantasies and historical discourse on masochism, sexologists reject the assumption that 
masculinist interests and standards define female sexual subjectivity. Imaginative space constitutes an environment where one can renegotiate constructions of reality. In the case of erotic rape fantasies, imaginative space provides a context where traditional-legal narratives of rape are eroticized without ascribing masochism, and the desire to be raped, to the fantasizer.

In the late $1980 \mathrm{~s}$, when discourse specifically addressing rape fantasies emerged, the construct of masochism was undergoing further reconstruction in a way that afforded the masochist sexual agency. In 1988, for example, Baumeister presented a theory of masochism as an escape from self or a way for one to achieve a loss of self-awareness so that the individual is left with a low-level self-awareness of the physical body and immediate sensations or a new socio-sexual identity. He writes that masochism is an effort to "eradicate (temporarily) the main features of the self" (p. 35). Bondage, for example, makes it impossible for a person to exert control and humiliation makes it impossible for a person to sustain dignity that supports one's social identity. Becoming a slave allows someone to become someone else. He argues that masochism is similar to activities such as sky driving or drug use. He rejects the idea that sexual practices are direct evidence of pathology. He also notes that masochists do not wish for pain or injury and take great efforts to avoid both experiences as evidenced by the manuals and workshops on pain and injury avoidance that are offered in sadomasochist subcultures. In a second article published in the same year, Baumeister (1988b) examines the role of gender differences and masochism. He rejects the claim that women are predominantly masochistic and argues that masochistic desires may influence men and women equally or may, perhaps, affect men more considering that the male sex role requires men to be 
dominant. He does note that male masochism does seem to be geared toward erasing the male sex role, but this is not the case for women who are masochists. He argues that women preserve femininity in masochism by creating an ultrafeminine role but notes that female masochists are not interested in being treated like babies or men and that they do retain the sexual allure. For example, Baumeister (1988b) writes, "humiliation in male masochism denies the man's masculinity and sexual appeal, whereas the humiliation in female masochism emphasizes a woman's femininity and sex appeal. The female masochist...is the center of attention" (p. 495). Masochism, for Baumeister (1988b), then, is a way of playing with hegemonic gender roles.

The work on masochism that emerged in the 1980s emphasized agency, particularly playing with hegemonic gender roles. Such work also complicated the idea that masochism was pathological. Instead, masochism was regarded as a normal means for playing with gender roles and norms. It is in this context that sexologists rejected the idea that rape fantasies represented masochistic desires to be raped in concrete reality. In the new fantasy themes of rape fantasies, sexologists had complicated "masochism" to the point where its original association with wish fulfillment for suffering was erased and it came to represent a method for playing with gender roles. The articles on rape fantasies that emerged in the 1980s, which addressed the argument that fantasies were actually masochistic, had the theoretical framework to begin a discourse that afforded the option for sexual pleasure in the context of what would be otherwise considered painful. The key, however, is context, which is imaginative space. The first article addressing rape fantasies, which is described below, illustrates how sexologists rejected masochism as an explanatory variable for rape fantasies and moved toward a discourse that 
distinguished between erotic rape fantasies and aversive rape. Erotic rape fantasies occur within imaginative space whereas aversive rape occurs in concrete reality.

The first article to appear in The Journal of Sex Research on rape fantasies was Bond and Mosher's (1986) article, "Guided Imagery of Rape: Fantasy, Reality, and the Willing Rape Victim Myth," which presented findings from experiments they constructed in order to "dispel the myth that women are secretly willing victims of rape" (p. 163), a myth they locate in the assumption that rape is sexual, rather than violent, in nature and that women want to be raped for sexual or masochistic motives. They argue that "rape," as an erotic fantasy, must be differentiated from the violent reality of rape to deneutralize and desexualize the willing victim myth" (p. 163) ${ }^{10}$. They support their argument by explaining that eroticized rape fantasies are characterized by a sexually desirable man who is aroused by the fantasizer's attractiveness and who uses just enough force to overcome her resistance. In contrast, aversive rape is "a crime in which a sexually and violently callous man motivated by power, anger, or sadism selects a victim of opportunity, uses force, often excessive force, to overcome resistance and degrade the victim" (p. 164). The issue is who has control in the experience. They write, "the fantasizer is in charge of her inner world and the meanings she assigns to her fantasy" ( $p$. 178). Fantasies about actual rape are never arousing because they are characterized by a lack of control or helplessness on the part of the fantasizer. Bond and Mosher (1986)

\footnotetext{
${ }^{10}$ I was surprised to find that the sexologists publishing articles that complicated sexological discourses on rape fantasies did not suggest altering the language that is used to characterize rape fantasies. Although one article used the phrase "forced submission fantasies" to indicate rape fantasies, the researchers did not provide a detailed argument for their use of the phrase "forced submission fantasies" nor did any sexologists publishing in the Journal of Sex Research critique how language was used in the discourse.
} 
conclude by arguing that researchers and those working within criminal justice need to understand that a woman can "enjoy a fantasy of rape without secretly desiring, enticing, or becoming a willing victim of rape" (p. 183). Their work represents a discursive turn toward eroticizing rape when it occurs within an imaginative space controlled by the fantasizer.

At this point in the history of discourse on rape fantasies in The Journal of Sex Research, a new rhetorical vision of rape fantasy that embraces eroticization of rape events within imaginative space is emerging. The vision supports the discourse that complicates masochism as indicative of a desire to be raped by maintaining the assumption that rape fantasies, under certain circumstances, are erotic and sexually arousing. Current research on rape fantasies is entertaining two theories of rape fantasies, blame-avoidance and adversarial transformation. These theories have not yet been incorporated into the rhetorical vision of the erotic rape fantasy (because of a lack of empirical support), however, they are being considered for possible inclusion in the new vision.

Blame avoidance theory suggests that rape fantasies allow women to have sexual fantasies without the guilt of submitting to their sexual desires. Critelli and Bivona (2008) note that according to this theory, women have been socialized to maintain the impression that they are not promiscuous or overly sexual. The theory suggests that women fantasize about sex in order to experience consensual sex without self-blame, sexual guilt and anxiety, or any other feelings that may inhibit sexual gratification. The rape fantasy allows the fantasizer to avoid these feelings by putting him or her in the position where they could not say no. Non-consent enhances sexual gratification and 
allows the fantasizer the opportunity to maintain a positive sense of self. Sexologists examining the literature on blame avoidance theory argue that the theory is sound, but have not yet incorporated it into the rhetorical vision of the erotic rape fantasy because of a lack of empirical support. In direct contrast to the blame avoidance theory is the sexual experience theory that holds that it's not repression that creates the motivation for rape fantasies, but is, instead, women's openness to sexuality and sexual experience; nevertheless, Critelli and Bivona (2008) illustrate that "[a]lthough the openness theory does appear to describe the rape fantasies of many women, it may be deficient in explaining why women would choose to include force in their fantasies, and if force is chosen, why the self character in these fantasies experiences nonconsent" (Critelli and Bivona, 2008, p. 64). Finally, some researchers addressing popular culture and sexual fantasies note that romance novels are a pervasive form of mass marketing in U.S. markets and that they are often written by women and for women. They are also likely to include scenes that correspond to legal definitions of rape. Some sexologists argue that romance novels and rape fantasies are structured erotic fantasies that represent the same theme. Typically, the rhetorical strategy that transforms the construct of sexuality in the romantic novel from a rape scene to an erotic scene is "adversarial transformation," which involves reconstructing the motivations and interpretations of the adversary in the fiction. However, like the research suggesting blame avoidance, research on popular culture and the technique of adversary transformation has not demonstrated an effect in empirical studies (Critelli and Bivona, 2008) and has not yet been fully incorporated in the new rhetorical vision of erotic rape fantasies. 
To reiterate, symbolic convergence occurs within rhetorical communities when fantasy themes are constructed and embraced by a rhetorical community. In the context of this chapter, I have shown how The Society for the Scientific Study of Sexuality has created symbolic convergence around the assumption that the occurrence of rape fantasies does not indicate that fantasizers secretly wish to be raped. The society has worked toward this convergence by eroticizing rape events that occur in imaginative space and by rejecting sexological theories that embrace masochism as an explanation for why individuals, in particular women, fantasize about an event that they would find abhorrent if it were to occur in "real life." Invoking imaginative space has allowed sexologists break the connection between fantasy and reality. In addition to renegotiating fantasy themes of erotized rape events, sexologists are also incorporating a variety of theoretical and methodological rhetorical innovations that seek to reconstruct the role of gender in rape fantasies.

\section{Re-Locating Critical Attention via Methodological and Theoretical Rhetorical} Innovations

According to Bormann (1985), "[r]hetorical innovation, on occasion, may begin when one creative person fantasizes a powerful personal consciousness and does so with such skill that his or her consciousness is shared by converts and becomes the rhetorical vision that forms a community's consciousness" (p. 9-10). Rhetorical innovation occurs when others provide feedback for ideas and new dramatizations about the vision in question (Bormann, 1985). Bormann (1985) argues that innovative dramas depart from the rhetorical visions that have been perpetuated throughout the rhetorical community. The rhetorical innovations characterizing the research on rape fantasies in the Journal of 
Sex Research concerned how rape fantasies are studied, conceptualized, and theorized.

In general, the society appears to be moving away from an emphasis on hetero-women in research on rape fantasies, which presents an opportunity for the introduction of queer theory in the theoretical frames of the journal. ${ }^{11}$

The methodological innovations presented in the journal concerned how the issues were described with respect to gender and sexuality and pointed to a concern with heterosexism and heteronormativity. In their research on rape fantasies and pathology and power, Hawley and Hensley (2009) for example, argued that researchers must analyze the fantasies of men and women because "such material holds little particular “significance” for women" (Hawley and Hensely, 2009, p. 570). Hawley and Hensley (2009) are challenging the assumption that rape is a "female" problem. Critelli and Bivona (2008) have also encouraged a new methodological approach that could, potentially, complicate the heterosexist/heteronormative nature of research on rape fantasies by arguing that researchers need to include rape fantasies of lesbian and bisexual women and focus on "samples from cultures that are both more androcentric and more egalitarian than that of the United States, as these will provide valuable evidence as to the relative biological and cultural contributions to rape fantasies (Critelli and Bivona, 2008, p. 69).

These methodological innovations, if followed through, could construct a queer rhetorical vision of rape fantasies that critiques the imaginative space of fantasies and

\footnotetext{
${ }^{11}$ I have conducted a search for research that draws on queer theory in the Journal of Sex Research, and thus far, there have been no articles that represent a queer analysis represented in the journal. The only articles that mention queer theory in the title are book reviews.
} 
heteronormative assumptions that drive constructions of current rhetorical visions of rape fantasies.

Theoretical innovation within the journal also included attention to the role of gender, and, ironically, encouraged a refreshed look at evolutionary theories on sexuality as an explanatory variable in rape fantasies. Researchers in this context suggested the use of the Rational Choice Theory as an evolutionary theory that differs from traditional evolutionary theories by focusing on gender similarities. The researchers explain that women are as self-interested and competitive as men, but that women's strategies are less apparent. They also argue that women's attractions to dominant men represent a lack of fear of the man. To support their argument, they suggest that "[i]f such fantasies reflect a masochistic desire for pain and humiliation perpetrated by a misogynistic and brutal aggressor....then the dominant woman should not entertain these fantasies because doing so would strip her of her power" (Hawley and Hensely, 2009. 571). They offer an alternative theory that suggests that erotic rape fantasies "reflect a passionate exchange with a powerful, resource-holding, and attentive suitor, then through them the dominant woman could reinforce her high standing in the group and her favorable opinion of herself" (Hawley and Hensely, 2009, pp. 570-571). Rape fantasies, then, do not represent a desire to be overpowered, but instead, according to these sexologists, represent the increased opportunities afforded to a powerful woman.

The fantasy theme analysis performed in this chapter illustrates that The Society for the Scientific Study of Sexuality has been, in the last decade, working toward a new rhetorical vision of the rape fantasy that eroticizes the rape event without presenting the fantasizer as a "willing rape victim." The eroticization of the rape event within sexual 
fantasies has created symbolic convergence around the assumption that the imagination does not represent or reflect lived reality. In this way, the society has renegotiated the paradox of rape fantasies by creating a new rhetorical vision that positions the imagination as a rhetorical space that exists independent of the site of "actual" rape. Consistent with Mountford's (2001) theory on rhetorical space as the "geography of a communicative event" (p. 41), rhetorical appeals to the imagination function to spatially communicate and structure relations of power.

The new rhetorical vision features a fantasizer who controls the imaginative space in which the rape event takes place. In short, the fantasizer does not receive pleasure from suffering, per se, but instead, from playing roles that may include the experience of surrender. In constructing, or moving toward, this new rhetorical vision of the eroticized rape fantasy, sexologists have reconstructed theories of masochism to create an imaginative space where one can enjoy an experience that contains elements associated with legal constructs of rape. This is not surprising considering that the crime of rape is a spatial-rhetorical concept.

Newer sexological research on rape fantasies has raised several questions, and has encouraged several rhetorical methodological and theoretical innovations, that address the role of gender in eroticizing rape fantasies. These innovations can potentially move the Society for the Scientific Study of Sexuality toward theories, like queer theory, that complicate heteronormative assumptions about gender, identity, desires, and sexual practices; however, they are also paradoxical because they maintain the spatial logics of heterosexuality and heteronormativity that distinguish between "good" and "bad" heterosexualities (see Natalie Oswin [2008] and Philip Hubbard [2000] for a discussion 
of moral heterosexualities). In the context of the research presented in this chapter, imaginative space provides a context for maintaining hetero-morality. Rape can be eroticized (and hence, experienced as pleasurable) in imaginative space, which also establishes "proper" heterosexual performances. Therefore, on the one hand, the new rhetorical vision of eroticized rape denaturalizes hegemonic gender norms via a rejection of "masochism;" however, it also normalizes sexual pleasure and sexual propriety.

\section{Chaining Out: A Suggestion for Future Research}

One of the most significant components of fantasy theme analysis is "chaining out" which Bormann (1972) uses to refer to how fantasy themes are embraced and transmitted throughout rhetorical communities. Members of rhetorical communities pick up these chains and improvise and respond to them as needed and in turn, the chained out fantasies become a force that structures social realities around the rhetorical vision. In their research on fantasies of sport in radio sports talk, for example, Zagacki and Grano (2005) demonstrated how sports fantasies chained from sports radio throughout various rhetorical communities in ways that established what it meant to be a member of the LSU football community, a member of LSU, and in some cases, the state of Louisiana. Zagacki and Grano (2005) noted that at the heart of this chaining process was Tiger Stadium, "where heroic acts take place. It is a sacred setting in which allegiance to the state, the manhood of the combatants, and the capitalist virtues of the system are tested. Fans and players alike fight for the pride of their community, and heroic achievements on the field exemplify the heroic virtues of the fan community" (p. 56). Zagacki and Grano (2005) also argued that talk shows allowed participants to perform hegemonic masculinity and femininity consistent with the rhetorical vision. They demonstrated, for 
example, that male callers often criticized players aggressively whereas women tended to offer nurturing support. Finally, they also found that sports fantasies informed official university narratives regarding the role of college athletics in the university. In this way, rhetorical visions chained out through a variety of contexts that could be described as rhetorical spaces.

Virginia Kidd (1998) has also described how discourse on teachers' pay chained out from comments made by Jerry Brown when he was the governor of California. In short, when Brown was governor, professors demanded a pay raise to which he responded they did not need because they were rewarded by the lives they touched through teaching. He referred to this, a rhetorical vision of teaching, as "psychic income." The construct of psychic income chained throughout a variety of rhetorical spaces including cartoons that showed professors using psychic dollars to pay for food and editorials debating how much psychic money professors should receive. There was also a letter campaign urging professors to donate psychic dollars to Brown's re-election campaign. Kidd's (1998) research, like Zagacki and Grano's research (2005), illustrates how rhetorical discourse moves through rhetorical communities. The spatial dimension of this process indicates an area deserving of further research for understanding how discourse is created, changed, and perpetuated through rhetorical communities.

The process of chaining out would be an insightful form of analysis to follow up on with respect to discourse on rape fantasies. As many sexologists noted in the articles referenced in this chapter, one of the problems with the assumption that rape fantasies indicate that women want to be raped is that these assumptions can be used in rape cases to exonerate those who have been accused of rape. The willing victim mythology 
suggests that women are consenting to rape. Tracing work through an organization like the Society for the Study of Sexuality would be particularly useful for considering how far the discourse reaches. Related to examinations of chaining out, a second area of further research should also consider how discourse from other rhetorical communities are chained into the discourse of a rhetorical community in order to show connection between rhetorical communities. In this chapter, I included a discussion of Deutsch's (1944) theory of masochism, which was not originally published in the Journal of Sex Research. Identifying and examining other widely cited articles outside of the community would also be beneficial for understanding the construction of specific rhetorical visions within interconnected rhetorical communities such as sexology, criminal justice, education, etc. 


\section{CHAPTER 4: VISUALIZING THE FIELD: SPATIAL METAPHORS, MEDICALIZATION OF SEXUALITY, AND DISCIPLINARY SPACE}

In 2012, the Society for the Scientific Study of Sexuality published a special issue of their Journal of Sex Research that featured articles on the medicalization of sexuality. The concept of medicalization, defined as the process by which non-medical issues are reconceptualized as medical problems, has often been used by scholars in a variety of fields to criticize how medicine, as a social institution, exercises social control (Conrad, 1992). The specific topics presented in the special issue include the implications of defining women's sexual pain as a form of female sexual dysfunction (Farrell \& Cacchioni, 2012), how notions of "healthy sex" have been incorporated into anti-aging discourse (Marshall, 2012), and how discourse on the vaccination for HPV has pathologized nascent sexual relationships as a threat to future sexual health (Polzer and Knabe, 2012). Together, these articles provide an overview of research on contemporary practices and consequences of medicalization, but the special issue is also notable for including rhetorical analysis as an analytic strategy and because the editors' and contributors' primary purpose for publishing articles on the medicalization of society was to encourage sexologists to renegotiate their disciplinary boundaries in an effort to complicate and challenge the medicalization of sexuality.

Rhetorical analysis is incorporated in several of the medicalization articles published in the special issue as an analytic strategy for conducting sex research. 
Medical rhetorician Judy Segal (2012), for instance, drew on rhetorical analysis and theory in her contribution to the special issue on medicalization, "The Sexualization of the Medical." In "The Sexualization of the Medical," Segal (2012) explained how medical persuasion functions in public accounts of cancer, which she frames as epideictic rhetoric (see also, Segal, 1998, 2007, 2009). Other contributors to the special issue on medicalization have considered how rhetoric contributes to social and cultural narratives of health and illness. In their work on HPV and the medicalization of nascent female sexuality, for example, Polzer \& Knabe (2012) examined the persuasive techniques medical professionals use to create cautionary tales and inspirational stories that encourage the view that women are morally obligated to take responsibility for their health or suffer the consequences. Also, Giami \& Perrey (2012) examined how biomedical recommendations, within the context of HIV prevention discourses, appeal to notions of individual responsibility. The contributors to the special issue suggested that rhetorical analysis contributes to our understanding of medicalization as a process by which issues are constructed and legitimated as medical problems that need to be treated by medical and scientific authorities. In doing so, rhetoric is presented as a tool scholars can use to drive their research questions, theory, and analyses.

A second notable feature of the special issue on medicalization is that the editors' and contributors' primary goal is to encourage sexologists to broaden their theoretical perspectives on sexuality and their secondary goal is to present research-based articles that highlight how medicalization influences the construction and control of sexuality. Although the special issue features research on medicalized constructions, and accompanying consequences, of sexuality, the stated purpose of the special issue is to 
motivate sexologists to renegotiate their disciplinary space. In the introduction to the special issue on medicalization, for instance, the editors, Cacchioni and Tiefer (2012), argued that:

Sexuality studies must strive to be more cross-disciplinary and interdisciplinary. Otherwise, we cannot hope to understand our amazing subject: sexuality....The advantages of this focus are that it highlights the socioeconomic and commercial context in which sex research is produced. The world and sexuality are both becoming more consumerist and technocentric, and it will be the broadly trained sexologist who will be able to offer the best research, education, and clinical work (p. 308).

In the previous passage, the editors intimate that sexologists, at present, are ill-equipped to address sexuality. Hence, the special issue on medicalization is a call for sexologists to alter their disciplinary field in order to maximize their effectiveness as sex researchers. In this chapter, I will examine how the editors and contributors to the special issue on medicalization utilize spatial rhetorics to persuade sexologists to alter the disciplinary space of sexology. In short, I argue that spatial rhetorics allow sexologists to "see" the problems associated with medicalization and intervene by renegotiating the boundaries of their disciplinary space.

In the following section, "Medicalization, Space, and Rhetoric," I review the secondary literature that theorizes the nature and practices of the medicalization of sexuality. I also conceptualize my use of "disciplinary space," and outline my methodological approach for the analysis of geographical metaphors in the special issue's articles on the medicalization of sexuality. 


\section{Medicalization, Space, and Rhetoric}

Rhetoric and spatiality are inherent to definitions and characterizations of medicalization. ${ }^{2}$ Leonore Tiefer (1996), a psychologist who further developed Peter Conrad's (1992) concept of the medicalization of sexuality, explained that "medicalization relocates activities or experiences (e.g., crimes, habits, or changes in physical or intellectual ability) from categories such as social deviance or ordinary aging to categories of medical expertise and dominion" (p. 74). Tiefer's (1996) characterization of medicalization points to the role of spatiality, by way of "location," in practices of medicalization. Tiefer (2010) has also critiqued the negative implications of medicalization by noting that:

The trouble comes when the medical model produces false expectations of diagnostics and treatments, drugs with unexpected side-effects and escalating costs, a disempowered public whose only coping skill for sexual problemsolving is consulting a doctor, new performance insecurities and a wholesale neglect of social, relationship and psychological factors. On balance,

\footnotetext{
${ }^{2}$ Historiographies of medicalization also highlight the role of rhetoric and space in our understanding of medicalization as a practice and critique of how medicine, the institution and discipline, has socially controlled sexual practices and identities. Historically, medicalization was rooted in nineteenth-century practices of science and medicine. In the twentieth-century, the locations of the medicalization of sexuality expanded with the association of sexuality with social practices and rhetorics centered on gender roles, the patriarchal construct of marriage, and the move toward egalitarian and companionate sexual relations between men and women (Tiefer, 2012; see also D'Emilio and Freedman, 1998). Late nineteenth-century and twentieth-century efforts at medicalization involved the relocation of sexual social control from the church to the doctor's office. When the authority over sexuality was transferred from the authority of religious leaders to doctors, the "appropriate" spaces of sexuality were altered as well. Sexuality was presented as a matter of health that required self, community, and medical surveillance (Foucault, 1984).
} 
medicalization does not deliver a better sexual world and so we find ourselves continuing to resist (p. 194).

As a social and political practice, medicalization occurs when people are persuaded that a non-medical issue is really a medical problem that is best addressed in a particular location such as the doctor's office. Hence, medicalization spatializes disciplinary power, and I conceptualize this practice in terms of disciplinary space.

My notion of disciplinary space relies on Michel Foucault's (1977) theory of disciplinary power that conceptualizes "discipline" as a branch of knowledge (e.g., sexology, biology, sociology) and as a normalizing strategy of power. Disciplinary power is a spatial practice of power that creates or functions as an "architecture of control" that determines who can speak with authority on an issue, what can be said about the issue, and to whom communicative acts should be directed. Within the context of spatial theories, the concept of disciplinary space represents a synthesis of Henri Lefebvre's (1974) theory of how space is socially produced and used by inhabitants. As discussed in chapter one of this dissertation, Lefebvre (1974) argued that spatiality is a triad based on perceived (or material) space, conceived (or represented) space that is created by authority figures and is transmitted through knowledge and ideology, and lived (or representational) space that is experienced and occupied by inhabitants. Disciplinary space synthesizes perceived, conceived, and lived space.

Disciplinary space is a rhetorical space, or communicative geography, that locates knowledge within a specific domain, and, in doing so, normalizes specific forms of action. As mentioned earlier in this chapter, the editors and contributors to the special issue on medicalization use the term "medicalization" to refer to an intervention into 
sexological disciplinary space. Hence, the editors and contributors encourage sexologists to (re)negotiate the rhetorical spaces that define their field and control discourses and practices related to sexuality. Deconstructing and reconstructing disciplinary space restructures who can speak authoritatively about sexuality and what their speech contains, and this restructuring also renegotiates rhetorics of sexuality and social control

The analysis presented in the current chapter follows applied social scientist Rudolf Schmitt's (2005) systematic metaphor analysis methodology (see also Schmitt 2000, 2003, 2004). Schmitt (2005) formalized a qualitative methodology of metaphor analysis based on George Lakoff's and Mark Turner's (2003) theories of conceptual metaphors. Schmitt's (2005) procedure involves identifying and analyzing conceptual metaphors in a discourse in order to understand how knowledge about a subject under examination is created. In this chapter, following Schmitt's methodology, I conceptually coded each of the nine articles published in the Journal of Sex Research's special issue on the medicalization of sexuality based on the form and content of the metaphors used by the editors and contributors to create exigence for their argument that sexologists need to renegotiate their disciplinary space. Schmitt's methodology for identifying and analyzing the role of conceptual metaphors in discourse involves four steps: (1) identification of the target area for metaphor analysis, which, in the research presented in this chapter, centered around the argument that sexologists need to broaden their disciplinary space; (2) collection of metaphors in the data, which, in this chapter, centered around metaphors that function to characterize the nature and consequences of medicalization; (3) the creation of subgroups, which, in this chapter, involved two subgroups: cartographic and 
topographic metaphors; and, (4) interpretation of the metaphors based on the action the metaphors encourage

The analysis featured in this chapter is presented in two parts. In the first section, "Setting the Scene: Contextualizing the Medicalization of Sexuality," I discuss how the editors and contributors appeal to contextualization as a spatial rhetoric that articulates and justifies their goals for the special issue on medicalization. I argue that the contributors' and editors' goals resonate with Leah Ceccarelli's (2001) notion of "interdisciplinary motivational works of science" that encourage sexologists to redraw their disciplinary boundaries. In the second section of this chapter, "Visualizing Medicalization via Spatial Metaphors," I provide an overview of the theories of metaphors and spatiality I draw on to frame my analysis of spatial metaphors and I present my analysis of how the contributors and editors use spatial metaphors to motivate disciplinary change.

\section{Setting the Scene: Contextualizing the Medicalization of Sexuality}

In the introduction to the special issue on the medicalization of sexuality, the editors of the issue, Cacchioni and Tiefer (2012) noted that:

This special issue grows out of the need to bring into focus the historical and sociocultural contextualization of sex to the sexological community. The specific focus is on analyzing how medicalization is affecting many areas of sexual life and discourse, but the larger goal is to help situate sexuality studies in its broadest perspective (p. 307).

The impetus for the special issue was sexologists' non-attendance at a Vancouver conference on the medicalization of sexuality, which the editors to the special issue, 
Cacchioni and Tiefer (2012), felt "seemed to confirm a trend within sexology to ignore social contexts or minimize them within an individualized psychological framework in pursuit of reified notions of gender, sexual activity, sexual identity, and so forth" (p. 308). Furthermore, the lack of attendance by sexologists at the Vancouver conference encouraged Cacchioni and Tiefer (2012) "to reach out to that audience through a mainstream sexological publication. $J S R$ was chosen as likely to reach the most interested segment of the sexological community" (p. 308). The special issue served to present research on the medicalization of sexuality and to engage the sexological community in a conversation about the disciplinary boundaries of the field. The editors argued that sexologists needed to embrace interdisciplinary approaches in sexuality studies in order to effectively contextualize their work.

As mentioned earlier in this chapter, the special issue editors Cacchioni and Tiefer (2012) argued that consumerism and new technologies require broadly trained sexologists. The editors offer interdisciplinarity as a corrective to decontextualized studies of sexuality. The arguments for taking an interdisciplinary approach when contextualizing sexuality are presented as a practical tool for disciplinary change. For this reason, the special issue represents an interdisciplinary inspirational work of science, which, according to Ceccarelli (2001), functions as a catalyst that motivates change in the disciplines. As an interdisciplinary motivational work of science, the special issue persuades, or inspires, sexologists to renegotiate the disciplinary space of their field by "showing" sexologists, via spatial rhetorics, how medicalization works, how medicalization creates problems related to sexual social control, and how sexologists can intervene in processes of medicalization. 
In the following section, "Visualizing Medicalization via Spatial Metaphors," I will illustrate how the editors and contributors draw on spatial metaphors to motivate a renegotiation of sexological disciplinary space. The section on visualizing medicalization begins with an overview of the theories on the nature and role of conceptual metaphors in science and medicine. Following the discussion of the theoretical and conceptual frame for the metaphor analysis, I present an analysis of how the editors and contributors to the special issue use agentic and ontological spatial metaphors in their articles published in the special issue on medicalization to demonstrate how medicalization maps the sexual landscape.

\section{Visualizing Medicalization via Spatial Metaphors}

Analyzing metaphors provides insight into the apparatus that creates knowledge and practice because such analyses help us understand how metaphors construct conceptual realities that allow us to access new and innovative ideas (see also Geary, 2011; Grothe, 2008; Kalyanaraman \& Sundar, 2008; Lakoff \& Turner, 1989; Lakoff \& Johnson, 2003; Maasen \& Weingart, 2000). In the context of science and medicine, metaphors work by connecting concepts in the mind and creating knowledge that transcends those concepts. Metaphors can also serve as models of processes or objects that scientists cannot see by concealing or highlighting particular realities (Segal, 2005). ${ }^{4}$

\footnotetext{
${ }^{4}$ In their work on DNA, Pramling \& Saljo (2007) support the notion that metaphors connect concepts in the mind. Pramling \& Saljo (2007) found that scientists often incorporate anthropomorphic metaphors to present DNA as human-like actors operating intentionally. In other situations, scientists present DNA as architecture, with DNA as the building blocks, as well as using metaphors based on puzzles, the theater, and recipes. These anthropomorphic and architectural metaphors are superimposed on abstract ideas in order to present the theory. Susan Sontag (2001) has illustrated how metaphors and social constructions of cancer and AIDS have influenced how we understand and experience disease. Similarly, Celeste Condit (2001, 2007, 2010) has identified how
} 
In doing so, metaphors are often theory-constitutive (Baake, 2003; Dexter \&

LaMagdeleine, 2002; Greenwood \& Bonner, 2008; Reeves, 2005). Metaphors also structure research designs and drive the conceptualization and operationalization of key terms under study (Fopp, 2009). ${ }^{5}$ Scientific and medical metaphors, as objects of analysis and intervention, provide insight into knowledge construction and comprehension.

Metaphors often involve spatiality (Lakoff \& Johnson, 2003; Flannery, 2001). Foucault (2007) has established a link between spatiality and metaphor in a lecture on language and spatiality. Foucault argues that language is "a thing of space... [that it is] the most obsessive of metaphors, it is not that it henceforth offers the only recourse; but it is in space that, from the outset, language unfurls, slips on itself, determines its choices, draws its figures and translations. It is in space that it transports itself, that its very being 'metaphorizes' itself' (p. 163). Foucault's argument suggests that spatiality and

"recipe" and "blueprint" metaphors construct popular understandings of genes that contribute to genetic determinism

${ }^{5}$ Visser-Wijnveen, Driel, van der Rijst, Verloop, \& Visser (2009) found that researchers differ in terms of characterizing their research as a puzzle, as a market, as an excavation, or as a journey. Pitcher and Akerlind (2009) described similar findings in their research; however, their research metaphors centered on exploration, spatiality, construction, and the organic.

Explorative metaphors were used to characterize research as traversing a terrain or path, spatial metaphors characterized research as spreading out into an area of knowledge, constructive metaphors represented metaphors as adding to, or filling in, gaps in knowledge or existing literature, and organic metaphors represented research in terms of life (for example, that research may die....). Also, Periyakoil (2008) found that two common uses of clinician-initiated metaphors included the introduction of unfamiliar material, which allowed the clinician to help patients and family members to understand information by connecting the new information to an existing schema in the mind.

Periyakoil's (2008) second finding on the uses of clinician-initiated metaphors was that metaphors allowed clinicians to "make the familiar strange," which allowed the clinicians and patients to break preexisting mind sets in order to understand something new about illness. 
language are intimately connected and metaphors are produced from the connection between space and language.

The contributors and editors of the special issue draw on spatial metaphors to characterize the practices and problems associated with medicalization to create exigencies and provide justifications for their argument that sexologists need to alter their disciplinary space. As will be shown below, spatial metaphors make disciplinary space visible. More specifically, agentic spatial metaphors present medicalization as a social force that maps locations for medicalized sexual social control, whereas ontological spatial metaphors represent the disciplinary terrain created by medicalization. Agentic spatial metaphors draw on the language of mapping to explain the "doing" of medicalization and ontological spatial metaphors draw on the language of terrain to represent the implications of medicalization and provide sites for sexological interventions in disciplinary space. Together, agentic and ontological spatial metaphors provide evidence of the characteristics and implications of medicalization that the editors and contributors use to motivate sexologists to reconstruct their disciplinary space.

In general, agent metaphors describe inanimate objects as the deliberate action of a living thing (e.g., "The Dow fought its way upward"). Agents are "anything to which we attribute human feelings, motives, and motivations.... We make agents out of objects...by imputing the characteristics of living things to them" (Geary, 2011, p. 32, 39). Agentic spatial metaphors provide structure to an abstract phenomenon and serve as a filter that reduces complexity (Gugerli, 2004).

The editors' and contributors' definitions of medicalization reveal the presence of agentic spatial metaphors that characterize medicalization as a social force that maps out 
the "appropriate" locations for sexual knowledge, practices, and interventions. In the introduction to the special issue on medicalization, for example, Cacchioni and Tiefer (2012) define medicalization as:

an evolving conceptual framework that charts the increasing power of medical concepts, institutions, and individual figures of authority....Medicine intervenes in women's life processes much more than in men's....Additionally, women are subjected to medicalization due to their roles in supervising the health care of families (p. 308; emphasis added).

Cacchioni and Tiefer's (2012) definition of medicalization emphasizes how medicalization functions to move medicalized definitions of sexuality into subjects' lives by way of intervention (and imposition). The editors' and contributors' definitions of medicalization also associate a cartographic, or mapping, function of medicalization with the subjugation of women, which is represented as an invisible force that structures women's sexual lives. Medicalization is personified as an agent (cartographer) who maps and charts sites for medical intervention in people's lives. The use of agentic, cartographic metaphors unmasks the invisible forces associated with the medicalization of sexuality.

The cartographic function of spatial metaphors is also represented in Tiefer's (2012) contribution to the special issue on medicalization, "Medicalizations and Demedicalizations of Sexuality Therapies." In her article, Tiefer (2012) argues that medicalization locates, or creates the locations for, authoritative areas for sexual interventions. She explained that: 
[T]he medicalization of sexuality locates sexual problems and interventions within a professionalized framework of diagnoses and therapies, identifies health-trained personnel (not just physicians) as sexuality experts, foregrounds traditional medical emphases of individual factors and universal processes as the important axes for understanding, and anoints biomedical strategies as the favored interventions (p. 311; emphasis added).

Tiefer's (2012) discussion of medicalization illustrates how medicalization is presented as cartographically creating, or mapping, locations that determine appropriate or legitimate interventions into sexuality. In the case of medicalization, proper interventions and treatment are centered around medical therapy and in medical sites. Tiefer's (2012) definition and overview of medicalization also illustrate how medicalization functions heuristically to control sexual knowledge and practices by creating the locations of sexuality that work as sites for social control. Ultimately, in the editors' and contributors' articles in the special issue, the agents of medicalization (medical professionals, pharmaceutical professionals, and insurance professionals) are displaced by medicalization itself. In other words, the "doer behind the deed" is erased and medicalization is ascribed an agentic function.

The definitions of medicalization presented in the special issue represent a cautionary tale of the problems that potentially occur when medicalization is allowed to create and control the disciplinary spaces associated with sexuality. Agentic cartographic metaphors function as a call for sexologists to examine how their disciplinary space is influenced by medicalization. As a call-to-action, the special issue on the medicalization 
of sexuality represents an interdisciplinary inspirational text that allows for sites of intervention on the part of sexologists.

The contributors provide additional support for their call to renegotiate disciplinary space by highlighting how medicalization has informed social experiences outside of areas typically considered to fall within the medical field. In an article on the medicalization of HIV prevention, for instance, Giami and Perrey (2012) focused on the transformative practices and effects of medicalization:

The concept of biomedicalization helps to better understand the passage from the medicalization of some conditions to the medicalization of health and ordinary lifestyles. It is not only the creation of new medical categories that is at stake here, but the radical transformation of everyday life (p. 353).

The appeal to "passages" and "transformations" featured in the previous quote indicates how spatial metaphors (zones and passages) support the contributors' and editors' cautionary tale of medicalization. The effects of medicalization have negative implications for sexuality in particular and everyday life in general.

In the special issue on the medicalization of sexuality, the contributors and editors also use spatial metaphors to problematize how medicalization maps the locations of "legitimate" sexual knowledge, practice, and treatment and establishes boundaries of authority and sexual social control within specific contexts and domains of disciplinary knowledge. The editors and contributors to the special issue position sexologists as agents for challenging how medicalization has mapped sexuality by altering sexological disciplinary space. The cautionary tale of medicalization indicates the need for 
sexologists to insert themselves into social and cultural discourses on sexuality. The editors and contributors essentially encourage sexologists to participate in such conversations by remapping the disciplinary space of sexology.

Medicalization, by moving knowledge and authority from one domain to another, or expanding into nonmedical domains indicates its function in the construction of disciplinary space that performs rhetorically by establishing who can speak of sex and what they can say. One of the most interesting aspects of the cautionary tale contained in the articles in the special issue on medicalization is that the contributors and editors draw on medicalization as a spatial rhetoric to influence disciplinary boundaries-a rhetorical move on the part of the editors and contributors that constitutes a call-to-action for sexologists to mobilize against medicalization. Their goal of addressing medicalization in the special issue, however, is not to establish or erase medical authority, but instead, to encourage sexologists to create a broader focus that situates sexuality culturally, politically, and historically.

Agentic spatial metaphors that function cartographically ascribe agency and purposeful behavior to inanimate processes and objects, i.e., medicalization. Medicalization is presented as a force (or cartographer) that maps the sexual landscape through various interventions in disciplinary space. Ontological spatial metaphors, on the other hand, represent outcomes of cartographical mappings. In the context of the medicalization of sexuality, ontological spatial metaphors that function topographically allow us to "see" the landscape created by medicalization.

The contributors to and editors of the special issue on the medicalization of sexuality draw on topographic metaphors related to fields, zones, domains, and borders to 
describe how medicalization has altered the sexual landscape, or topos. In "Medicalization and the Refashioning of Age-Related Limits on Sexuality," Marshall (2012) used the "field" as a topographic metaphor to illustrate how medicalization has co-opted the construct of "sexual health" in the interests of age-related sexual social control:

The field of sexual health, once primarily concerned with the prevention of sexually transmitted diseases and reproductive matters has become increasingly focused on sexual desire and performance where older people are concerned. Sexual health is equated with sexual function and underpinned by biomedically driven, anti-decline narratives (p. 337). Similarly, in "Medicalizations and Demedicalizations of Sexuality Therapies," Tiefer (2012) invokes the "field" to emphasize how medicalization is connected to sexological disciplinary space:

In the field of sexology, medicalization can be seen in the growing authority over sexual matters given to medical experts in the past two centuries, but especially in the growing visibility of a new cadre of "sexual medicine" specialists backed by the pharmaceutical industry in the past two decades (p. 311).

In Tiefer's (2012) and Marshall's (2012) passages quoted above, the field metaphor functions topographically to indicate how sexual knowledge and practices are organized spatially. In common parlance, a field is typically defined as a bounded area that serves a purpose (e.g., military field, baseball field, wheat field, etc.). The field metaphor actualizes medicalization by allowing us to "picture" the sexual landscape. It is also 
worth noting that topographical metaphors also indicate the precariousness of

medicalization. In "The Sexualization of the Medical," for instance, Segal (2012) explained that "[b]orders that separate the realms of the moral, the psychological, the relational, the cultural, the social, the economic, and the medical are porous, permeable, and partial" (p. 376). Segal's (2012) characterization of various components of fields (moral, psychological, etc.) as permeable also indicates that the landscape created by medicalization is provisional.

The contributors and editors also appeal to the notion of spatial or structural expansion to illustrate how medicalization has altered the sexual landscape. In her work on medicalized constructions of sexuality and age, for example, Marshall (2012) explains that:

In the $19^{\text {th }}$ century, medicine articulated natural laws and clinical "truth" about climacteric and sexual decline. Subsequent waves of medicalization have intensified the notion of midlife decline, expanding the space for biomedical intervention - that is, medicine has created a model of senescent sexuality as a problem for which sexual "health" (which tends to be understood rather narrowly as the continued ability to perform heterosexual intercourse) has become conterminous with successful aging (p. 337).

Marshall's (2012) notion of "waves of medicalization" highlights how medicalized social control associated with aging has created additional opportunities for biomedical intervention, and potentially, sexual social control. 
The issue of the expansion of medicalized space is also raised in contributors' and editors' critique of how the zones of medicalization have moved into new locations, or sectors, such as cyberspace and consumer markets. In her overview of medicalization and demedicalization, for example Tiefer (2012) argued that medicalization and biomedicalization were intersecting with nonmedicalizing trends such as "an escalating non-expert commercial sexuality sector on the Internet, as well as a long history of anarchic and democratizing social politics, such as 'the counterculture' and 'free love movements"” (p. 311). Furthermore, Tiefer (2012) explained that the nonmedicalizing trends have a view of "sexual problems and solutions as far broader than sexual dysfunctions and sex therapies, a belief in the social determinants of individuals' sexual experiences, and a deep concern regarding the socially harmful consequences of medicalization" (p. 311). Nevertheless, Tiefer (2012) called attention to the formation of a new cadre of sexual medicine specialists who are implicated in biomedicalization via the pharmaceutical industry by noting that "[e]xperts live not only in the world of bricks and mortar, but in cyberspace. As the Internet has grown as a source of information and products for sexuality, both individual and corporate medical entrepreneurs are represented by Web sites and blogs touting their expertise and their products' effectiveness to solve sexual problems" (p. 311). Tiefer's (2012) use of "sector" as a spatial metaphor also illustrates the spatiality of medicalization by way of the Internet, pharmaceutical industry, and world of "bricks and mortars."

In the introduction to the special issue, Cacchioni and Tiefer (2012) raise the concern about movement in and out of spaces by explaining that: 
Recent discussions of medicalization highlight its massive expansion through new mechanisms and markets created by the pharmaceutical industry, health insurance companies, hospitals, HMOs, and governmental agencies....These multiplying discourses are only further evidence of the centrality of these concepts to every part of life, including the sexual (p. $308)$.

The appeal to "massive expansion" illustrates how disciplinary space has been created and altered by new mechanisms and markets. The concern with the addition of new zones and the alteration of existing zones is based on the standards and motivations of those controlling the zones. The contributors and editors address issues of social control by way of "domain" metaphors.

The phrase "domains of knowledge" indicates the issue of authority and power over the creation and control of zones. When a zone is associated with consumerism, for instance, the "proper" domain of knowledge is associated with corporate rather than scientific interests. For example, pharmaceutical companies that gain from commercialization of the medicalization of sexuality are constructed as the authoritative source on issues related to sexuality. They occupy the allegedly proper domains of sexuality and medicine. In "Medicalizing Reproduction: The Pill and Home Pregnancy Tests," Tone (2012) addressed the role of consumerism and pharmaceuticals in efforts of sexual social control by noting that:

Since the 1970s, scholars have debated the multiple meanings of medicalization — that nebulous but dynamic process by which aspects of everyday life come to be pushed and pulled into a medical domain. Critics 
have questioned the authority doctors wield as purveyors of medical knowledge and prescribers of potent pharmaceuticals, they have analyzed the therapeutic necessity of costly and sometimes risky diagnostic tests, and they have evaluated the machinations of pharmaceutical companies to recode what might once have been considered the ordinary vicissitudes of life into medical problems that require drugs and a doctor's care (p. 319, emphasis added).

Tone (2012) also explained that in the history of medicalization of reproductive technology that the interpretation of knowledge and knowledge have been culturally and socially mediated, which accounts for how such medicalizations have changed historically. Tone (2012) essentially indicates that questions concerning the domain of knowledge are connected with the disciplinary (and cultural) authority to produce and disseminate knowledge. They are associated less with the content of the knowledge and more with the site of its dissemination.

Spatial metaphors are rhetorical devices the contributors and editors draw on to concretize the movement of medicalization and the sexological disciplinary field. Agentic, often cartographic, spatial metaphors represent medicalization as an agent constructing the sexual landscape. As an agent, medicalization intervenes in people's lives, imposes responsibility for sexual control, locates sites for intervention, and transforms everyday life. Essentially, medicalization functions as a cartographer that maps sexuality. Ontological, topographic, metaphors illustrate the terrain created by medicalization. Realms, domains, and permeable sectors represent the terrain created by medicalization. 


\section{Conclusions}

Medicalization is an inherently spatial concept that is based on location (i.e., locations of expert authority, normalized and institutional practice, etc.) and medicalization is also rhetorical: sexual subjects (consumers, patients, doctors, sexologists) have to be persuaded that medicine is the proper authority on issues related to sexuality. The special issue on the medicalization of sexuality represents an interdisciplinary motivational work of science that motivates sexologists to alter their disciplinary space. Spatial metaphors are rhetorical devices that the editors and contributors to the special issue have drawn on to create exigence and provide justifications for reconstructing the boundaries of sexology. Spatial metaphors are efficacious tools for constructing a motivational text because they allow us to "see" the processes and outcomes of medicalization. Furthermore, medicalization is inherently a rhetorical and spatial concept that indicates how persuasion and location are interconnected in discourse on sexuality.

Together, the agentic and ontological spatial metaphors represent medicalization as a social force that spatializes sexuality and social control. These metaphors render something that is typically abstract and invisible as a concrete and visible reality, which potentially encourages reflexiveness and praxis on the part of sexologists. Spatial metaphors allow sexologists to see how medicalization maps the sexual landscape in terms of practice and outcomes.

Considering that medicalization involves persuasion and location, or rhetoric and spatiality, it is not surprising that spatial metaphors provide a technique for critiquing the 
process of medicalization, and more generally, for encouraging an interdisciplinary approach in sexology. Elements of agentic and ontological spatial metaphors include various rhetorical gestures and appeals to expanding zones, articulations of knowledge domains, and porous surfaces. These rhetorical gestures establish rhetorical disciplinary spaces that allow sexologists to critically examine medicalization of sexuality by establishing sexology as a proper disciplinary location for understanding the medicalization of sexuality. The appeal to expanding zones of medicalization, for example, serves as a call-to-action for sexologists to get involved in discourses of sexuality. Domains of knowledge justify and privilege medical and scientific authority over sexuality. And, appeals to border crossings by alternative communities generate knowledge about sexuality and indicate sites of resistance. The ability to picture the movement and terrain of medicalization also offers the opportunity to identify points of intervention into the discourse and practices of medicalization.

Examining the construction of disciplinary rhetorical spaces provides an opportunity to reflect on the implications of specific discursive systems. Foucault (1977) would argue that medicalization accomplishes two goals of bio-power: disciplining the body and the population. Critiquing this process allows scholars of sexuality to participate in the discourse on medicalization in a critical or reflexive way. Furthermore, the creation and alteration of disciplinary spaces allows sexologists to participate in larger social formations of sexuality.

The findings in this chapter encourage new lines of questioning and further research into the construction of sexological knowledge. Examining the construction of disciplinary space, and the geographical metaphors that make disciplinary space 
“visible," provides an opportunity to reflect on, and intervene in, specific discursive systems. 


\section{CHAPTER 5: CONCLUSIONS}

In rhetoric and composition, theories of rhetorical space can be classified as contextual or praxical. Contextual theories of rhetorical space define rhetorical spaces as geographical locations that influence the nature and content of communicative events and acts. In contextual theories of rhetorical space, spatiality references physical places that serve as containers, or locations, for writing and presenting texts. Lorraine Code's (1995) work on gendered locations, for instance, exemplifies a contextual theory of rhetorical space. For Code, (1995), rhetorical spaces are territories or territorial imperatives that structure and limit speech-acts. Compositionist Nedra Reynolds (2004) has also adopted a contextual theory of rhetorical space by focusing on how geographical locations inform the development of writing. Furthermore, Code's (1995) and Reynolds's (2004) research reflects the assumption that spaces or places pre-exist rhetorical acts but, nevertheless, influence the nature and content of those acts.

Praxical theories of rhetorical space recognize the importance of location in rhetorical acts, but they do not limit spatiality as a "container" for rhetorical acts. Instead, praxical theories of rhetorical space emphasize the rhetorical "doing," or performativity, of space. Moreover, praxical theories include the assumption that rhetorical spaces are not neutral, nor necessarily drawn on intentionally by rhetors as rhetorical devices in communicative acts (see Mountford, 2001). Praxical theories of rhetorical space emphasize the multidimensional nature of spatiality (e.g., conceptual, lived, and material space), the malleability of rhetorical space, and the role of power in 
creating or influencing rhetorical spaces (see Enoch, 2008; Jack, 2009; Marback, 2004; Mountford, 2001; and, Wright, 2005).

In this dissertation, I adopted a praxical theory of rhetorical space to identify and examine how members of The Society for the Scientific Study of Sexuality draw on or invoke rhetorical spatiality in their research published in the Journal of Sex Research. My specific research questions were: (1) What types of rhetorical spaces do sexologists create? and, (2) What rhetorical strategies do sexologists use to create rhetorical spaces?

To review from chapter one of this dissertation, The Society for the Scientific Study of Sexuality's primary goal is to create scientific literature on sexuality that can be incorporated into sexological practice. In their mission statement, for instance, The Society for the Scientific Study of Sexuality writes: "Scientific knowledge of sexuality forms the foundation for all professional services [e.g., therapy, legislation, sex education, etc.] in sexuality. This knowledge is different from opinion, requiring the collection and interpretation of evidence using public, universal, and critical scholarly standards" (para. 2, Mission). The Society for the Scientific Study of Sexuality accomplishes their goal of developing sexological research that informs practice by incorporating multiple disciplines (e.g., anthropology, law, medicine, theology, sociology, psychology, and biology) into their theoretical perspectives, by offering continuing education through the American Psychological Association, American Association of Sexuality Educators, Counselors and Therapists, National Association of Social Workers, National Commission for Health Education Credentialing, National Board for Certified Counselors (para. 4, Join Today!), and by offering social networking, mentoring, and an ambassador program to members. Given their reach and goal, The 
Society for the Study of Sexuality's research provides a point of intervention into the connection between scientific discourse and institutional social practice.

Considering the mission and reputation of The Society for the Scientific Study of Sexuality, I approached the articles published in the Journal for Sex Research as "blueprints" for rhetorical spaces that create, alter, maintain, and reify cultural assumptions about sexuality. I drew upon qualitative research methods to examine how scholars and practitioners publishing in the journal have invoked spatiality as a rhetorical device in their invention of arguments about the relationship between sexuality and social control, agency, and disciplinarity.

Rhetorical Space as an Invention Strategy

Each substantive chapter of this dissertation focused on one specific type of rhetorical space sexologists use to create and support their theories, discoveries, and interpretations of data. The three types of rhetorical spaces are cyber thirdspace, imaginative space, and disciplinary space. I found that each rhetorical space was invoked as an invention device to create or support an argument about sexual social control, agency, or disciplinary boundaries.

In chapter two, I presented an examination of how sexologists have constructed different images of cyberspace as rhetorical space to debate the relationship between, and implications of, the Internet and sexual social control. All of the articles I examined for chapter two framed the issue of the Internet and sexuality in relation to the rhetoric of the democratization of sexuality, which characterized the Internet as an unregulated and uncontrolled sexual arena. The scholarship differed, however, with regard to how the authors theorized the implications of the democratization of sexuality and how these 
differences in perspectives on democratization were reflected in the construction of cyber rhetorical space.

My analysis of the articles on the Internet and sexuality revealed that sexologists representing the Internet as an erotic oasis characterized cyberspace as a sexual arena that allowed inhabitants to safely and agentically engage in sexual practices without the ascription of hegemonic sexual identities and normalization of hegemonic sexual values. In contrast, the pornosphere, as a rhetorical space, was represented by sexologists as dangerous because of the lack of normative social control, which the authors perceived as threatening the traditional family, hetero-coupling, and hegemonic gender identities. And, with the third cyber rhetorical space, the Jim Crow Cyb, sexologists illustrated the problems with either/or approaches to debates about the implications of the Internet for sex and the democratization of sexuality. According to those characterizing the Internet as a Jim Crow Cyb, cyberspace recreates patterns of segregation, racism, and ethnocentrism that are found in conventional geographical locations. Sexologists highlighting racism and ethnocentrism raised the issue of what, and who, is being socially controlled or sexually liberated in eroticized cyberplaces. Together, the erotic oasis, pornosphere, and Jim Crow cyb function as rhetorical spaces that are invoked by sexologists to engage discussions about sexual social control.

Imaginative space, the subject of chapter three, illustrates how spatiality serves as a rhetorical device in the reinvention of sexological arguments regarding the nature and effects of women's rape fantasies. Sexologists renegotiate an existing rhetorical space (the imagination) in order to persuade interested others that their assumption that women who have rape fantasies secretly wish to be raped is misguided and unsupported. The 
research on rape fantasies published in the Journal of Sex Research has created a new rhetorical vision of rape fantasies that complicates the notion that the imagination represents a site of unmitigated truth and that rape fantasies represent a desire to be raped in reality. In sexologists' revised rhetorical vision of rape fantasies, the imagination has been renegotiated as a site for gendered sexual agency rather than a representation of internalized oppression. In this way, the imagination as a rhetorical space serves praxically to reinvent arguments about rape fantasies and women's sexual agency.

Chapter four examined the role of spatial rhetorics in arguments about the medicalization of sexuality. Scholars inside and outside of The Society for the Scientific Study of Sexuality used the Journal of Sex Research's special issue on the medicalization of sexuality as an opportunity to persuade sexologists to recreate the boundaries of sexology as a discipline in an effort to thwart the problems associated with medicalization. Disciplinary space, as a rhetorical space, was invoked for two reasons: to persuade sexologists that institutional agents and contemporary practices that medicalize sexuality have appropriated their field and to illustrate how sexologists can confront the problems associated with medicalization. Disciplinary rhetorical space functions as a "showing" device that the contributors and editors use to convince sexologists to broaden the boundaries of their disciplinary fields. The contributors and editors to the special issue utilize cartographic and topographic spatial metaphors to create a "picture" of the disciplinary field in the same way that a map creates a representation of an area that allows us to see geographical structures.

My research on cyber thirdspace, imaginative space, and disciplinary space in sexological discourse answered my research questions concerning the types of rhetorical 
spaces that are constructed in sexological research and how these spaces are constructed. Cyber thirdspace, imaginative space, and disciplinary space are types of rhetorical spaces that are invoked as (re)invention strategies in sexological discourse about sexual social control, sexual agency, and disciplinary boundaries. Although cyber, imaginative, and disciplinary rhetorical spaces are conceptual spaces and invention strategies, they are not simply figurative devices. Cyber, imaginative, and disciplinary spaces are experienced as lived places: We go on the Internet, navigate Internet traffic, access the Internet from a physical place; we escape into our imaginations; and, we work within disciplinary fields. These rhetorical spaces are malleable; which is to say that they can be invented (cyber thirdspaces), reinvented (imaginative), and highlighted (discipinary). Furthermore, they are sites for the transfer of power by negotiating debates about social control, sexual agency, and disciplinary fields.

The analyses in this dissertation contribute to existing scholarship that draws on Mountford's (2001) construction of rhetorical space. Mountford (2001) introduced a praxical theory of rhetorical space that emphasized the generative role of spatiality in communicative acts and those who followed her refined and elaborated her work by demonstrating the malleability of rhetorical spaces (Marback, 2004; Wright, 2005), the role of spatiality in social relations of power (Enoch, 2008; Jack, 2009; Marback, 2004; Mountford, 2001; Wright, 2005), and the role of rhetorical space in institutional normalizing practices (Enoch, 2008; Jack, 2009). These previous studies of rhetorical space focused primarily on conceptual and lived rhetorical spaces. Conceived rhetorical spaces (Lefebvre, 1990; Soja, 1989) are products of written discourse created by those in charge of constructing places. Rhetorical critics Ackerman (2003) and Matus and Talburt 
(2009) have emphasized the importance of documents that prefigure social spaces but ultimately construct social realities that we encounter and move through in our daily lives. The analysis in this dissertation answers Ackerman's (2003) and Matus and Talburt's (2009) call by focusing on research articles as documents that invent rhetorical spaces that serve as sites for negotiating issues related to social control.

The analyses of cyber thirdspace, imaginative space, and disciplinary space highlight how spatiality is used as a rhetorical device and set the stage and impetus for further research on the institutionalization of sexological discourse and the formation of lived spaces. To encourage such research, I conclude this chapter with theoretical and methodological suggestions for investigating the institutionalization of sexological research in the interests of understanding how spatial rhetoric informs lived practice. Toward an Understanding of the Institutionalization of Rhetorical Spaces: Suggestions for Further Research

To develop an understanding of how sexological research has been institutionalized in social structures, and to what ends, I propose further research that traces how the published research I examined has been cited and used by other scholars, as well as interviews with those working within, or influenced by, the areas under examination: cyberspace, the imagination and rape fantasies, medicalization, and disciplinary fields. Philosopher and sociologist Bruno Latour's 1987 theory ${ }^{12}$ of science

\footnotetext{
${ }^{12}$ Recent rhetorical studies of science that draw on Latour's theories of science include Jouni-Matti Kuukkanen's (2012) research on narrativist historiographies of science; Chantal Benoit-Barne's (2007) work on the rhetorical practices of socio-technical deliberations about open-source software; Nathaniel Rivers's (2008) work on technical and professional writing; and Richard Besel's (2011) use of Latour's theories to analyze rhetorics of climate change in congressional discourse.
} 
provides a useful framework for directing further research into the institutionalization of rhetorical spaces because his theory demonstrates the connection between micro-level scientific discourse and macro-level scientific practices.

In Science in Action, Latour (1987) argued that science is always "in action" through practices such as black boxing (reifying scientific statements) and unpacking (uncomplicating scientific statements). Latour (1987) also noted that scientific literature is used to support scientific rhetoric by creating allies among scientists who agree with conclusions. Literature that is ignored does not effectively exist and literature that is contested is perceived as unstable. Latour (1987) also argues that we need to focus on how research is transformed by others and maintains inside/outside links that direct practice or science in action. Some potential Latourian research questions for making the connection between sexological research and practice include:

- How has The Society for the Study of Sexuality's research on cyberspace, rape fantasies, and medicalization been received by scholars outside of sexology and/or SSSS?

- How, if at all, has The Society for the Study of Sexuality's research findings on cyberspace, rape fantasies, and medicalization been black boxed, unpacked, ignored, argued with, or dismissed outside SSSS?

- In what disciplines and practical contexts has The Society for the Study of Sexuality's research on cyberspace, rape fantasies, and medicalization been cited and to what ends? 
- How has The Society for the Study of Sexuality's research on cyberspace, rape fantasies, and medicalization been transformed by other scholars or practitioners? For what reasons?

- How have cyber, imaginative, and disciplinary rhetorical spaces produced in The Society's research been re-created or transformed in other contexts? By whom? To what ends?

- What assumptions about sexuality have been institutionalized? How? What are the potential effects for sexual practices and identities?

These research questions can be answered by conducting tracing exercises on the reception and transformation of The Society for the Study of Sexuality's research on cyberspace, rape fantasies, and medicalization in databases such as Social Sciences Citation Index, Science Citation Expanded, Science Direct, LexisNexis Academic, and LexisNexis Congressional. Feminist scholar Dorothy Smith's (2005) institutional ethnography methodology would also provide useful information on how sexological rhetorical spaces have been institutionalized.

Briefly, institutional ethnography is a research method that researchers can use to investigate micro- and macro-level links among knowledge, discourse, and practice. Textual analysis and interviews are two institutional ethnography techniques that researchers employ to connect discourse and structure. According to Smith (2005), texts transport ideologies that inform practices within institutional sites. Those working within institutional sites activate the ideologies that are represented in the texts. In the case of further research into sexological rhetorical spaces, the tracing exercise mentioned earlier could be used to uncover a sample of black boxed research and the scholars conducting 
and disseminating the research could be interviewed to trace how their research has been institutionalized (e.g., presented at conferences, used to support community efforts associated with sexuality and rhetorical spaces, incorporated into policies, legislation, and plans for sex education, etc.).

An institutional ethnography and tracing exercise methodology can contribute to our understanding of how sexological rhetorical spaces are institutionalized into practice. Such a project would also contribute to rhetoricians' recent call for analyses of the relationship between rhetoric and lived experience. In "Rhetorical Criticism and the Rhetoric of Science," for example, Leah Ceccarelli (2001) argued that "Rhetoricians need to position rhetorical criticism as a study of the connections between words and substance (or between words and actions)....” (p. 317). Other rhetoricians have suggested future research that emphasizes the implications of science in policy and other deliberations (see Nelson, 1993; Wander \& Jaehne, 2000). My proposed institutional ethnography and tracing exercise would fulfill such a call by focusing on how sexological research is activated in social policies and institutional practices, thereby allowing us to understand the social and political implications of rhetorical space. 


\section{REFERENCES}

Ackerman, J. (2003). The space for rhetoric in everyday life. In M. Nystrand \& J. Duffy (Eds.), Towards a rhetoric of everyday life. Madison: University of Wisconsin Press.

Albright, J. M. (2008). Sex in America online: An exploration of sex, marital status, and sexual identity in internet sex seeking and its impacts. Journal of Sex Research, $45(2), 175-86$.

Arsenault, D. J. (1997). The proclamation of restoration of the independent nation of Hawaii: A fantasy theme analysis. Thesis. Available from: http://www.hawaiination.org/analysis/contents.html.

Bachelard, G. (1994). The poetics of space. New York: Beacon Press.

Baake, K. (2003). Metaphor and knowledge: The challenges of writing science. New York: SUNY Press.

Ball, M. A. (2001). Ernest G. Bormann: Roots, revelations, and results of symbolic convergence theory. Twentieth-Century Roots of Rhetorical Studies, 210-233.

Bakhtin, M. M. (1981). The dialogic imagination: Four essays. Austin: University of Texas Press.

Bakhtin, M. M. (1986). Speech genres and other late essays. University of Texas Press.

Bammer, A., Gwin, M., Katz, C., \& Meese, E. (1998). The place of the letter: An epistolary exchange. Making Worlds: Gender, Metaphor, Materiality, 161-202.

Barak, A., \& Fisher, W. A. (2001). Toward an internet-driven, theoretically-based, 
innovative approach to sex education. The Journal of Sex Research, 38(4), 324-332.

Barnett, S. (2012). Psychogeographies of writing: Ma(r)king space at the limits of representation. Kairos: A Journal of Rhetoric, Technology, and Pedagogy, 16(3), n3.

Barron, M., \& Kimmel, M. (2000). Sexual violence in three pornographic media: Toward a sociological explanation. The Journal of Sex Research, 37(2), 161-168.

Baumeister, R. F. (1988a). Gender differences in masochistic scripts. Journal of Sex Research, 25(4), 478-499.

Baumeister, R. F. (1988b). Masochism as escape from self. Journal of Sex Research, 25(1), 28-59.

Benoit-Barne, C. (2007). Socio-technical deliberation about free and open-source software: Accounting for the status of artifacts in public life. Quarterly Journal of Speech, 93(2), 211-235.

Benoit, W., Klyukovaki, A., McHale, J., \& Airne, D. (2001). A fantasy theme analysis of political cartoons on the Clinton-Lewinsky-Starr affair. Critical Studies in Media Communication, 18(4), 377-394.

Besel, R. (2011). Opening the "Black Box" of climate change science: Actor-network theory and rhetorical practice in scientific controversies. Southern Communication Journal, 76(2), 120-136.

Binik, Y. M. (2001). Sexuality and the internet: Lots of hyp(otheses): Only a little data. Journal of Sex Research, 38(4), 281-282.

Binkley, R., \& Smith, M. (2006). Re-composing space: Composition's rhetorical geography. Composition forum (Vol. 15).

Bitzer, L. F. (1968). The rhetorical situation. Philosophy \& Rhetoric, 1-14. 
Bivona, J., \& Critelli, J. (2009). The nature of women's rape fantasies: An analysis of prevalence, frequency, and contents. Journal of Sex Research, 46(1), 33-45.

Blackburn, M. V., \& Smith, J. M. (2010). Moving beyond the inclusion of LGBT-themed literature in English language arts classrooms: Interrogating heteronormativity and exploring intersectionality. Journal of Adolescent \& Adult Literacy, 53(8), 625-634.

Bleakley, A., Hennessy, M., \& Fishbein, M. (2011). A model of adolescents' seeking of sexual content in their media choices. Journal of Sex Research, 48(4), 309-15.

Bond, S. B., \& Mosher, D. L. (1986). Guided imagery of rape: Fantasy, reality, and the willing victim myth. Journal of Sex Research, 22(2), 162-183.

Bormann, E. (1971). Forerunners of Black power: The rhetoric of abolition. Prentice Hall.

Bormann, E. (1972). Fantasy and rhetorical vision: The rhetorical criticism of social reality. Quarterly Journal of Speech, 58(4), 396-407.

Bormann, E. (1980). Communication theory. New York: Holt, Rinehart, and Winston.

Bormann, E. (1982a). A fantasy theme analysis of the television coverage of the hostage release and the Reagan inaugural. Quarterly Journal of Speech, 68(2), 133-145.

Bormann, E. (1982b) Fantasy and rhetorical vision: Ten years later. Quarterly Journal of Speech, 68(3), 288-305.

Bormann, E. G., \& Bormann, N. C. (1986). Speech communication: A basic approach. Harper \& Row.

Bormann, E. G., Golden, J. L., Berquist, G. F., \& Coleman, W. E. (1983). Rhetoric as a way of knowing: Ernest Bormann and fantasy theme analysis. The Rhetoric of Western Thought, 431-449. 
Bormann, E. G. (2001). The force of fantasy: Restoring the American dream. Southern Illinois University Press.

Bormann, E. G. (2006). Symbolic convergence theory: A communication formulation. Journal of Communication, 35(4), 128-138.

Brown, G., Maycock, B., \& Burns, S. (2005). Your picture is your bait: Use and meaning of cyberspace among gay men. Journal of Sex Research, 42(1), 63-73.

Brown, M. P. (2000). Closet space : Geographies of metaphor from the body to the globe. New York: Routledge.

Brownmiller, S. (1975) Against our will: Men, women and rape. Pearson Education New Zealand.

Bullough, V. L. (1985). Problems of research on a delicate topic: A personal view. Journal of Sex Research, 21(4), 375-386.

Bullough, V. L. (1995). Science in the bedroom: A history of sex research. Basic Books.

Burbules, M. C. (2002). The web as a rhetorical place. In Snyder (Ed.), Silicon literacies: Communication, innovation and education in the electronic age (pp. 75-85). New York: Psychology Press.

Burns, W. (2009). PublicandPrivate: The trialectics of public writing on the street, on campus, and in third space. Composition Studies, 37(1), 19.

Cacchioni, T., \& Tiefer, L. (2012). Why medicalization? Introduction to the special issue on the medicalization of sex. Journal of Sex Research, 49(4), 307-310.

Cameron, L., \& Seu, I. B. (2012). Landscapes of empathy: Spatial scenarios, metaphors and metonymies in responses to distant suffering. Text and Talk, 32(3), 281-305. 
Ceccareli, L. (2001). Shaping science with rhetoric: The cases of Dobzhansky,

Schrodinger, and Wilson. Chicago: University of Chicago Press.

de Certeau, M. (1984). The practice of everyday life. Berkeley: University of California Press.

Chesebro, J. W. (1980). Paradoxical views of "homosexuality" in the rhetoric of social scientists: A fantasy theme analysis. Quarterly Journal of Speech, 66(2), 127-139.

Code, L. (1995). Rhetorical spaces: Essays on gendered locations. New York:

Routledge.

Condit, C. (2002). Recipes or blueprints for our genes? How contexts selectively activate the multiple meanings of metaphors. Quarterly Journal of Speech, 88(3).

Condit, C. (2007). How geneticists can help reporters get their story right. Nature Reviews Genetics, 8, 815-820.

Condit, C., \& Shen, L. (2011). Public understanding of risks from gene-environment interaction in common diseases: Implications for public communication. Public Health Genomics, 14(2), 115-124.

Conrad, P. (1992). Deviance and medicalization: From badness to sickness. Philadelphia: Temple University Press.

Conrad, P. (2005). The shifting engines of medicalization. Journal of Health and Social Behavior, 46(1), 3-14.

Conrad, P. (2007). The medicalization of society: On the transformation of human conditions into treatable disorders. Baltimore: Johns Hopkins University Press.

Cooper, B. (2002). Boys don't cry and female masculinity: Reclaiming a life \& dismantling the politics of normative heterosexuality. Critical Studies in Media 
Communication, 19(1), 44-63.

Critelli, J. W., \& Bivona, J. M. (2008). Women's erotic rape fantasies: An evaluation of theory and research. Journal of Sex Research, 45(1), 57-70.

Crouse-Dick, C. E. (2002). She designed: Deciphering messages targeting women in commercials aired during Ally McBeal. Women and Language, 25(1), 18-28.

Curran, M. E. (2005). Geographic theorizations of sexuality: A review of recent works. Feminist Studies, 31(2), 380-398.

D'Emilio, J., \& Freedman, E. B. (1998). Intimate matters: A history of sexuality in America. University of Chicago Press.

Dahms, H. (2009). Retheorizing global space in sociology: Towards a new kind of discipline. In B. Warf \& S. Arias (Eds.) The spatial turn: Interdisciplinary perspectives (pp. 88-101). New York: Routledge.

Dawney, L. (2011). Social imaginaries and therapeutic self-work: The ethics of the embodied imagination. The Sociological Review, 59(3), 535-552.

Dexter, S., \& LaMagdeleine, D. R. (2002). Dominance theater, slam-a-thon, and cargo cults: Three illustrations of how using conceptual metaphors in qualitative research works. Qualitative Inquiry, 8(3), 362-380.

Duffy, M. E. (2003). Web of hate: A fantasy theme analysis of the rhetorical vision of hate groups online. Journal of Communication Inquiry, 27(3), 291-312.

Dobris, C. A., \& White-Mills, K. (2009). Rhetorical visions of motherhood: A feminist analysis of the What to Expect series. Women and Language, 29(1).

Enoch, J. (2008). A woman's place is in the school: Rhetorics of gendered space in Nineteenth-Century America. College English, 70(3), 275-295. 
Farrell J., \& Cacchioni, T. (2012). The medicalization of women's sexual pain. Journal of Sex Research, 49(4), 328-336.

Flannery, M. C. (2001). Quilting: A feminist metaphor for scientific inquiry. Qualitative Inquiry, 7(5), 628-645.

Feldman, A. M. (2008). Making writing matter: Composition in the engaged university. Albany, NY: State University of New York.

Fisher, W. A., \& Barak, A. (2001). Internet pornography: A social psychological perspective on internet sexuality. Journal of Sex Research, 38(4), 312-323.

Flanagan, M. (2000). Navigating the narrative in space: Gender and spatiality in virtual worlds. Art Journal, 59(3), 74-85.

Fopp, R. (2009). Metaphors in homelessness Discourse and research: Exploring "pathways," "careers" and "safety nets." Housing, Theory and Society, 26(4), 271291.

Foucault, M. (1977a). Discipline and punish, trans. Alan Sheridan. New York: Vintage Foucault, M. (1977b). Questions on geography. In Space, knowledge and power:

Foucault and geography. Ashgate Publishing Company.

Foucault, M. (1984). The history of sexuality. New York: Vintage.

Foucault, M. (1986). Of other spaces. Diacritics, 16(1), 22-27.

Foucault, M. (2007). The language of space. In S. Elden \& J. Crampton (Eds.), Space, knowledge, and power: Foucault and geography (pp. 163-168). Birmingham: Ashgate Publishing, Ltd.

Fox, C. (2007). From transaction to transformation: (En)countering white heteronormativity in "safe spaces". College English, 69(5), 496-511. 
Gamson, J., \& Moon, D. (2004). The sociology of sexualities: Queer and beyond. Annual Review of Sociology, 30, 47-64.

Gardiner, M. (1992). The dialogics of critique: MM Bakhtin and the theory of ideology. New York: Routledge.

Geary, J. (2012). I is an other: The secret life of metaphor and how it shapes the way we see the world. New York: Harper Perennial.

Giami, A., \& Perrey, C. (2012). Transformations in the medicalization of sex: HIV prevention between discipline and biopolitics. Journal of Sex Research, 49(4), 353361.

Glaser, B. G., \& Strauss, A. L. (1967). The discovery of grounded theory: Strategies for qualitative research. New York: Aldine de Gruyter.

Griffiths, M. (2001). Sex on the internet: Observations and implications for internet sex addiction. The Journal of Sex Research, 38(4), 333-342.

Green, A. I., Follert, M., Osterlund, K., \& Paquin, J. (2008). Space, place and sexual sociality: Towards an 'atmospheric analysis'. Gender, Work \& Organization.

Greenwood, J., \& Bonner, A. (2008). The role of theory-constitutive metaphor in nursing science. Nursing Philosophy, 9(3), 154-168.

Groethe, M. (2008). I never metaphor I didn't like. New York: Harper Collins. Gugerli, D. (2004). Mapping: A communicative strategy. In J.-P. Gaudilliere \& H.-J. Rheinberger (Eds.), Molecular genetics to genomics: The mapping cultures of twentieth-century genetics. New York: Routledge.

Guldi, J. (2009). The spatial turn. Spatial Humanities: A Project of the Institute for Enabling. 
Gunn, J. (2003). Refiguring fantasy: Imagination and its decline in U.S. rhetorical studies. Quarterly Journal of Speech, 89(1), 41-59.

Haeberle, E. J. (2006). History of sexology. Available from Archive for Sexology web site:

http://www2.huberlin.de/sexology/Entrance\_Page/History\of\_Sexology/history\_o f_sexology. htm.

Harrison, D. (2010). No body there: Notes on the queer migration to cyberspace. The Journal of Popular Culture, 43(2), 286-308.

Hausman, B. L. (2000). Rational management: Medical authority and ideological conflict in Ruth Lawrence's Breastfeeding: A guide for the medical profession. Technical Communication Quarterly, 9(3), 271-289.

Hawley, P. H., \& Hensley, W. A. (2009). Social dominance and forceful submission fantasies: Feminine pathology or power? Journal of Sex Research, 46(6), 568-85.

Hubbard, P. (2000). Desire/disgust: Mapping the moral contours of heterosexuality. Progress in Human Geography, 24(2), 191-217.

Hubbard, P., Matthews, R., Scoular, J., \& Agustin, L. (2008). Away from prying eyes? The urban geographies of 'adult entertainment'. Progress in Human Geography, 32(3), 363-381.

Illouz, E., Seidman, S., \& Fischer, N. (2011). Romantic love: Interview with eva illouz. In Introducing the new sexuality studies: Original essays and interviews (2 ed.) (pp. 36-44). New York: Routledge.

Illich, I. (1976). Limits to medicine: Medical nemesis. London: Marion Boyers Publishers. 
Jack, J. (2009). Acts of institution: Embodying feminist rhetorical methodologies in space and time. Rhetoric Review, 28(3), 285-303.

Jacobs, K. (2004). Pornography in small places and other spaces. Cultural Studies, 18(1), $67-83$.

Jansson, A., \& Lagerkvist, A. (2009). Strange spaces: Explorations into mediated obscurity. New York: Ashgate Publishing.

Jasper, J. M., \& Young, M. P. (2007). The rhetoric of sociological facts. Sociological Forum, 22(3), 270-299.

Jeyasingham, D. (2010). Building heteronormativity: The social and material reconstruction of men's public toilets as spaces of heterosexuality. Social \& Cultural Geography, 11(4), 307-325.

Johnson, N. (2002). Gender and rhetorical space in American life, 1866-1910. Southern Illinois University Press.

Johnson, N. (2000). Reigning in the court of silence: Women and rhetorical space in postbellum America. Philosophy \& Rhetoric, 33(3), 221-242.

Johnston, L., \& Longhurst, R. (2010). Space, place, and sex: Geographies of sexualities. New York: Rowman \& Littlefield Pub Inc.

Kalyanaraman, S., \& Sundar, S. S. (2008). Portrait of the portal as a metaphor: Explicating Web portals for communication research. Journalism \& Mass Communication Quarterly, 85(2), 239-256.

Katz, J. N. (2007). The invention of heterosexuality. University of Chicago Press.

Kelly, B., \& Munoz-Laboy-M. (2005). Sexual place, spatial change, and the social reorganization of sexual culture. Journal of Sex Research, 42(4), 359-366. 
Kendall, J. E., Kendall, K. E., \& Kah, M. M. O. (2006). Examining virtual organizations using fantasy theme analysis: A study of ICT policy advisors' discourse about developing countries. Journal of Information Technology Theory and Application (JITTA), 8(2), 3 .

Kettman, S. (2001). 1,001 Arabian nights of sex'. Wired . Retrieved from http://www.wired.com/culture/lifestyle/news/2001/04/43243?currentPage=all

Kidd, V. (1998). Fantasy theme analysis. Retrieved from http://www.csus.edu/indiv/k/kiddv/FTA_reading.html

Kipnis, L. (2003). Against love: A polemic. New York: Pantheon.

Kitzinger, C. (2005). Heteronormativity in action: Reproducing the heterosexual nuclear family in after-hours medical calls. Social Problems, 52(4), 477-498.

Knopp, L. (2007). On the relationship between queer and feminist geographies. The Professional Geographer, 59(1), 47-55.

Kuukkanen, J.-M. (2012). The missing narrativist turn in the historiography of science. History and Theory, 51(3), 340-363.

Lakoff, G., \& Turner, M. (1989). More than cool reason: A field guide to poetic metaphor. Chicago: University of Chicago Press.

Lakoff, G., \& Johnson, M. (2003). Metaphors we live by. Chicago: University of Chicago Press.

Latour, B. (1987). Science in action: How to follow scientists and engineers through society. Boston: Harvard University Press.

Lauer, C. (2009). Constructing the self in/as thirdspace: New potentials for identity exploration in the composition classroom. Composition Studies, 37(2), 22. 
Lefebvre, H. (1974). The production of space.(Trans. D. Nicholson-Smith). Oxford: Blackwell.

Marback, R. (2004). The rhetorical space of Robben Island. Rhetoric Society Quarterly, $34(2), 7-27$.

Marshall, B. L. (2012). Medicalization and the refashioning of age-related limits on sexuality. Journal of Sex Research, 49(4), 337-343.

Massan, S., \& Weingart, P. (2000). Metaphors and the dynamics of knowledge. New York: Routledge.

Massey, D. B. (1994). Space, place, and gender. Minnesota: University of Minnesota Press.

Matus, C., \& Talburt, S. (2009). Spatial imaginaries: Universities, internationalization, and Feminist geographies. Discourse: Studies in the Cultural Politics of Education, $30(4), 515-527$.

McKenna, K. Y. A., Green, A. S., \& Smith, P. K. (2001). Demarginalizing the sexual self. Journal of Sex Research, 38(4), 302-311.

McLean, K. (2008). 'Coming out, again': Boundaries, identities and spaces of belonging. Australian Geographer, 39(3), 303-313.

Mountford, R. (2001). On gender and rhetorical space. Rhetoric Society Quarterly, 31(1), 41-71.

Oswin, N. (2008). Critical geographies and the uses of sexuality: Deconstructing queer space. Progress in Human Geography, 32(1), 89-103.

Nelson, J. (1993). Approaches, opportunities, and priorities in the rhetoric of political inquiry: A critical synthesis. In M. Good. (Ed.), The Recovery of Rhetoric: 
Persuasive Discourse and Disciplinarity in the Human Sciences. Charlottesville:

University of Virginia Press.

Niebert, K., Marsch, S., \& Treagust, D. F. (2012). Understanding needs embodiment: A theory-guided reanalysis of the role of metaphors and analogies in understanding science. Science Education, 96(5), 849-877.

Paul, B. (2009). Predicting internet pornography use and arousal: The role of individual difference variables. Journal of Sex Research, 46(4), 344-57.

Paul, J. P., Ayala, G., \& Choi, K. H. (2010). Internet sex ads for MSM and partner selection criteria: The potency of race/ethnicity online. Journal of Sex Research, $47(6), 528-38$.

Periyakoil, V. S. (2008). Using metaphors in medicine. Journal of Palliative Medicine, $11(6), 842-844$.

Peterson, R. A. (2001). On the use of college students in social science research: Insights from a second-order meta-analysis. Journal of Consumer Research, 28(3), 450-461.

Plante, R. F. (2006). Sexualities in context: A social perspective. New York: Westview Press.

Polzer, J. C., \& Knabe, S. M. (2012). From desire to disease: Human papillomavirus (HPV) and the medicalization of nascent female sexuality. Journal of Sex Research, 49(4), 344-352.

Pramling, N., \& Säljö, R. (2007). Scientific knowledge, popularization, and the use of metaphors: Modern genetics in popular science magazines. Scandinavian Journal of Educational Research, 51(3), 275-295.

Ragin, C. C., \& Amoroso, L. (2010). Constructing social research: The unity and 
diversity of method. Thousand Oaks, CA: Pine Forge Press.

Reeves, C. (2005). Language of science. New York: Routledge.

Reid, B. (1993). History of the usenet. Retrieved from

http://www.livinginternet.com/u/ui alt.htm

Reynolds, N. (1998). Composition's imagined geographies: The politics of space in the frontier, city, and cyberspace. College Composition and Communication, 50(1), 1235.

Rivers, N. (2008). Some assembly required: The Latourian collective and the banal work of technical and professional societies. Journal of Technical Writing and Communication, 38(3), 189-206.

Robertiello, R. C. (1970). Masochism and the female sexual role. Journal of Sex Research, 6(1), 56-58.

Robertiello, R. C. (1976). The decline and fall of sex. Journal of Sex Research, 12(1), 7073.

Rogers, K. L. (1986). Decoding a city of words: Fantasy theme analysis and the interpretation of oral interviews. International Journal of Oral History, 43-56.

Ross, Michael. (2005). Typing, doing, and being: Sexuality and the internet. Journal of Sex Research, 42(4), 342-352.

Ross, Michael, Rosser, B.R. Simon, McCurdy, Sheryl, \& Feldman, Jamie. (2007). The advantages and limitations of seeking sex online: A comparison of reasons given for online and offline sexual liaisons by men who have sex with men. Journal of Sex Research, 44(1), 59-71.

Ruddick, S. M. (1995). Young and homeless in Hollywood: Mapping social identities. 
New York: Psychology Press.

Sandelowski, M., \& Barroso, J. (2008). Reading qualitative studies. International Journal of Qualitative Methods, 1(1), 74-108.

Schmitt, R. (2000). Notes toward the analysis of metaphor. Forum: Qualitative Social Research, 1(1).

Schmitt, R. (2003). The interaction between research method and subjective competence in systematic metaphor analysis. Forum: Qualitative Social Research, 4(2).

Schmitt, R. (2004). Review essay: Argument is war, love is a journey, and qualitative research needs a pair of glasses. Forum: Qualitative Social Research, 5(2).

Schmitt, R. (2005). Systematic metaphor analysis as a method of qualitative research. The Qualitative Report, 10(2), 358-394.

Segal, J. Z. (1997). Public discourse and public policy: Some ways that metaphor constrains health (care). Journal of Medical Humanities, 18(4), 217-231.

Segal, J. Z. (1998). Writing and medicine. In R. Spilka (Ed.), Writing in the Workplace: New Research Perspectives (pp. 84-97). New York: SIU Press.

Segal, J. Z. (2000). Contesting death, speaking of dying. Journal of Medical Humanities, 21(1), 29-44.

Segal, J. Z. (2005). Interdisciplinarity and bibliography in rhetoric of health and medicine. Technical Communication Quarterly, 14(3), 311-318.

Segal, J. Z. (2007). What is a story of breast cancer? Proceedings of the 4th International Symposium on Genre Studies. University of Southern Santa Catarina, Turbao, Brazil, 158-163. 
Segal, J.Z. (2008) Health and the rhetoric of medicine. Carbondale: Southern Illinois University Press.

Segal, J. Z. (2009). Internet Health and the 21st-Century Patient: A Rhetorical View. Written Communication, 26(4), 351-369.

Segal, J. Z. (2012). The sexualization of the medical. Journal of Sex Research, 49(4), 369-378.

Seidman, S. (2009). The social construction of sexuality (Second ed.). New York: Norton.

Shields, D. C., \& Preston, C. T. (1985). Fantasy theme analysis in competitive rhetorical criticism. National Forensic Journal, 3, 102-115.

Shulman, J, \& Horne, S. (2006). Guilty or not? A path model of women's sexual force fantasies. Journal of Sex Research, 43(4), 368-377.

Skeggs, B. (1999). Matter out of place: Visibility and sexualities in leisure spaces. Leisure Studies, 18(3), 213-232.

Smith, D. (2005). Institutional ethnography: sociology for people. New York: AltaMira Press.

Society for the Scientific Study of Sexuality (2013) Join Today! Available from: http://www.sexscience.org/about/jointoday/ Mission. Available from: http://www.sexscience.org/about/mission_statement/

Soja, E. W. (1989). Postmodern geographies: The reassertion of space in critical social theory. New York: Verso Books.

Soja, E. W. (1996). Thirdspace: Journeys to Los Angeles and other real-and-imagined places. New York: Wiley Online Library. 
Sontag, S. (2001). Illness as metaphor and AIDS as metaphor. New York: Picador Press.

Suddaby, R. (2006). From the editors: What grounded theory is not. The Academy of Management, 49(4), 633-642.

Tiefer, L. (1996). The medicalization of sexuality: Conceptual, normative. Annual Review of Sex Research, 7(1), 252-282.

Tiefer, L. (2000). Sexology and the pharmaceutical industry: The threat of co-optation. Journal of Sex Research, 37(3), 273-283.

Tiefer, L. (2012). Medicalizations and demedicalizations of sexuality therapies. Journal of Sex Research, 49(4), 311-318.

Tewksbury, R. (2002). Bathhouse intercourse: Structural and behavioral aspects of an erotic oasis. Deviant Behavior, 23, 75-112.

Tone, A. (2012). Medicalizing reproduction: the pill and home pregnancy tests. Journal of Sex Research, 49(4), 319-327.

Torres-Olava, B. (2012). Imaginative geographies: Identity, difference, and English as the language of instruction in a Mexican university program. Higher Education. 63(3): 317-335.

Tuan, Y. F. (2001). Space and place: The perspective of experience. Minneapolis: University of Minnesota Press.

Turkle, S. (2011). Alone together: Why we expect more from technology and less from each other. New York: Basic Books.

Valentine, G. (2007). Theorizing and researching intersectionality: A challenge for Feminist geography. The Professional Geographer, 59(1), 10-21. 
Visser-Wijnveen, G. J., Van Driel, J. H., Van der Rijst, R. M., Verloop, N., \& Visser, A. (2009). The relationship between academics' conceptions of knowledge, research and teaching - a metaphor study. Teaching in Higher Education, 14(6), 673-686.

Waitt, G., Markwell, K., \& Gorman-Murray, A. (2008). Challenging heteronormativity in tourism studies: Locating progress. Progress in Human Geography, 32(6), 781-800.

Wall, A. (2009). Myth, metaphor, and science. Chester: Chester Academic Press.

Wander, P., \& Jaehne, D. (2000). Prospects for a "rhetoric of science." Social Epistemology, 14(2/3), 211-233.

Warf, B. \& Arias, C. (2008). The spatial turn: Interdisciplinary perspectives (Vol. 26). New York: Routledge.

Warner, M., \& Berlant, L. (2002). Sex in public. Publics and Counterpublics, 187-208.

Warnick, B. (2007). Rhetoric online: Persuasion and politics on the world wide web. New York: Peter Lang Publisher.

Webster, G. R., Chapman, T., \& Leib, J. (2010). Sustaining the societal and scriptural fence: Cultural, social, and political topographies of same-sex marriage in Alabama. The Professional Geographer, 62(2), 211-229.

Winfield, Bonnie. (2003). Turning the kaleidoscope: Telling stories in rhetorical spaces. Journal of Sociology and Social Welfare, XXX(1), 23-40.

Wolfe, J. (2010). Rhetorical numbers: A case for quantitative writing in the composition classroom. College Composition and Communication, 61(3), 452-475.

Wood, J. M., Koch, P. B., \& Mansfield, P. K. (2006). Women's sexual desire: A feminist critique. Journal of Sex Research, 43(3), 236-244. 
Wright, E. (2005). Rhetorical spaces in memorial places: The cemetery as a rhetorical memory place/space. Rhetoric Society Quarterly, 35(4), 51-81.

Zagacki, K. S., \& Grano, D. (2005). Radio sports talk and the fantasies of sport. Critical Studies in Media Communication, 22(1), 45-63.

Zhao, S. (1991). Rhetoric as praxis: An alternative to the epistemic approach. Philosophy \& Rhetoric, 24(3), 255-266.

Zurbriggen, E. L., \& Yost, M. R. (2004). Power, desire, and pleasure in sexual fantasies. Journal of Sex Research, 41(3), 288-300. 


\section{CURRICULUM VITAE Deanna McGaughey-Summers}

329 Biltmore Road

Louisville, KY 40207

502-415-9586

dlms@deannasummers.com

dlmcga01@exchange.louisville.edu

EDUCATION

Ph.D. Rhetoric and Composition, University of Louisville, Louisville, KY. Graduation Date: December 2013

Director: Dr. Karen Kopelson

M.S. Administration of Justice, University of Louisville, Louisville, KY.

Graduation Date: May 2002.

Culminating Project: The Uses of Critical Pedagogies for Justice

Director: Richard Tewksbury

M.A. Sociology, Ohio University, Athens, OH.

Graduation Date: May 2000.

Thesis: A Foucauldian Analysis of Child Sexual Abuse Discourse

Director: Mary Beth Krouse

B.S. Administration of Justice, University of Louisville, KY.

Graduation Date: 1996.

TEACHING EXPERIENCE

2000-present University of Louisville, Department of Sociology, Adjunct

Courses Taught: Introduction to Sociology; Social Problems; Diversity and Inequality; Research Methods; Social Theory; Social Stratification; Race and Ethnicity in the United States; and, Sociology of Sexuality Distance Learning: Social Problems; Social Stratification; Research Methods; Social Theory

2004-present University of Louisville, Department of English, Adjunct Courses Taught: Introduction to College Writing; Intermediate College Writing; Honors College Writing; Advanced Academic Writing

2013-2013 Indiana Tech, College of Professional Studies, Adjunct 
2003-2013 KCTCS-Jefferson, Department of Social and Behavioral Sciences, Adjunct

Courses Taught: Introduction to Sociology and Criminology

2003-present KCTCS-Jefferson, Prison Program, Department of Social and Behavioral Sciences and Department of Humanities, Adjunct

Institutions: Roederer Correctional Complex; Luther Luckett Correctional Complex; Kentucky State Reformatory; Kentucky Correctional Institute for Women

Courses Taught: Eng 101; Eng 102; Introduction to Literature; Introduction to Film; Introduction to Sociology; Social Problems; Inequality in Society; and, Family Studies

2007-2008 Kentucky State Reformatory, Adult Basic Education and GED, Correctional Psychiatric and Treatment Unit, Instructor Courses Taught: Literacy/GED

2011-2011 Indiana University Southeast, Department of Sociology, Adjunct Courses Taught: Social Problems

2004-2005 Spalding University, Louisville, KY, Department of Sociology, Adjunct Instructor

Courses Taught: Introduction to Sociology and Social Problems

2000-2003 University of Louisville, Administration of Justice, GTA

Courses Taught: Corrections in the U.S.

1997-2000 Ohio University, Department of Sociology, GTA

Courses Taught: Introduction to Sociology and Social Problems

\section{RESEARCH AND SOCIAL SERVICE}

2006-2007 Prison Program Coordinator (interim), Roederer Correctional Complex, Louisville, KY.

2000-2001 Dissemination and Research Specialist, Center for Safe Urban School Communities, University of Louisville, Louisville, KY.

1998-2000 Research Specialist, Ohio University, School of Osteopathic Medicine, Department of Social Medicine, Athens, Ohio.

1998 Coordinator, Hidden from History No More: Gay, Lesbian, Bisexual, and Transgender Documentaries, Film Festival, Ohio University.

1995-1996 Undergraduate Research Assistant to Dr. Richard Tewksbury, U.S. Mayor's Conference on HIV Prevention and Education, Louisville, KY. 
1994-1996 Advocate/Outreach, RAPE Crisis Center, Center for Women and Families. Louisville, KY.

1995-1996 Advocate/Outreach, Public Education Committee, Exploited Children's Help Organization, Louisville, KY.

\section{PUBLICATIONS}

McGaughey-Summers, D. \& Summers, R. (2007) Gaming, Agency, and Imagination: Locating Gaming within a Larger Constellation Literacies. In Gaming Lives in the Twenty-First Century. Edited by Cynthia Selfe and Gail Hawisher. New York, NY: Palgrave MacMillan.

Gagne, P. \& McGaughey, D. (2002). Designing Women: Cultural Hegemony and the Exercise of Power among Women Who Have Undergone Elective Mammoplasty. Gender and Society, Vol. 16, No. 6, pp. 814-838.

Reprinted in: Weitz, R. (2010) Politics of Women's Bodies, 3rd Edition, Edited by Rose Weitz. Oxford University Press.

Schwaner, S., McGaughey, D., \& Tewksbury, R. (1998) Situational Constraints and Absconding Behavior: Toward a Typology of Parole Fugitives. Journal of Offender Rehabilitation. Vol 27, No. 1/2. pp. 37-55.

McGaughey, D. (1998) Book Review of: Unspeakable Acts: Why Men Sexually Abuse Children. In the American Journal of Criminal Justice. Vol. 21, No.1.pp. 117-119.

McGaughey, D. (1998) Instructor's Manual to Accompany Reading Between the Lines: Toward and Understanding of Current Social Problems. Edited by Amanda Konradi and Martha Schmidt. New York, NY: McGraw-Hill.

Tewksbury, R. \& McGaughey, D. (1998) Identities and Identity Transformations among Persons with HIV Disease. International Journal of Sexuality and Gender Studies. Vol. 3, No. 3.

Tewksbury, R. \& McGaughey, D. (1997) Stigmatization of Persons with HIV Disease: Perceptions, Management, and Consequences of AIDS. Sociological Spectrum, Vol. 4, No. 3.

Reprinted in: Thio, A (2009) Readings in Deviant Behavior. Allyn and Bacon: NY

Gagne, P., Tewksbury, R., \& McGaughey, D. (1997) Coming Out and Crossing Over: Identity Formation and Proclamation in a Transgender Community. Gender and Society, Vol. 11, No. 4. pp. 478-508. 
Reprinted in:

Preves, S. E.\& Mortimer, E. (2010) Classic and Contemporary Readings in Social Psychology. New York, NY: Oxford University Press;

Kaler, A., Kimmel, M. S., \& Aronson, A. (2008) The Gendered Society Reader. New York, NY: Oxford University Press;

Kimmel, M. \& Plante, R. (2004) Sexualities: Identities, Behavior, and Society.

New York, NY: Oxford University Press;

Welzer, R. (2001) Deviance and Social Control. New York, NY: McGraw-Hill

\section{RECENT BOOK REVIEWS}

Seidman, S. (2013). Contested Knowledge : Social Theory Today. Hoboken, N.J.: John Wiley \& Sons.

Reis, E. (2012). American Sexual Histories (Vol. 1). 2nd Edition. New York, NY: Wiley-Blackwell.

Rosenblum, K. E., \& Travis, T. -M. (2012). The Meaning of Difference : American Constructions of Race, Sex and Gender, Social Class, Sexual Orientation, and Disability : A Text/Reader. New York, NY: McGraw-Hill.

Stombler, M. (2010). Sex Matters : The Sexuality and Society Reader. Boston, MA: Allyn \& Bacon.

Bugeja, M. J. (TBA). Interpersonal Divide : The Search for Community in a Technological Age. New York, NY: Oxford University Press.

\section{AWARDS AND HONORS}

2010 Department of English, University of Louisville, Part-Time Lecturer Award.

2010 Delphi Center for Teaching and Learning, University of Louisville, Faculty Favorites.

2008 Delphi Center for Teaching and Learning, University of Louisville, Faculty Favorites.

2006 Delphi Center for Teaching and Learning, University of Louisville, Faculty Favorites.

2001 Outstanding Graduate Student, Southern Criminal Justice Association.

1999 Nominee, Ohio University's Outstanding Graduate Teaching Associate. 
1999 Outstanding Graduate Teaching Associate, Ohio University, College of Arts and Sciences, Department of Sociology.

1998 Nominee, Ohio University's Outstanding Graduate Teaching Associate.

1998 Outstanding Graduate Teaching Associate, Ohio University, College of Arts and Sciences, Department of Sociology

1997 Outstanding Graduate Teaching Associate, Ohio University, College of Arts and Sciences, Department of Sociology.

1997 Finalist, Ohio University's Outstanding Master's Student.

1996 Outstanding Undergraduate Student, Southern Criminal Justice Association.

1996 Nominee, Kenneth R. Nally Award, University of Louisville, Louisville, Kentucky, Administration of Justice. 